\title{
Influence of the breakaway friction on the seismic response of buildings isolated with curved surface sliders: Parametric study and design recommendations
}

\author{
Emanuele Gandelli ${ }^{1}$, Dario De Domenico ${ }^{2 *}$, Paolo Dubini ${ }^{3}$, Matteo Besio ${ }^{1}$, Eleonora Bruschi ${ }^{1}$, \\ Virginio Quaglini ${ }^{1}$

\footnotetext{
${ }^{1}$ Department of Architecture, Built Environment and Construction Engineering, Politecnico di Milano, Piazza Leonardo da Vinci 31, 20133 Milano, Italy

${ }^{2}$ Department of Engineering, University of Messina, Contrada Di Dio, 98166 Sant'Agata, Messina, Italy

${ }^{3}$ EUCENTRE, European Centre for Training and Research in Earthquake Engineering, Via A. Ferrata 1, 27100 Pavia, Italy

* Corresponding author: Dario De Domenico, University of Messina, Italy. Email: dario.dedomenico@unime.it
}

\begin{abstract}
The breakaway friction coefficient of curved surface sliders (CSSs) governs the transition between the sticking and the sliding behavior of the isolators, and hence affects the response of an isolated building during an earthquake. When the inertia forces induced by low-to-moderate intensity excitations are not able to overcome the breakaway frictional resistance of the CSS isolation system, the structure behaves as a fixed-base building, thus experiencing higher accelerations, interstorey drifts and internal forces than the isolated building. The majority of structural analysis programs disregard the static coefficient of friction, and implement the dynamic friction coefficient only throughout the response history analysis, which implies an increased displacement demand for the isolation system but may concurrently lead to an unsafe design for the superstructure. In this paper, the frictional resistance to sliding before the breakaway is simulated through a bidirectional plasticity domain, which has been coded in a finite element of the isolator formulated in OpenSees to incorporate the transition between the breakaway friction in the sticking phase and the velocity-dependent friction model in the subsequent sliding phase. Based on this formulation, the influence of the breakaway friction on the response of buildings isolated with CSSs is investigated numerically through an extensive parametric study comprising more than 9000 bidirectional nonlinear time history analyses (NLTHAs). The parameters cover a range of friction coefficients, superstructure properties and a large group of natural spectrum-compatible bidirectional ground motions having different intensity levels and frequency contents. The results from NLTHAs are processed statistically to elaborate regression formulae and design recommendations that can be useful to predict the trigger acceleration at which sliding motion starts, as well as to suggest how to achieve more accurate estimates of the seismic response when the breakaway friction is ignored in the structural analysis model.
\end{abstract}

KEY WORDS: Base isolation; Curved Surface Slider; Friction coefficient; Breakaway effect; Nonlinear time history analyses; Seismic response. 


\section{INTRODUCTION}

Seismic isolation is an effective technology for the enhancing the seismic protection of structures and their contents. Typical isolation devices include elastomeric bearings (rubber, recycled rubber or fiber-reinforced rubber [1]-[3]) and sliding supports with curved surfaces [4]-[7]. The Curved Surface Slider (CSS), introduced in the '80s in the version called Friction Pendulum System ${ }^{\circledR}$ (FPS) [8]-[10], is one of the most popular isolation hardware worldwide owing to its inherent simplicity. Indeed, it provides the four main functions required to the isolation system, i.e. carrying vertical loads from the superstructure, lateral flexibility, energy dissipation and re-centering capability, in a single, compact design. In its basic configuration, the CSS consists of a concave sliding plate and an articulated slider. The surface of the slider in contact with the concave plate is lined by a low-friction thermoplastic material, which is responsible for the energy dissipation during the sliding between the slider and the concave plate (Figure 1-left). Though improved versions featuring multiple sliding surfaces have been proposed in recent years, e.g., the Double Friction Pendulum [11], [12], featuring a displacement capacity twice larger than its single surface counterpart, and the Triple Friction Pendulum [13]-[15], characterized by an adaptive stiffness and damping behavior at different intensity levels of the earthquake excitation, their mechanical behavior follows the same fundamental principles. The coefficient of friction $\left(\mu_{d y n}\right)$ and the effective radius of curvature $\left(R_{\text {eff }}\right)$ of the sliding surfaces determine the dynamic behavior of the device.
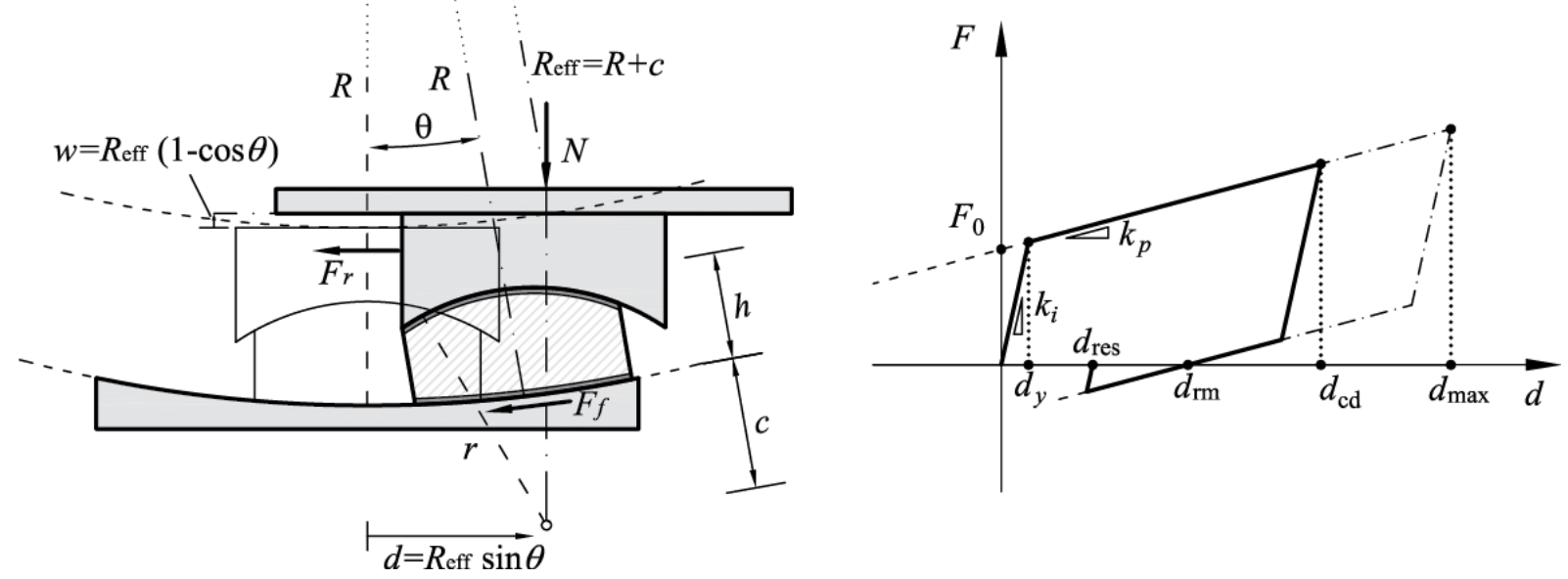

Figure 1 Kinematics and free body diagram of CSS (left) and idealized force-displacement relationship (right)

The total resisting force $(F)$ of the CSS is given by the sum of two contributions: a restoring force $\left(F_{r}\right)$ that is proportional to the horizontal displacement $(d)$ and is provided by the concave surface based on the pendulum mechanism, and a pure friction force $\left(F_{f}\right)$ developed at the sliding interface that controls the energy dissipation capability:

$$
F=F_{r}+F_{f}=k_{p} d+F_{0} \operatorname{sgn}(V) .
$$

In Eq. (1) $F_{0}=\mu_{d y n} \cdot N$ represents the characteristic strength of the CSS, with $N$ denoting the vertical load, $k_{p}=N / R_{\text {eff }}$ is the restoring stiffness, $d$ and $V$ indicate the horizontal displacement and velocity, respectively, and $\operatorname{sgn}(\cdot)$ is the signum function. Moreover, in Figure $1 d_{\max }$ is the maximum displacement, $d_{\mathrm{cd}}$ represents the design displacement, $d_{\text {res }}$ is the residual displacement at the end of the earthquake shaking and $d_{\text {rm }}$ denotes the so-called maximum static residual displacement identified 
by the equilibrium condition between the restoring force $F_{r}$ and the pure friction force $F_{f}$ in an idealized force-displacement cycle, namely $d_{\mathrm{rm}}=\mu_{d} \cdot R_{\text {eff }}$. The initial stiffness of the CSS (relevant to the presliding phase) is very high, typically two-folds higher than the restoring stiffness, e.g. $k_{i}=100 k_{p}$ [16] (value adopted in this paper). Based on Eq. (1), the dynamic friction coefficient $\mu_{d y n}$, which depends on the sliding material used at the interface, has a prominent role on the hysteretic behavior of the CSS. Besides conventional PTFE, whose first applications in sliding bearings for bridges date back to the '60s [17], filled PTFE [18], [19], Ultra High Molecular Weight Polyethylene (UHMWPE) [20], and Polyamide (PA) [21] have been more recently used as lining materials of the slider under a wide range of loads and environmental conditions.

a)

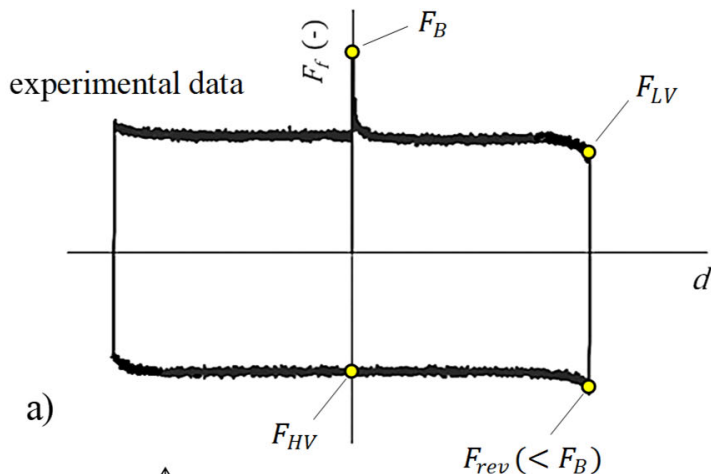

b)

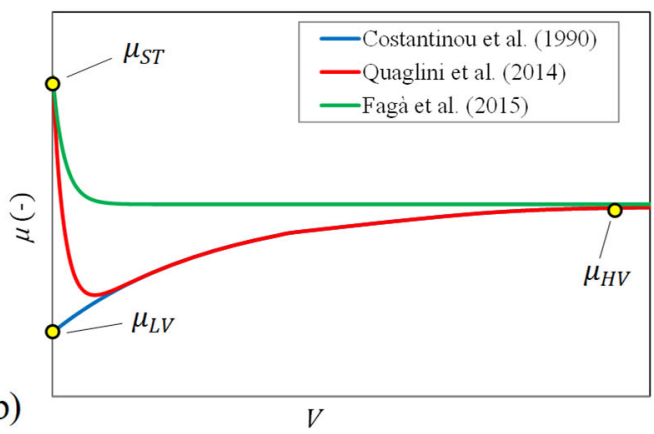

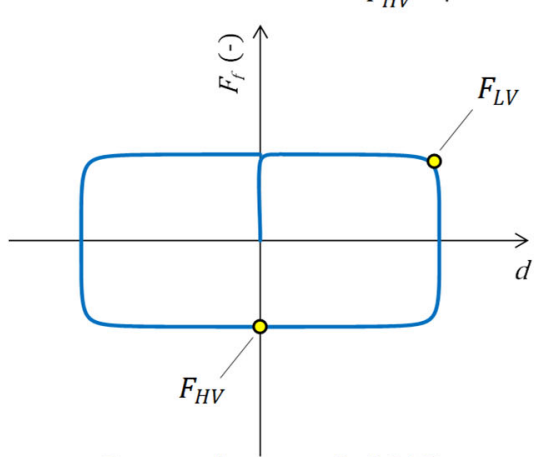

c) Constantinou et al. (1990)
$F_{\text {rev }}\left(<F_{B}\right)$

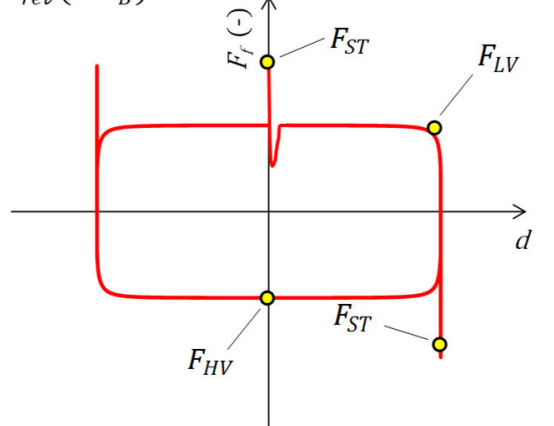

d) Quaglini et al. (2014)

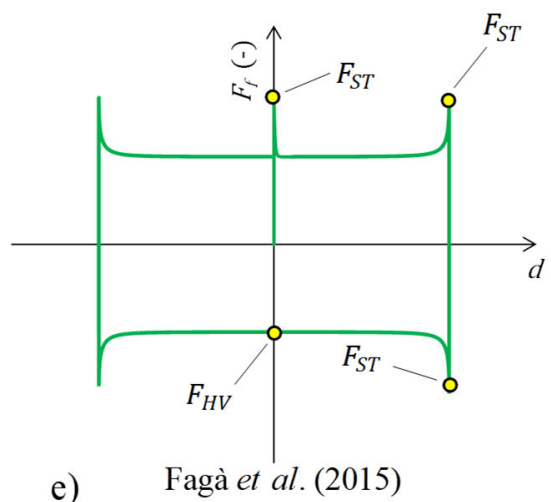

e)

Fagà et al. (2015)

Figure 2 Experimental friction loop measured on a steel-PTFE flat slider under unidirectional sinusoidal motion (a) and graphical comparison between Constantinou et al. [34], Quaglini et al. [27], and Fagà et al. [35] velocitydependent friction models (b) along with corresponding qualitative friction loops (c,d,e)

The coefficient of friction of thermoplastic materials changes with a number of factors including applied pressure, velocity of sliding, temperature, manufacturing variability, ageing and environmental effects, roughness of the mating surface, wear and contamination of the sliding surfaces [22]-[29]. For this reason, current code provisions, e.g. ASCE 7-16 [30], Eurocode 8 Part 2 - Bridges [31] and AASHTO Guide Specification for Seismic Isolation Design [32], allow incorporating so-called property modification factors $\lambda$ (whose theoretical basis dates back almost twenty years, see e.g. Constantinou et al. [22]) to account for variations of the design properties of seismic isolator units and, hence, of the isolation system as a whole. The advantage of this approach lies in its practical simplicity: the inherent variability of the seismic isolation properties during the service life of the structure is studied through two structural models based on upper-bound and lower-bound design properties of the isolators, which amplify or reduce their nominal properties (while keeping them confined within appropriately calibrated boundary limits) in order to account for the aforementioned variability effects 
(heating, velocity, manufacturing, ageing, environmental exposure, and contamination effects) in a simplified manner. The validity and reliability of this approach is strictly related to the capability of standardized prototype testing protocols to capture the main sources of variability of the isolators' behavior that are reflected in the property modification factors. Some critical remarks in the context of friction isolators were recently discussed by Benzoni and Lomiento [33].

Experimental research demonstrated the complexity of the friction mechanism especially regarding the dependence on the sliding velocity (see e.g. the experimental friction loop in Figure 2a), relevant to a steel-PTFE flat slider under unidirectional sinusoidal motion. During the motion of the CSS, the dynamic friction coefficient at sliding surface $\mu_{d y n}$ usually increases from a minimum value $\mu_{L V}$, in the low-velocity regime, to a steady value $\mu_{H V}$, in the high-velocity range (Figure $2 \mathrm{~b}$ ). This behavior can be modeled by using an exponential expression proposed by Constantinou et al. [34]

$$
\mu_{d y n}=\mu_{H V}-\left(\mu_{H V}-\mu_{L V}\right) \cdot e^{(-\alpha V)}
$$

where $\alpha$ is a transition rate parameter. The corresponding qualitative friction loop is shown in Figure 2c. However, this formulation is not able to predict the actual response of CSS isolators in the sticking phase preceding the triggering of the sliding motion. Experimental findings reveal that at the beginning of the motion and at any momentary sticking of the sliding surfaces, e.g. at motion reversals, the friction coefficient attains a higher value than the dynamic friction coefficient, which is known as static friction $\mu_{S T}$. In particular, the static coefficient of friction that contrasts the start of the motion is denoted as the breakaway friction coefficient $\mu_{B}$. The initiation of the sliding phase is accompanied by a clear drop in the frictional resistance, and, depending on the sliding material at the interface, $\mu_{B}$ can be 1.5 to 4.5 times larger than $\mu_{L V}$ [35]; moreover, the value of $\mu_{B}$ is affected by temperature, wear and contamination of the surfaces [24], [36]-[41]. Based on experiments on steel-PTFE interfaces, Constantinou et al. [34] suggested that for unworn PTFE a viable assumption for the ratio of the static to the low-velocity friction coefficient is about 4, and similar figures apply also to other sliding materials used by European manufacturers, including filled PTFE, UHMWPE and PA [21], [27], [42]. The static friction is governed by chemical bonds arising at the interface between the contact surfaces during the sticking phase. Since the number and strength of these bonds increases with the duration of sticking, the static friction coefficient at the breakaway $\mu_{B}$ is reasonably larger than the value observed at motion reversal $\mu_{\text {rev }}$ (cf. again Figure 2a). Therefore, to properly simulate the actual response of CSSs during both the breakaway (pre-sliding) and the sliding phases, the numerical formulation should include the breakaway friction coefficient besides the dynamic friction coefficient. Some modelling assumptions of the breakaway friction from earlier literature studies as well as the numerical formulation adopted in this paper are described in the next Section.

\section{MODELLING THE BREAKAWAY FRICTION}

Since the early 90's, several studies have investigated the dependence of the dynamic coefficient of friction on the contact pressure, velocity, temperature and travelled distance [34], [43]-[46], whereas both the breakaway $\mu_{B}$ and the motion reversal $\mu_{\text {rev }}$ coefficients of friction have been generally disregarded. In this context, experimental works demonstrated that the breakaway friction for PTFEstainless steel interfaces disappears after just one cycle of loading [38], [47] while for other sliding materials it persists even after several cycles, manifesting itself when the transition from the sticking phase to the motion implies a certain idle time [42]. 
A formulation suitable to account for both forms of static coefficient of friction, at breakaway and at motion reversal, respectively, was proposed by Quaglini et al. [27] by introducing a second exponential term in Eq. (2) to describe a smooth transition from $\mu_{S T}$ to $\mu_{L V}$ (Figure $2 \mathrm{~b}$ and $2 \mathrm{~d}$ ):

$$
\mu_{d y n}=\mu_{H V}-\left(\mu_{H V}-\mu_{L V}\right) \cdot e^{\left(-\alpha_{1} V\right)}+\left(\mu_{S T}-\mu_{L V}\right) \cdot e^{\left(-\alpha_{2} V\right)} \cdot\left(\frac{|\operatorname{sgn}(V)-\operatorname{sgn}(d)|}{2}\right)
$$

where, similar to Eq. (2), $\alpha_{2}$ is an additional parameter governing the change of friction from the static to the dynamic regime. In a general unidirectional cyclic motion, the conditional function in round brackets at the end of Eq. (3) is nonzero only at motion reversal, thus governing the transition from the dynamic to the static friction coefficient when the sliding pad reverses its motion after a stop. However, to capture the breakaway friction, this conditional function is eliminated at the initiation of motion when velocity and displacement have the same sign. This formulation was implemented into the general-purpose ABAQUS finite element (FE) program [48] and used to investigate the response of a CSS under unidirectional displacement-controlled time histories. Besides being limited to unidirectional trajectories, the main drawback of this formulation is represented by its inability to account for different values of the friction coefficient at the breakaway and at motion reversal, as it implicitly assumes $\mu_{B}=\mu_{\text {rev }}=\mu_{S T}$. Although this issue is still unresolved even in more recent formulations, it is worth noting that in real implementations the CSS isolators are subjected to threedimensional earthquake excitations, therefore a new sticking phase following the breakaway is very unlikely to occur (although the velocity along one direction may be zero, the component in the orthogonal direction is nonzero).

Due to the complexity encountered when handling the non-monotonic dependency of friction on velocity associated with the drop of friction at the breakaway and at motion reversal, available commercial FE codes are still nowadays based on the friction model developed by Constantinou et al. [34]. A simple bilinear force-displacement behaviour can be indeed easily reproduced in nonlinear time history analyses (NLTHAs). This can be accomplished by means of either a coupled plasticity model [49], in which the plastic deformation corresponds to the displacement occurring during the accommodated sliding motion and the elastic deformation to the shear deformation of the sliding material, or a generalized Bouc-Wen smoothed plasticity model [50], whose parameters satisfy an evolutionary differential equation extended to seismic isolation bearings by Nagarajaiah et al. [51]. The coupled plasticity model is used, for instance, in OpenSees [52], whereas the generalized BoucWen model is implemented in SAP2000 [53], MIDAS GEN [54] and 3-D BASIS [55], [56], among others. Hence, all these calculation tools are unable to account for the static friction coefficient and disregard its effect on the response history analysis, which may lead to an underestimation of the peak floor accelerations and maximum inter-storey drifts transferred to the superstructure, which are indeed likely to be experienced in the sticking phase before the breakaway. To overcome this issue, both European and the North American seismic design codes [57]-[59] allow one to model the forcedisplacement response of CSSs through a simple bilinear constitutive law whose constitutive parameters are adjusted by applying suitable property variation factors so as to indirectly incorporate all sources of variability, including the breakaway friction, in the response of the isolators.

The effect of breakaway friction $\mu_{B}$ was firstly introduced in NLTHAs by Constantinou et al. [34] by adapting the Bouc-Wen model. The response of a rigid mass supported by flat sliding bearings and excited at the base by a unidirectional sine waveform was investigated, outlining that the effects of the breakaway friction become important when the ratio of breakaway to low-velocity friction coefficient 
$\left(\mu_{B} / \mu_{L V}\right)$ is larger than the ratio of high- to low-velocity friction coefficient $\left(\mu_{H V} / \mu_{L V}\right)$.

In recent years, Fagà et al. [35] carried out several unidirectional NLTHAs in OpenSees FE code [60] considering different layouts of both multi-storey isolated buildings and CSS isolators and replacing the low velocity $\mu_{L V}$ with the static coefficient of friction $\mu_{S T}$ in Eq. (2)

$$
\mu_{d y n}=\mu_{H V}-\left(\mu_{H V}-\mu_{S T}\right) \cdot e^{(-\alpha V)}
$$

The adopted friction model and the relevant force-displacement loop are represented in Figure $2 \mathrm{~b}$ and 2e. It can be noted that, besides the peaks of the friction force at breakaway and at sliding motion reversal, further peaks (all having amplitudes $F_{S T}=\mu_{S T} \cdot N$ ) are generated also in the slow-down phase when the CSS approaches the maximum displacement. To the authors' knowledge, only the polyamide exhibits such frictional behaviour [42], while the majority of the sliding materials are compliant with the velocity dependent formulation by Quaglini et al. [27]. For such materials, the model by Fagà et al. [35] in NLTHAs could lead to an underestimation of the maximum displacement $d_{\text {max }}$, as well as to an overestimation of the residual displacements $d_{\text {res }}$. Indeed, when the CSS is slowly oscillating during the coda-stage of the quake, the model would provide a higher friction force that opposes the motion. However, in the referred study the authors concluded that ignoring the static friction seems to have a small effect on the maximum displacement, but leads to a not negligible underestimation of the internal forces in the structure [35].

Gandelli et al. [61] studied the effect of different breakaway levels and friction materials on the response of a mid-rise building protected by means of CSS isolators. Unidirectional NLTHAs were carried out in OpenSees code [60], by modelling the CSS units through the standard "SingleFrictionPendulumBearingElement" (SFPBE) with an associated "VelDependent" friction model [62] in line with Eq. (2). The breakaway friction was introduced in the structural model through a one-directional "Truss" element acting in parallel to the isolator element (hence aligned to the direction of ground motion) whose stress-strain behaviour was described through the "MinMax" material object (Figure 3). The "MinMaxTruss" (MMT) reproduces a linear elastic force-displacement behaviour as long as the strain is below a given threshold, whereas for higher deformations the material fails, and from that point on, it provides zero axial strength and stiffness. A criterion to define the constitutive parameters of the element was provided in order to achieve the desired (target) breakaway friction level [61]. The study confirmed that the breakaway friction has a major effect on the peak floor acceleration (PFA) and on the shear at the isolation level, whereas in general the influence on the maximum displacements of CSS units is modest. In particular, the effect on PFA and base shear is negligible for low-friction $\left(\mu_{d y n}=0.01 \div 0.03\right)$ materials and becomes important for medium$\left(\mu_{d y n}=0.03 \div 0.08\right)$ and high-friction $\left(\mu_{d y n}=0.05 \div 0.13\right)$ materials when the ratio between the breakaway and the low-velocity friction coefficients is larger than $2.5\left(\mu_{B} / \mu_{L V}>2.5\right)$. This conclusion is somehow consistent with previous numerical observations made by Constantinou et al. [34]. 

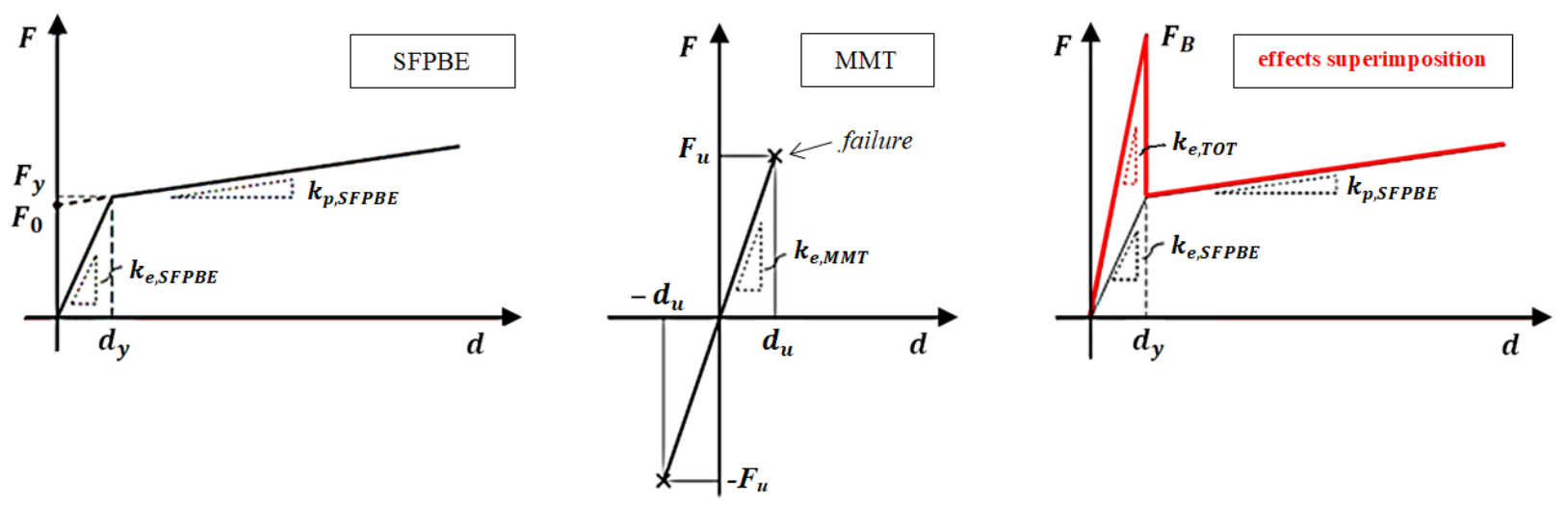

Figure 3 Force-displacement response of the SFPBE element (left), MMT element (centre), and effects superimposition (right)

Despite the interesting hints on the effects of the breakaway friction derived from the latter study [61], the authors could not claim a general validity for its conclusions, since only one building prototype under unidirectional ground motions with a narrow frequency content was analysed. Moreover, the MMT formulation is only suitable for unidirectional seismic inputs acting along the direction of the truss, thus it is unable to deal with bidirectional ground motions. To this aim, a more extensive parametric study turns out to be necessary to draw more general conclusions on the effect of the breakaway friction, which has motivated this research work.

Only very recently, a novel "CSSBearing_BVNC" (hereafter called BVNC) element with an ad-hoc associated friction model has been developed in a customized version of OpenSees [63]. Similar to the conventional "VelocityAndNormalForceDependentFriction" already implemented in the standard OpenSees code [62], the BVNC element can be used in NLTHAs of structures subjected to bidirectional ground motions and is capable to account for the dependence of friction on the instantaneous sliding velocity (effect $V$ ) and normal load (effect $N$ ) as the standard element does. The two main novelties of the BVNC element are represented by the capability to reproduce the degradation of the kinetic friction induced by the heating of the sliding material occurring during the cyclic motion of the articulated slider (effect $C$ ) and the inclusion of the breakaway friction (effect $B$ ). By properly setting the eight constitutive parameters of the BVNC element, it is possible to selectively account for or neglect each of the four aforementioned effects. 

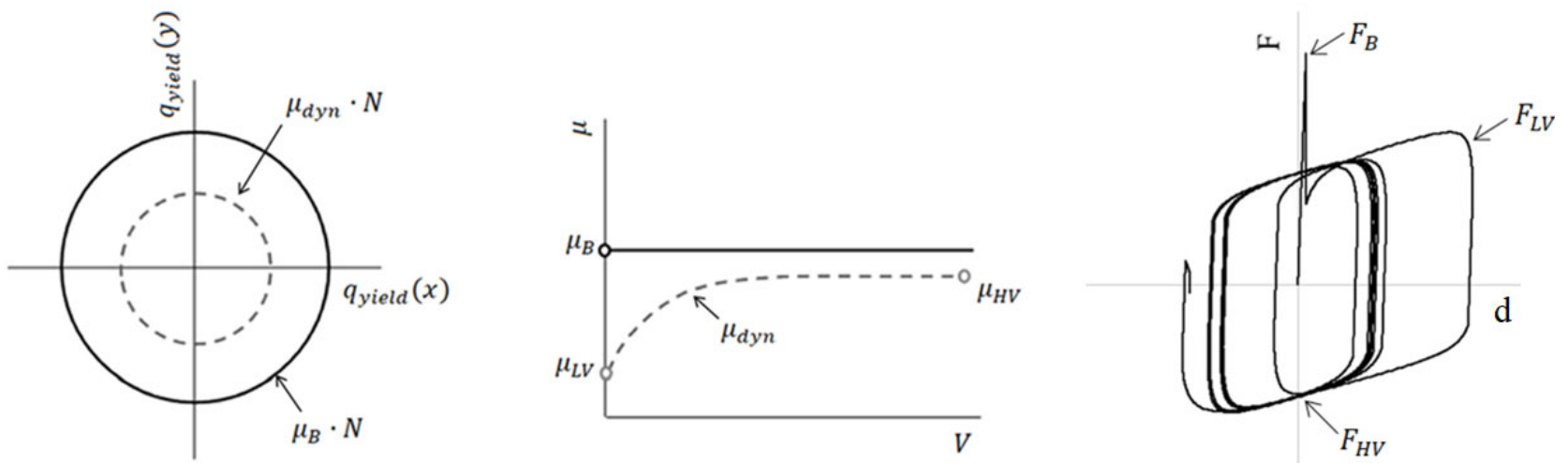

Figure 4 The " $B V$ " element adopted in the present study: relevant bidirectional plasticity domain (left), associated friction model (centre) and response of the element to a sinusoidal excitation [adapted from Gandelli et al. [63]]

In the present work, a reduced version of the BVNC element accounting for the breakaway and the velocity effects only ("BV" model), as represented in Figure 4, is adopted. The transition between static and dynamic friction is accomplished by two distinct plastic material models, one for the static friction ruling the breakaway phenomenon, and the other for the dynamic friction after the initiation of the sliding motion. In particular, at each time instant, the bidirectional plasticity domain of the element is computed according to the following conditional expression

$$
F_{f} \cong q_{\text {yield }}= \begin{cases}\mu_{B} \cdot N & h<1 \\ \mu_{\text {dyn }} \cdot N & h \geq 1\end{cases}
$$

where $h$ is an internal variable that is incremented by one every time that the plastic threshold is reached and $\mu_{d y n}=\mu_{d y n}(V)$ is expressed by Eq. (2). Therefore, at the beginning of the analysis $h=$ 0 and the yield force is defined by a circular yield domain $q_{y i e l d}=\mu_{B} \cdot N$ according to a Coulomb friction model, whereas at the first yielding the variable $h$ is updated to $h=1$ and the plasticity algorithm switches to the velocity-dependent friction model $q_{y i e l d}=\mu_{d y n}(V) \cdot N$. Figure 4-right shows an example of the force-displacement loops of the BV element subjected to a sinusoidal groundmotion acceleration. The formulation presented in Eq. (5) has the following advantages in comparison with the previous formulations: 1) it allows performing bi-directional NLTHAs accounting for the breakaway friction, which was not possible in the formulation developed by Quaglini et al. 2014 [27]; 2) it explicitly incorporates two friction behaviours for the breakaway and for the sliding phase separately, namely a Coulomb-type friction model and a velocity-dependent friction model. In the initial sticking phase, the plastic threshold of the proposed formulation is ruled by the Coulomb friction model with $\mu=\mu_{B}$, so that the corresponding strength is independent from the velocity variable. It must be remarked indeed that the OpenSees software accounts in a single variable for two contributions, namely the plastic (i.e. sliding) and the elastic deformation rates. Although the latter contribution associated with the elastic deformation in shear of the isolator element is reasonably small in typical modelling assumptions of curved surface sliders, it is never null and the OpenSees code computes a non-zero velocity value even in the sticking phase [60]. Therefore, in the Fagà et al. [35] formulation, this non-zero velocity value produces an instantaneous friction value that is lower than the original static friction value $\mu_{S T}$ (based on Eq. (4)), thus underestimating the actual plastic threshold associated with the breakaway phenomenon. 
Based on the BV formulation described above, the influence of the breakaway friction on the seismic response of buildings isolated with CSS is investigated numerically in this paper. The parameters adopted for the numerical analyses are described in the next Section, while the results and some design recommendations are discussed in Section 4.

\section{PARAMETRIC STUDY}

A broad parametric study is carried out, which comprises 9072 bidirectional NLTHAs including different properties of the superstructure, of the CSS isolation system, as well as a large group of ground-motion records having different intensity levels and frequency contents. The NLTHAs are performed with the structural analysis program OpenSees v. 2.5.4 [60], using the BV friction element described in Section 2. A statistical elaboration of the obtained results is then performed to obtain useful design recommendations regarding the influence of the breakaway friction on the trigger acceleration at which sliding motion is engaged, as well as the influence of the breakaway friction on the seismic response in terms of peak floor acceleration, inter-storey drift, base shear and CSS displacement demand.

\subsection{Structural models}

Three different structural models representative of a double-symmetric, square-plan two-storey, four-storey and six-storey reinforced concrete $(\mathrm{RC})$ building frames are analyzed, as shown in Figure 5. The buildings, conceived as moment-resisting frames, are designed according to the Italian Building Code NTC2018 [64] $]^{1}$. They are constituted by four structural frames with $6 \mathrm{~m}$ long bays in both the longitudinal $(x)$ and the transversal $(y)$ direction, while the interstorey height is taken as $3 \mathrm{~m}$ at all levels. Concrete grade is taken as $\mathrm{C} 25 / 30$ and steel reinforcement as B450C grade (yield stress equal to $450 \mathrm{MPa}$ ), while the modulus of elasticity and density of RC members is assumed as $31.476 \mathrm{GPa}$ and $25 \mathrm{kN} / \mathrm{m}^{3}$, respectively. As illustrated in Figure 5, the cross-section of the columns varies along the building height, while the cross-section of all the beams is assumed to be $30 \times 60 \mathrm{~cm}$ for every frame and for every building. A $20-\mathrm{cm}$ thick RC slab is considered at every level, which results in a characteristic value of the dead loads of $g_{k}=5 \mathrm{kN} / \mathrm{m}^{2}$, while the characteristic value of the live loads for residential buildings is $q_{k}=2 \mathrm{kN} / \mathrm{m}^{2}$ [64]. Based on the combination coefficients of the NTC2018 [64], the design load per unit area considered in the seismic combination of actions is

$$
q_{d}=\gamma_{G} \cdot g_{k}+\gamma_{Q} \cdot \psi_{2} \cdot q_{k}=1.3 \cdot 5+1.5 \cdot 0.3 \cdot 2=7.4 \mathrm{kN} / \mathrm{m}^{2}
$$

which, multiplied by the floor area $\left(18 \times 18 \mathrm{~m}^{2}=324 \mathrm{~m}^{2}\right)$ gives a floor weight of $w_{f}=2397.6 \mathrm{kN}$, corresponding to a floor mass of $m_{f}=244.404 \mathrm{t}$. A "RigidFloorDiaphragm" multi-points constraint [62] is introduced in the OpenSees model to simulate the behavior of a rigid floor. Therefore, the floor mass $m_{f}$ can be lumped at a master node located at the centroid of each floor (centre of mass), along with a mass moment of inertia about vertical axis $(z)$ (rotary inertia of floor about master node) equal to $I_{0}=\frac{m_{f}\left(18^{2} \times 18^{2}\right)}{12}$, which is consistent with the assumption of uniformly distributed mass per unit area [53], [62].

\footnotetext{
${ }^{1}$ The NTC2018 [64] is based on theoretical principles that are similar to the European Design Code EC8 [65].
} 


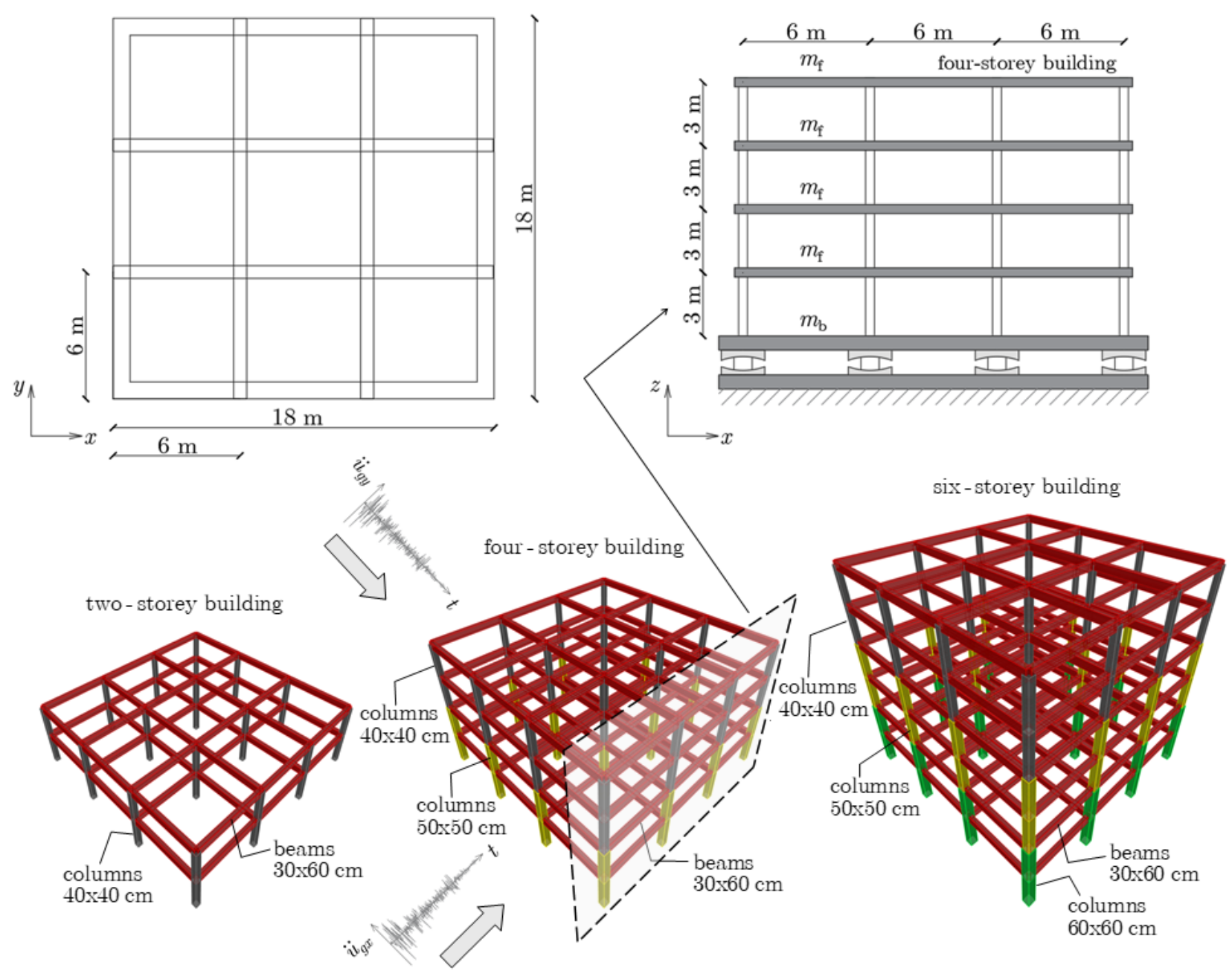

Figure 5 Structural model considered in the parametric study: plan view and front view of representative fourstorey building (top), 3D view of double-symmetric two-, four- and six-storey moment resisting frames (bottom)

Table 1 Fundamental period of the three moment resistant concrete frames analyzed in the parametric study

\begin{tabular}{ccc}
\hline $\begin{array}{c}\text { Number of } \\
\text { floors }\end{array}$ & $\begin{array}{c}\text { Fundamental period from modal } \\
\text { analysis on 3D frame } T_{s S 1}[\mathrm{~s}]\end{array}$ & $\begin{array}{c}\text { Approximated fundamental period for a } \\
\text { moment resistant concrete frame } T_{s s 1}^{\text {appr }}[\mathrm{s}]^{\dagger}\end{array}$ \\
\hline 2 & 0.290 & 0.287 \\
4 & 0.477 & 0.484 \\
6 & 0.648 & 0.655 \\
\hline
\end{tabular}

† based on NTC2018 [64] and EC8 [65] formula $T_{1}=C_{t} \cdot H^{3 / 4}$, with $C_{t}=0.075$ and $H$ the height of the building in [m]

The superstructure is modeled as a linear elastic system with "ElasticBeamColumn" elements [62] for beams and columns with appropriate cross-sectional characteristics. Given the perfect symmetry along the two $x$ and $y$ directions in terms of mass and stiffness, the first two modes of vibration of the superstructure are purely translational and the third is purely torsional. The fundamental period $T_{s s 1}$ for the three superstructures (associated with both the translational modes of vibration) is reported in Table 1. It is worth noting that the calculated period $T_{S S 1}$ is very close to the approximated fundamental period that can obtained by the analytical formula reported in NTC2018 [64] and EC8 [65] for a moment resistant space concrete frame (see e.g. EC8 [65], Eq. (4.6)). From Table 1 it can be observed that the three fundamental periods cover a range of practical situations that can be observed in typical 


\section{RC framed buildings.}

The buildings are isolated with sixteen CSS isolators located underneath each column, and connected to each other via a base slab of mass $m_{b}$ acting as a rigid diaphragm, which prevents differential displacements. Two mass ratios $m_{b} / m_{f}=1.0$ and 2.0 between the base mass and the floor mass are considered for each building, thus including six different building configurations in the parametric study, whose designation is listed in Table 2.

Table 2 Building configurations considered in the parametric study

\begin{tabular}{cccc}
\hline \multirow{2}{*}{ Number of storeys } & Building class & Base mass to floor mass ratio $m_{b} / m_{f}$ & Building ID \\
\hline \multirow{2}{*}{2} & $2 \mathrm{~S}$ & 1 & $2 \mathrm{~S} \_1$ \\
& & 2 & $2 \mathrm{~S} \_2$ \\
4 & $4 \mathrm{~S}$ & 1 & $4 \mathrm{~S} \_1$ \\
& \multirow{2}{*}{$6 \mathrm{~S}$} & 2 & $4 \mathrm{~S} 22$ \\
& & 1 & $6 \mathrm{~S} \_1$ \\
\end{tabular}

Table 3 Parameters of the dynamic friction and of the breakaway friction considered in the parametric study

\begin{tabular}{|c|c|c|c|c|c|}
\hline $\begin{array}{l}\text { Friction } \\
\text { class }\end{array}$ & $\begin{array}{l}\text { Representative } \\
\text { case }\end{array}$ & $\begin{array}{l}\text { Friction coefficient } \\
\qquad\left(\mu_{L V}, \mu_{H V}\right)\end{array}$ & $\begin{array}{l}\text { Breakaway } \\
\text { class }\end{array}$ & $\begin{array}{l}\text { Breakaway } \\
\text { friction } \mu_{B}\end{array}$ & $\begin{array}{l}\text { Friction } \\
\quad \text { ID }\end{array}$ \\
\hline \multirow{3}{*}{$\mathrm{LF}$} & \multirow{3}{*}{ lubricated PTFE / UHMWPE } & \multirow{3}{*}{$(0.01,0.025)$} & $\mu_{B} / \mu_{L V}=1$ & 0.01 & LF_1 \\
\hline & & & $\mu_{B} / \mu_{L V}=2$ & 0.02 & LF_2 \\
\hline & & & $\mu_{B} / \mu_{L V}=4$ & 0.04 & $\mathrm{LF}_{-} 4$ \\
\hline \multirow{3}{*}{ MF } & \multirow{3}{*}{ unlubricated PTFE / UHMWPE } & \multirow{3}{*}{$(0.03,0.075)$} & $\mu_{B} / \mu_{L V}=1$ & 0.03 & MF_1 \\
\hline & & & $\mu_{B} / \mu_{L V}=2$ & 0.06 & MF_2 \\
\hline & & & $\mu_{B} / \mu_{L V}=4$ & 0.12 & MF_4 \\
\hline \multirow{3}{*}{$\mathrm{HF}$} & \multirow{3}{*}{ filled PTFE } & \multirow{3}{*}{$(0.05,0.125)$} & $\mu_{B} / \mu_{L V}=1$ & 0.05 & $\mathrm{HF}_{-} 1$ \\
\hline & & & $\mu_{B} / \mu_{L V}=2$ & 0.10 & HF_2 \\
\hline & & & $\mu_{B} / \mu_{L V}=4$ & 0.20 & $\mathrm{HF}_{-} 4$ \\
\hline
\end{tabular}

The CSSs have an effective radius of curvature $R_{\text {eff }}=3000 \mathrm{~mm}$, which corresponds to an undamped period $T_{i s o}=2 \pi \sqrt{R_{\text {eff }} / \mathrm{g}}=3.48 \mathrm{~s}$. The CSS isolators are modeled with the "BV" elements described in Section 2. In particular, the "VelDependent" friction model of the "SingleFPSSimple3d" OpenSees element is used to describe the dynamic friction coefficient, according to the exponential formulation of Eq. (2). This assumption implicitly neglects the influence of the normal force and of the heating phenomena on the variation of the friction coefficient. Three friction classes representative of low friction (LF), moderate friction (MF), and high-friction (HF) sliding materials are included in this study, whose low-velocity and high-velocity friction coefficients are listed in Table 3 . These friction classes correspond to the behavior at regular temperature $\left(10-30^{\circ} \mathrm{C}\right)$ of three representative cases of sliding interface, namely lubricated PTFE and UHMWPE pads against polished steel (LF), 
unlubricated PTFE and UHMWPE (MF), and filled PTFE (HF), respectively [25]. According to previous literature studies [20], [66], a ratio of $\mu_{H V} / \mu_{L V}=2.5$ was assumed for all friction classes, and the transition rate parameter $\alpha$ from the low-velocity to the high-velocity friction was set to $\alpha=$ $0.0055 \mathrm{~s} / \mathrm{mm}$. As to the influence of the breakaway friction, three breakaway classes for each friction class are considered depending on the $\mu_{B} / \mu_{L V}$ ratio: no breakaway for $\mu_{B} / \mu_{L V}=1$, intermediate breakaway for $\mu_{B} / \mu_{L V}=2$, and high breakaway for $\mu_{B} / \mu_{L V}=4$. The first case $\left(\mu_{B} / \mu_{L V}=1\right)$ corresponds to friction models implemented in conventional structural analysis programs, which neglect the breakaway friction; this model will represent the baseline reference for comparisons. The third case $\left(\mu_{B} / \mu_{L V}=4\right)$ is motivated by the study of Constantinou et al. [34] in which it was shown that the breakaway friction has considerable effects when $\mu_{B}$ is around four times the low-velocity friction coefficient. Representative cases of $\mu_{B} / \mu_{L V}=4$ may be caused by unfavourable effects induced by low temperature, poor maintenance conditions of the sliding surfaces, mounting defects [67], as well as possible permanent setting of the surfaces. The second case $\mu_{B} / \mu_{L V}=2$ represents a typical situation occurring with lubricated sliding materials. Combining the values of friction class and breakaway class, 9 sets of friction parameters are considered, as listed in Table 3, which multiplied by the 6 building configurations in Table 2 leads to a total of 54 structural cases of base-isolated buildings included in this parametric study.

Damping assumption in a base-isolated structure is notoriously made with a substructure approach, by separating the superstructure component alone from the base-isolation system [68]. Building on suggestions from the relevant literature on the improper use of superstructure Rayleigh damping [69], [70], the superstructure damping has been modeled with a stiffness proportional formulation, whose parameters are calibrated to achieve a $5 \%$ viscous damping ratio at $T=T_{\text {iso }}$.

\subsection{Seismic input}

Two horizontal components of the ground-motion acceleration were applied to the structures, whereas the vertical component of the seismic input was ignored in the NLTHAs. As a result, the influence of the normal force on the friction coefficient was neglected in this study. The "BV" elements described in Section 2 makes it possible to perform bidirectional NLTHAs incorporating the effect of the breakaway friction in the sticking phase, as well as a velocity-dependent friction model in the sliding phase. Therefore, bidirectional components of natural ground-motion records are selected for this parametric study. For the sake of generality, two installation sites located in southern Italy, characterized by two different levels of seismic hazard, are considered: the site of Lamezia Terme (latitude $38.58^{\circ}$, longitude $16.18^{\circ}$ ) belongs to the seismic zone 1 of the old national seismic classification [71] (the most dangerous area, with high probability of occurrence of strong earthquakes), while the site of Naples (latitude $40.86^{\circ}, 14.28^{\circ}$ ) belongs to the seismic zone 2 of the old national seismic classification [71] (strong earthquake may occur in this area). Assuming a typical residential building use, ordinary structure with nominal life $V_{N}=50$ years, functional class II corresponding to $C_{U}=1.0$, the resulting reference life of the structure is $V_{R}=V_{N} \cdot C_{U}=50$ years. Based on performance-based design principles, the seismic action is defined according to two distinct limit states or design levels. The acronyms of these two limit states in the NTC2018 [64] are "SLD" and "SLV": the former corresponds to a serviceability state associated with damage-limitation requirement and a $63 \%$ probability of exceedance during $V_{R}$ (return period of the design earthquake of 50 years), the latter denotes an ultimate limit state associated with life safety requirement and a $10 \%$ 
probability of exceedance during $V_{R}$ (return period of the design earthquake of 475 years). A topography condition $T_{1}$ is assumed, while two different soil conditions designated as soil class A and soil class $\mathrm{C}$ are considered, which correspond to a rock-like geological formation (very rigid soil) and to a medium-dense sand, gravel or stiff clay formation, respectively.
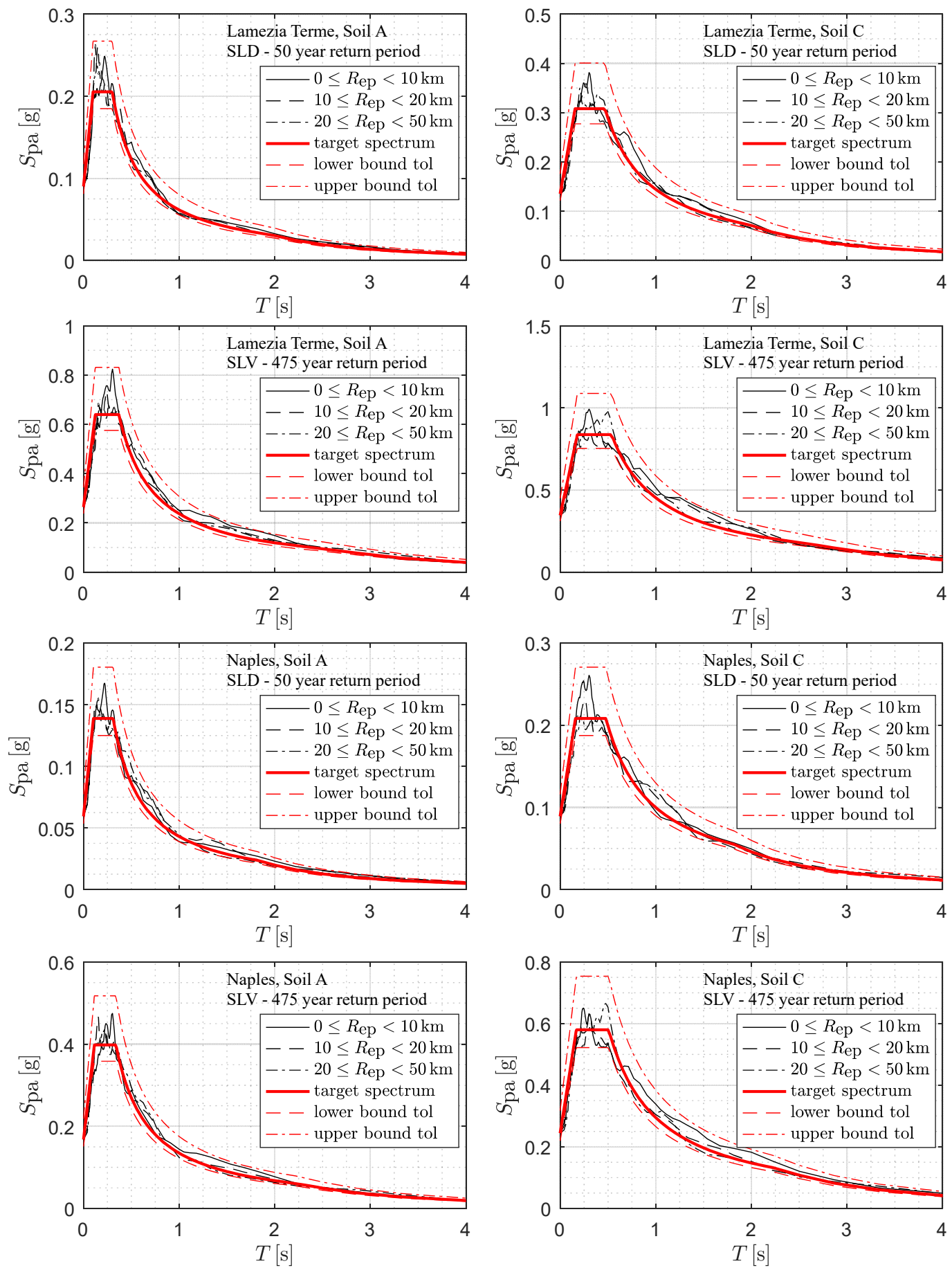

Figure 6 Comparison between target response spectrum and median response spectrum (average of 14 components for each class) for the two installation sites, two soil classes, and three epicentral distances

For each installation site, soil class and limit state $(2 \times 2 \times 2=8$ combinations), a suite of 21 independent bidirectional ( $x$ and $y$ components of the earthquake excitation) natural ground-motion records are selected from the European strong-motion database [72] among earthquakes with moment 
magnitude $5 \leq M_{w} \leq 8$. These 21 records include 7 events recorded at epicentral distance $0 \leq R_{e p}<$ $10 \mathrm{~km}$ ( $\mathrm{R}_{1}$ class), 7 events with $10 \leq R_{e p}<20 \mathrm{~km}$ ( $\mathrm{R}_{2}$ class), and the remaining 7 events with $20 \leq$ $R_{e p}<50 \mathrm{~km}$ ( $\mathrm{R}_{3}$ class), so as to include different fault distances. The records have been selected by means of the software REXEL v. 3.5 [73] to be spectrum-compatible with the response spectrum of the 8 aforementioned combinations of installation site, soil class and limit state. The acceleration time histories are scaled in magnitude with two scale factors in either direction $\left(\mathrm{SF}_{\mathrm{x}}\right.$ and $\left.\mathrm{SF}_{\mathrm{y}}\right)$ in order to match the target acceleration response spectrum at 5\% damping level in the range of periods [0.15 - 4.00] s, with an acceptable lower and upper tolerance of $10 \%$ and $30 \%$. Maximum average of the scale factors for each set of accelerograms (seven pairs) has been selected equal to 5. The Peak Ground Acceleration (PGA) values of the 8 target response spectra are listed in Table 4, while a comparison between the median response spectrum from the seven pairs of records (14 components in each epicentral distance range) and the target response spectrum is illustrated in Figure 6. Full seismological details of the selected ground motions including the original (unscaled) PGA and peak ground velocity (PGV) are reported in Appendix A - Table 6, Table 7, Table 8 and Table 9. The ground motions have been coded according to the following nomenclature: "SITE NAME - SOIL CLASS LIMIT STATE - EPICENTRAL RANGE - RECORD NUMBER". As an example, LA-C-SLV-R2$\mathrm{S} 3$ corresponds to the third (out of the seven) earthquake event selected for the Lamezia Terme site, soil class C, SLV limit state and epicentral range such that $10 \leq R_{e p}<20 \mathrm{~km}$.

Table 4 Peak ground acceleration relevant to the 8 target response spectra considered in the parametric study

\begin{tabular}{cccc}
\hline Installation site & Soil class & Limit state & PGA [g] \\
\hline \multirow{3}{*}{ Lamezia Terme } & \multirow{2}{*}{ A } & SLD & 0.090 \\
& & SLV & 0.264 \\
& $\mathrm{C}$ & SLD & 0.135 \\
\multirow{3}{*}{ Naples } & $\mathrm{A}$ & SLV & 0.346 \\
& & SLD & 0.059 \\
& $\mathrm{C}$ & SLV & 0.168 \\
& $\mathrm{C}$ & SLD & 0.089 \\
& & SLV & 0.244 \\
\hline
\end{tabular}

\section{RESULTS AND DISCUSSION}

\subsection{Influence of the breakaway on the trigger acceleration}

As already highlighted in previous studies [34], [35], [61], [63], in the sticking phase preceding the sliding motion of CSS, the structure behaves as a conventional fixed-base frame entirely subjected to the ground-motion acceleration. The higher the breakaway friction, the longer the duration of the initial sticking phase and the higher the effects of ground motion acceleration on peak floor accelerations, base-shear, and inter-storey drift [61]. Therefore, an essential piece of information for structural designers is the trigger acceleration $a_{\text {trigger }}$, meant as the minimum value of the ground acceleration needed to engage the sliding of CSS units; indeed, for earthquakes characterized by a peak ground acceleration lower than $a_{\text {trigger }}$, the isolation system would not be activated, with potential detrimental consequences on the internal forces in the superstructure.

A simplified analytical approach to calculate $a_{\text {trigger }}$ can be easily derived by the analysis of the simple two-degree-of-freedom (2DOF) system represented in Figure 7, which consists of two masses, 
namely $M_{S S}$ (superstructure mass) and $M_{B S}$ (base mass), connected to the ground by a CSS bearing with coefficient of friction at breakaway $\mu_{B}$ and dynamic coefficient of friction $\mu_{d y n}$ in accordance with Eq. (2). Whilst the CSS is in the sticking phase, the system behaves as a single-degree-of-freedom (SDOF) system with fundamental period $T_{S S}=2 \pi \sqrt{M_{S S} / K_{S S}}, K_{S S}$ denoting the lateral stiffness of the superstructure. The sliding motion is triggered when the shear force through the CSS, which results from the inertial forces acting on the superstructure mass $M_{S S}$ and on the base mass $M_{B S}$, exceeds the resisting breakaway frictional force $F_{B}=\mu_{B}\left(M_{S S}+M_{B S}\right) \mathrm{g}$, g being the acceleration of gravity. This condition is achieved when the ground-motion acceleration $a_{\mathrm{g}}$ is larger than the trigger value $a_{\text {trigger }}$ [21]

$$
a_{\text {trigger }}^{\text {analytical }}=\mu_{B}\left(\frac{M_{S S}+M_{B S}}{\beta \cdot M_{S S}+M_{B S}}\right) \mathrm{g}
$$

where $\beta$ is the ratio between the spectral acceleration evaluated at the superstructure fundamental period $S_{a}\left(T_{S S 1}\right)$ and the PGA. It is worth noting that according to Eq. (7) the trigger acceleration depends on the breakaway coefficient of friction $\mu_{B}$, on the characteristics of the superstructure (mass distribution between base and superstructure, and fundamental period), and on the shape of the elastic response spectrum of the ground motion (hence on its frequency content). Neglecting the breakaway coefficient of friction and adopting Eq. (2) to model the frictional behaviour of the CSS would lead to an underestimation of the trigger acceleration, since $\mu_{L V}$ would replace $\mu_{B}$ in Eq. (4), thereby leading to unsafe design for the superstructure. Indeed, the designer would assume that, for a certain earthquake excitation, the isolation system is in a sliding phase whereas it may still persist in a sticking phase and the ground motion acceleration would be entirely transferred to the superstructure.

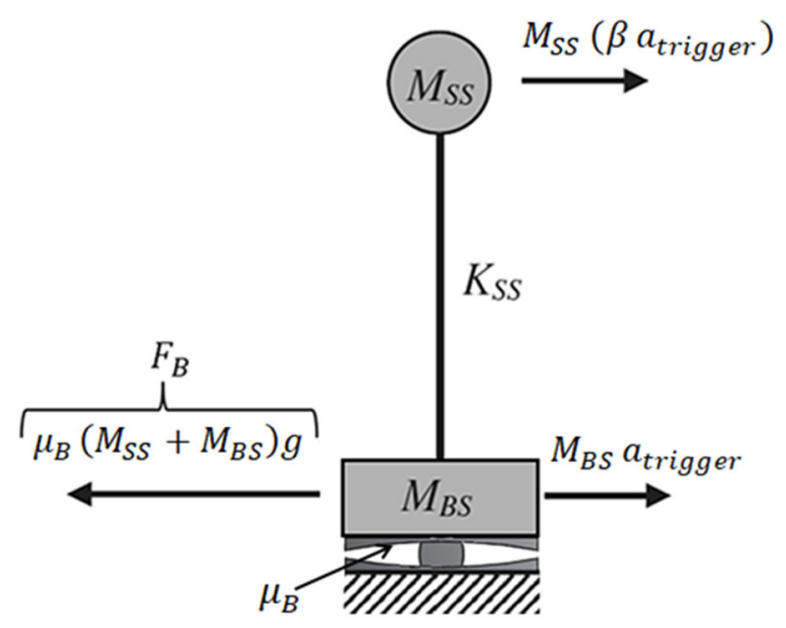

Figure 7 Dynamic equilibrium of horizontal forces acting on a 2DOF lumped mass structural model before sliding initiation (breakaway phase) of CSS isolators, adapted from [61]

Since the breakaway friction coefficient affects the transition between the sticking and the sliding phases of the CSSs, it influences the time-history response of the isolated building. In Figure 8 the displacement bidirectional orbits described by the CSS isolation system of the building 6S_1, friction class MF subjected to the earthquake LA-A-SLD-R1-S1 are shown for three different values of the breakaway friction coefficient. The yield domain is constructed as a circular domain having radius $d_{y}=F_{B} / k_{i}$, being $d_{y}$ the yield displacement of the CSS (cf. Figure 1-right). Based on the assumption 
on the initial stiffness of CSSs $k_{i}=100 k_{p}$ [16], the yield displacement is expressed as a function of the breakaway friction and the radius of curvature only, namely $d_{y}=\mu_{B} R_{\text {eff }} / 100$. It is clearly seen that in the case $\mu_{B} / \mu_{L V}=4.0$, the yield domain is not crossed by the displacement orbit, which implies that the CSS persists in the sticking phase throughout the time-history response, and the building behaves as a fixed-base structure accordingly. This occurs because the ground-motion acceleration of the assumed low intensity earthquake is not able to overcome the breakaway frictional resistance.
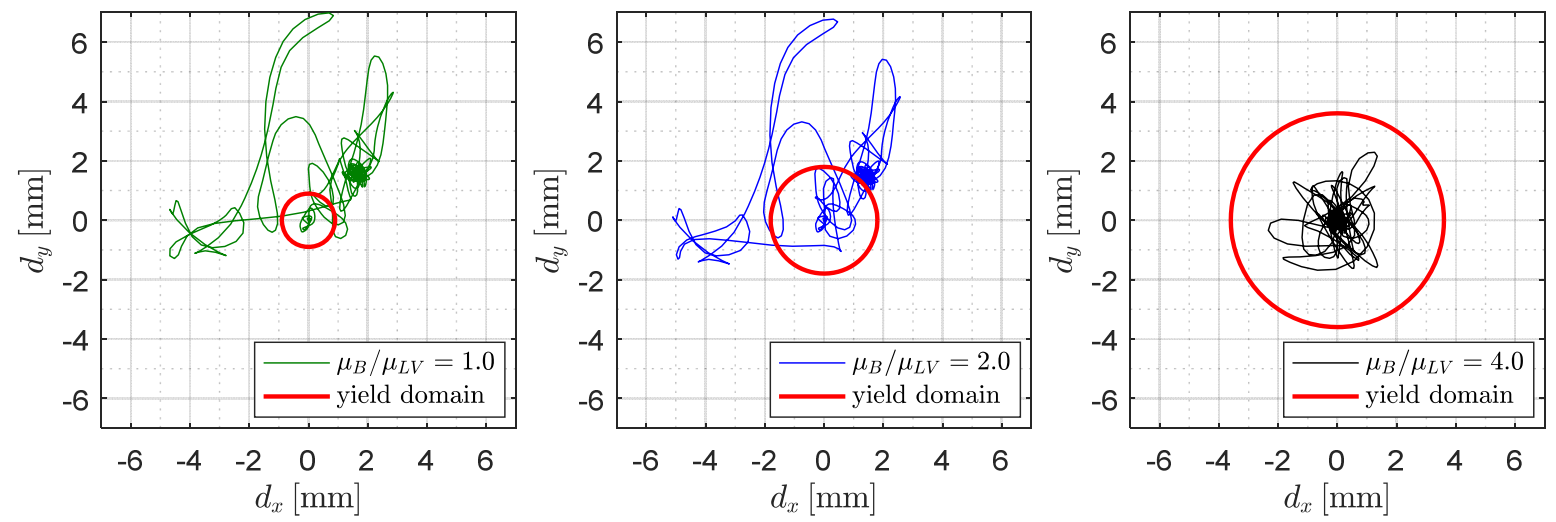

Figure 8 Displacement orbits described by CSSs for LA-A-SLD-R1-S1 earthquake, building ID 6S_1, friction class MF and different values of the $\boldsymbol{\mu}_{B} / \boldsymbol{\mu}_{L V}$ ratio

Based on the previous considerations, it would seem that the breakaway friction only affects the response of isolated buildings subjected to low-to-moderate intensity earthquakes, i.e. in the case of serviceability ground motions included in the SLD class of this study. However, this is not true, as the breakaway friction also entails a delay in the engagement of sliding of the CSSs for more severe earthquakes. Moreover, in the pre-sliding phase the breakaway friction resistance is responsible for the transfer of acceleration from the ground to the superstructure, which is expected to increase with increasing the $\mu_{B}$ value. An example of time-history displacement response along the $x$ and $y$ direction of the building $6 \mathrm{~S} \_1$, friction class MF subjected to the more severe design earthquake LA-A-SLV$\mathrm{R} 3-\mathrm{S} 2$ is shown in Figure 9. In this case, the main differences between the curves relevant to the three $\mu_{B} / \mu_{L V}$ ratios occur in the first instants of the response, i.e. in the sticking phase, which has a different duration depending on the value of the breakaway coefficient of friction. It is worth noting that the displacements computed in OpenSees have both an elastic and plastic component, therefore they are non-zero even in the sticking phase preceding the sliding motion. In order to identify the activation instants of the three considered $\mu_{B} / \mu_{L V}$ ratios, the bottom part of Figure 9 shows the first segment of the time history (i.e. the first $12 \mathrm{~s}$ ) of the norm of the displacements $d$ computed as $d=\sqrt{d_{x}^{2}+d_{y}^{2}}$. The three values of the yield displacement $d_{y}$ are reported as dashed horizontal lines along the considered time segment. In this example, the displacement threshold $d_{y}$ is exceeded for the first time at $t \approx 2 \mathrm{~s}, t \approx 7 \mathrm{~s}$ and $t \approx 10 \mathrm{~s}$ for $\mu_{B} / \mu_{L V}=1.0,2.0$ and 4.0, respectively. This implies that the sticking phase of the CSS isolation system having $\mu_{B} / \mu_{L V}=4.0$ is around $8 \mathrm{~s}$ longer than that of the CSS isolation system having $\mu_{B} / \mu_{L V}=1.0$ for this specific case. As soon as the sliding motion starts, the three curves are almost superimposed to each other. However, in the sticking phase the breakaway friction may give rise to a non-negligible increase of the absolute acceleration response of the superstructure, which, depending on the severity of the earthquake excitation, can be even higher than the maximum acceleration response experienced in the course of the following sliding phase. To 
demonstrate this, the profiles along the building height of the peak floor acceleration (PFA) for the SLD and SLV earthquakes considered above (LA-A-SLD-R1-S1 and LA-A-SLV-R3-S2 records, respectively) are comparatively illustrated in Figure 10.
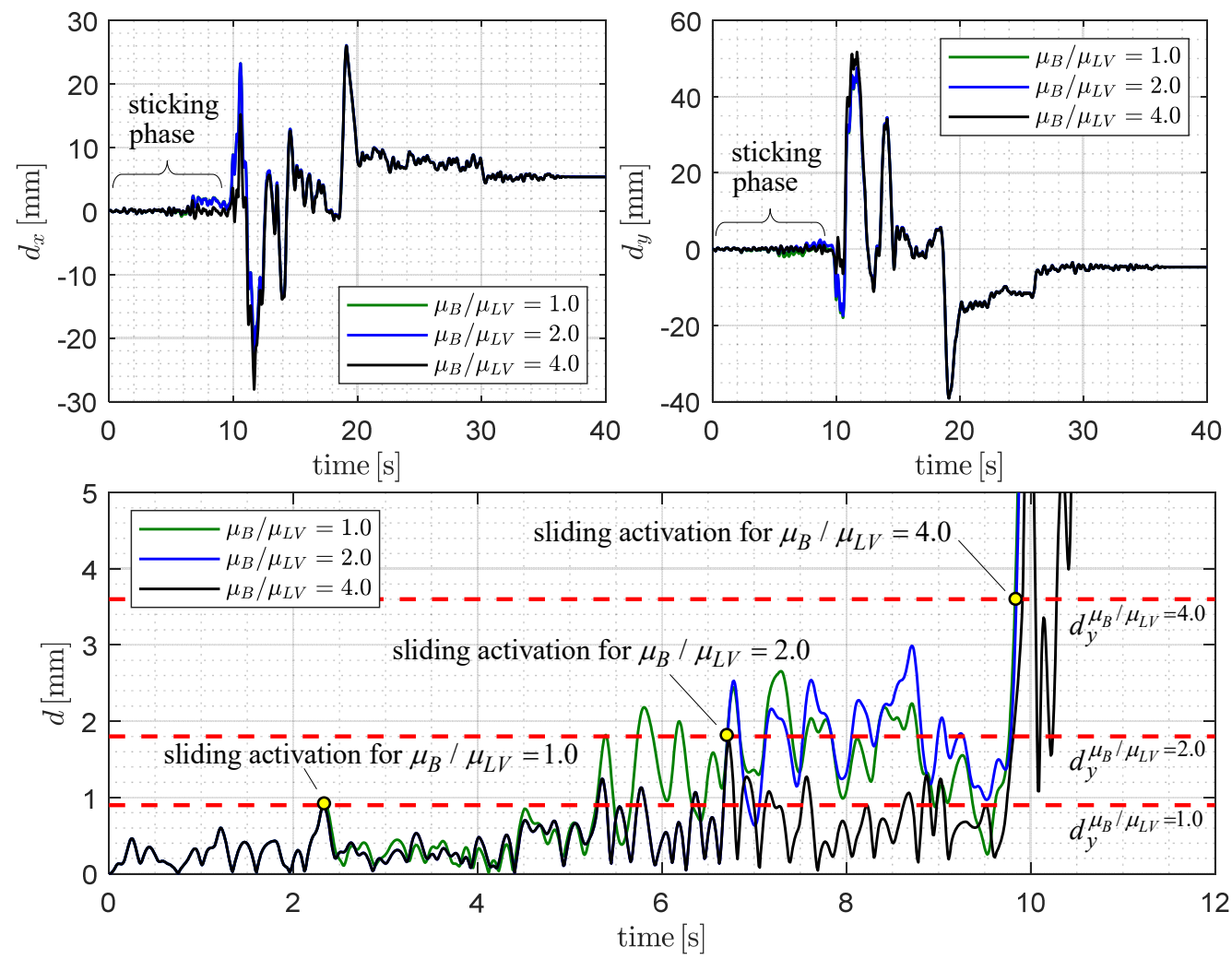

Figure 9 Time-history of the isolators' displacement response along $x$ (top-left) and $y$ (top-right) direction and limited time segment of the norm of displacements (bottom) for LA-A-SLV-R3-S2 earthquake, building ID $6 \mathrm{~S} \_1$, friction class MF and different values of the $\boldsymbol{\mu}_{B} / \boldsymbol{\mu}_{L V}$ ratio
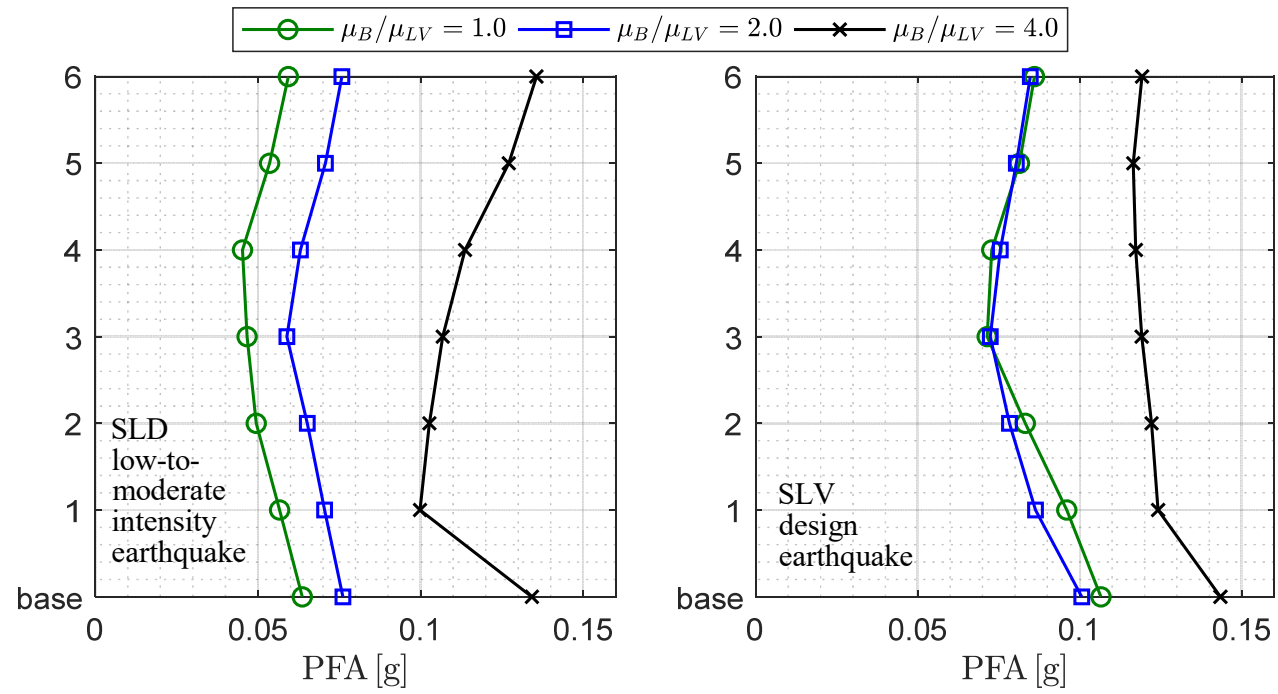

Figure 10 Influence of the breakaway friction at SLD (left) and SLV (right) on the peak floor acceleration (PFA) profile along the building height for LA-A-SLD-R1-S1 and LA-A-SLV-R3-S2 earthquakes, building ID $6 \mathrm{~S} \_1$, friction class MF and different values of the $\boldsymbol{\mu}_{B} / \boldsymbol{\mu}_{L V}$ ratio

It is noticed that the breakaway friction dramatically increases the PFA for low-to-moderate 
earthquakes typical of the serviceability limit state. In the analysis at SLD the values of PFA obtained with $\mu_{B} / \mu_{L V}=4.0$ are even twice higher than the values obtained by ignoring the breakaway friction (i.e., assuming $\mu_{B}=\mu_{L V}$ in the baseline reference model). This result, analyzed more in-depth in the following subsections, has important implications in view of serviceability requirements for the protection of non-structural components and acceleration-sensitive equipment in buildings during moderate-intensity earthquakes. Additionally, it is noted that the breakaway friction also has a certain effect on the PFA for more severe SLV (design) earthquakes. Indeed, an increase of about 15\% is observed for $\mu_{B} / \mu_{L V}=4.0$ compared to the reference case $\mu_{B} / \mu_{L V}=1.0$, whereas the value $\mu_{B} / \mu_{L V}=2.0$ does not seem to affect the PFA for this example. This confirms that ignoring the breakaway friction can lead to non-conservative evaluation of the structural response of the isolated building, not only for low-to-moderate intensity earthquakes, but also for SLV design earthquakes. Interestingly, based on Figure 10 it is seen that the PFAs at SLD obtained with the high breakaway friction ratio $\mu_{B} / \mu_{L V}=4.0$, which prevents the engagement of sliding, can be of comparable order or even higher than the PFAs obtained at SLV.
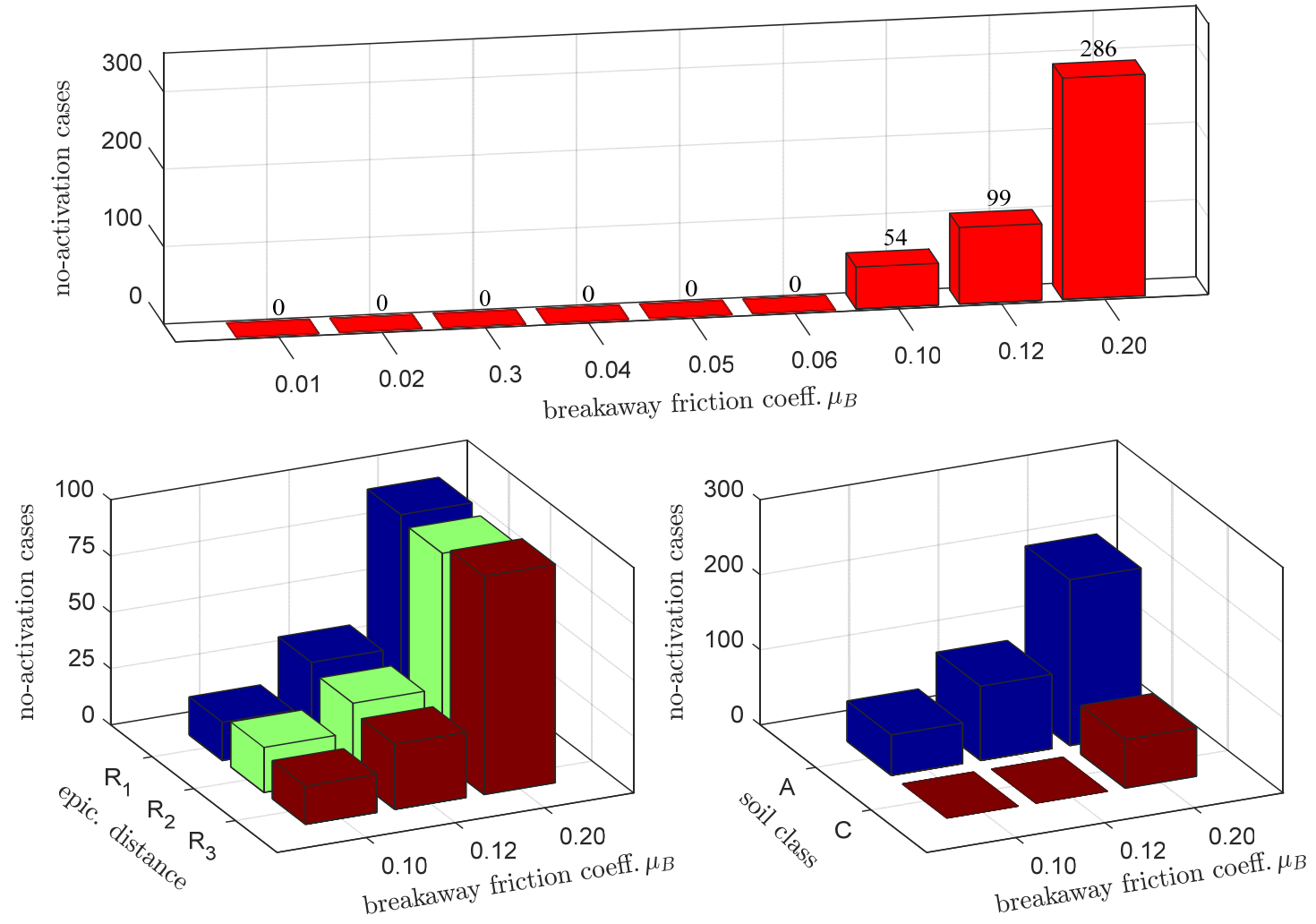

Figure 11 No-activation cases in relationship to the breakaway friction coefficient (top) and sub-analysis depending on the epicentral distance (bottom left) and soil class (bottom right)

In 439 out of 9072 NLTHAs the CSSs were not engaged at all over the duration of the ground motion, meaning that the inertia force induced by the ground-motion acceleration was not able to overcome the breakaway frictional resistance of the isolation system $F_{B}$, see again Figure 7 . As reasonably expected, all these 439 cases belong to the low-intensity serviceability earthquakes (SLD class). As a result, under low-to-moderate excitation the ground-motion acceleration may not be sufficient to trigger the sliding motion, and the structure behaves as a fixed-base building, thus experiencing higher peak floor accelerations (PFAs) than the baseline condition of $\mu_{B} / \mu_{L V}=1.0$ 
(corresponding to a model in which the breakaway friction is neglected at all). These cases are then analyzed in terms of the breakaway friction coefficient $\mu_{B}$ as well as in terms of the soil class of the related earthquake excitation, see histograms in Figure 11. It is evident that the number of the noactivation cases increases with increasing the $\mu_{B}$ coefficient: all the cases were observed for $\mu_{B}$ values ranging from 0.10 to 0.20 . It seems that the no-activation cases were marginally influenced by the epicentral distance of the earthquake (at least for the earthquake records considered in this study), as the trend of the cases shown in the bottom-left part of Figure 11 is almost equally distributed among the three values $R_{1}, R_{2}, R_{3}$. Moreover, the soil class seems to have a significant influence on the occurrence of no-activation conditions: 374 out of the 439 cases were obtained for rigid soil conditions (soil A), and only the remaining 65 cases were observed for medium soil conditions (soil C). Therefore, more than the $85 \%$ of all the no-activation cases occurred for ground-motion records having a frequency content falling in the low-period (high-frequency) range. It is likely that this occurs because both the PGA and the spectral acceleration corresponding to the fundamental period of the superstructure $S_{a}\left(T_{s s 1}\right)$ are higher in the soil class $\mathrm{C}$ than in the soil class A.

\subsection{Statistical regression formula of trigger acceleration}

By eliminating the 439 no-activation cases from the overall group of 9072 NLTHAs, it is possible to assess the reliability of the analytical formula (7) to estimate the trigger acceleration. On the other hand, the actual value of the trigger acceleration computed from the NLTHAs is identified as the ground-motion acceleration corresponding to the first time instant in which the isolator displacement $d=\sqrt{d_{x}^{2}+d_{y}^{2}}$ exceeds the yield displacement $d_{y}=F_{B} / k_{i}$, where $F_{B}=\mu_{B} \cdot N$ denotes the breakaway frictional resistance (cf. again Figure 7). This value, denoted as $a_{\text {trigger }}^{\text {numerical }}$ in the sequel of the paper, is compared to the analytical value provided by Eq. (7). To this aim, the following measure of relative error is introduced

$$
\epsilon=\frac{a_{\text {trigger }}^{\text {analytical }}-a_{\text {trigger }}^{\text {numerical }}}{a_{\text {trigger }}^{\text {numerical }}}
$$

which is equal to zero for perfect prediction by the analytical formula, is negative for underestimation and positive for overestimation as compared to the actual trigger acceleration obtained by NLTHAs. Due to the large scatter of the obtained results (see Figure 12-top left), the values of the relative error $\epsilon$ are processed statistically in order to construct a discrete probability density function (PDF) (see Figure 12-top right). The large range of $\epsilon$ obtained and reported in the PDF confirms a high dispersion of the data, which makes Eq. (7) unable to predict the trigger acceleration value with sufficient reliability. Moreover, the observation of the PDF shape reveals that the underestimation cases (corresponding to $\epsilon<0$ ) are statistically higher than the overestimation cases $(\epsilon>0)$, thus making the analytical formula (7) non-conservative for design purposes, on average. Indeed, underestimating the trigger acceleration implies that, in practical cases, the designer would calculate the peak floor accelerations at low-intensity earthquakes as if the building were isolated, whereas in reality it would behave as a fixed-base structure with the isolators persisting in the sticking phase. The average value of the $a_{\text {trigger }}^{\text {analytical }} / a_{\text {trigger }}^{\text {numerical }}$ ratio for the overall group of data (i.e., considering all the numerical cases of this parametric study) is 0.83 , which signifies that a mean underestimation of the trigger acceleration of about $20 \%$ is obtained with the analytical formula (7). A closer look at the distribution 
of the $a_{\text {trigger }}^{\text {analytical }} / a_{\text {trigger }}^{\text {numerical }}$ ratio reveals that underestimation cases are more frequent for relatively low breakaway friction coefficients (see Figure 12-bottom), which are also pertinent to the common sliding materials adopted by manufacturing companies. This is an important result demonstrating the critical role of the breakaway friction coefficient not only for high friction coefficients (representative of exceptional situations induced by low temperatures, contamination of surfaces, poor maintenance etc.), but also for ordinary CSSs made of lubricated sliding materials. In these "ordinary" situations, the analytical formula (7) would lead to non-conservative conclusions, as the isolator's sliding motion would be activated by a higher value of acceleration.
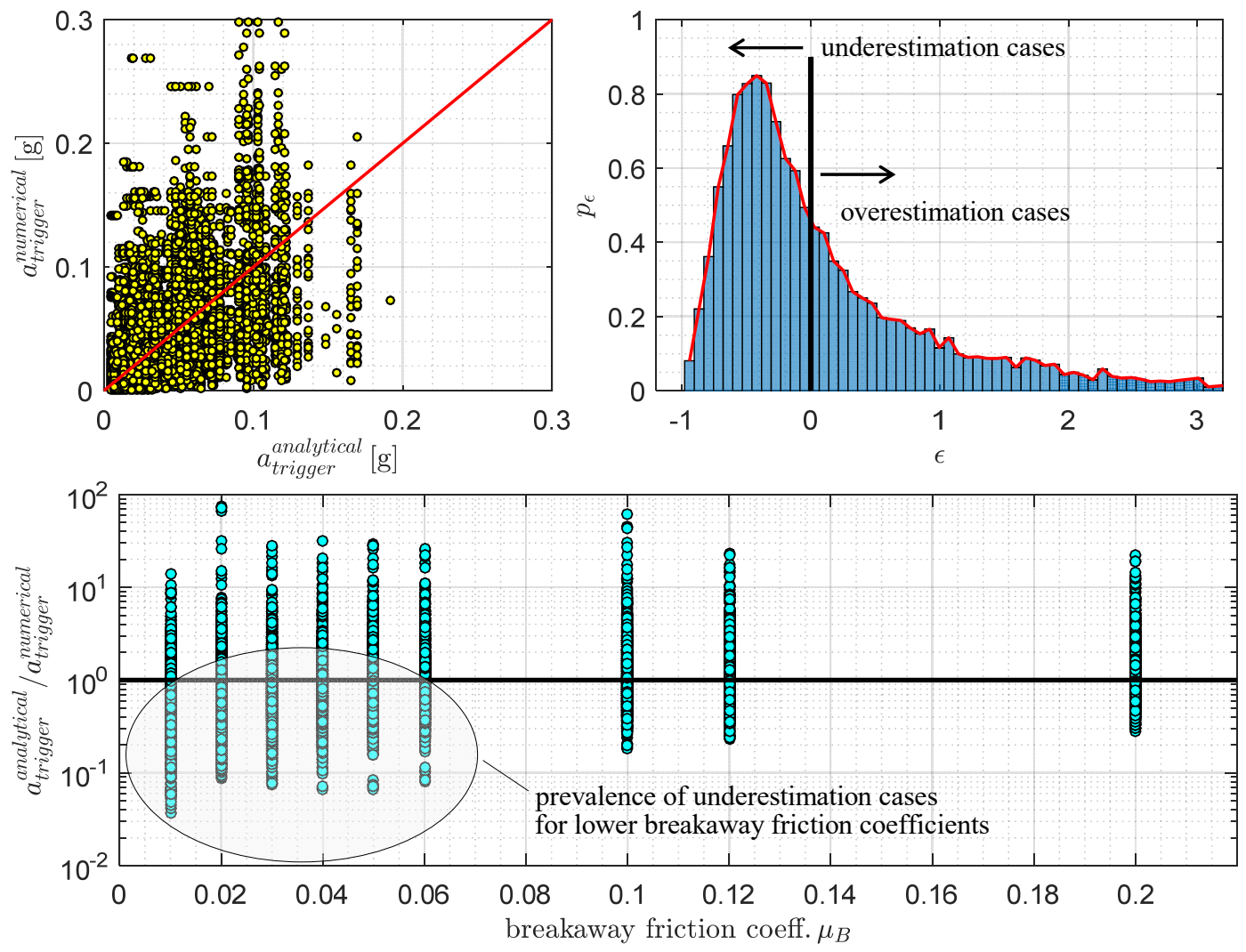

Figure 12 Comparison between analytical and numerical trigger acceleration (top left), PDF of the relative error measurements given by Eq. (8) (top right), and distribution of the $\boldsymbol{a}_{\text {trigger }}^{\text {analytical }} / \boldsymbol{a}_{\text {trigger }}^{\text {numerical }}$ ratio depending on the breakaway fricton coefficient (bottom)

Due to the inability of the analytical formula (7) to predict the trigger acceleration with satisfactory accuracy, regression analysis relations are derived by processing the numerical data. To this aim, we construct the cumulative distribution function (CDF) of the discrete variable $X=a_{\text {trigger }}^{\text {numerical }}$ (which attains values $x_{1}, x_{2}, \ldots$ with probability $p_{i}=\mathrm{P}\left(x_{i}\right)$ ), which is defined as follows

$$
\Phi_{X}(x)=\mathrm{P}(X \leq x)=\sum_{x_{i} \leq x} \mathrm{P}\left(X=x_{i}\right)=\sum_{x_{i} \leq x} p\left(x_{i}\right) .
$$

The CDF is an important piece of information for defining a design value of the trigger acceleration as a percentile computed from the relevant $\mathrm{CDF}$, considering the uncertainties inherent in its calculation. In this paper, the $90^{\text {th }}$ percentile (i.e. $90 \%$ of the $a_{\text {trigger }}^{\text {numerical }}$ values do not exceed this threshold) is proposed by the authors as a design value and called $a_{\text {trigger. }}^{90}$. As illustrated in Figure 13top, the $a_{\text {trigger }}^{90}$ value changes depending on the considered breakaway friction coefficient, because it 
increases with increasing $\mu_{B}$ (as reasonably expected). Obviously, the same result holds true for any other percentile value as well as for the mean value of the trigger acceleration $a_{\text {trigger }}^{\text {mean }}$ Note that the latter value is different from the $50^{\text {th }}$ percentile (or median) because of the asymmetric shape of the PDF.
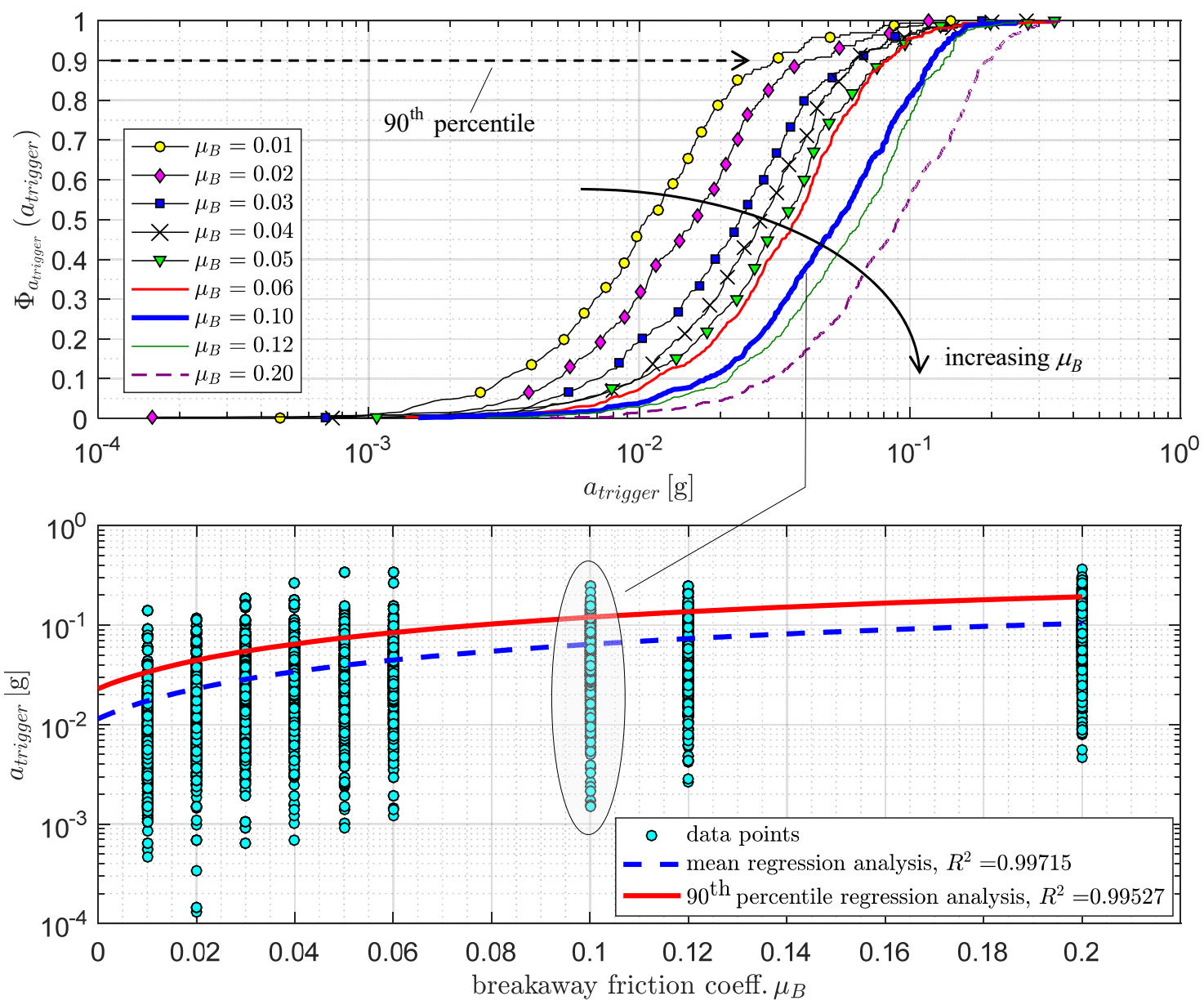

Figure 13 Statistical post-processing of $\boldsymbol{a}_{\text {trigger }}^{\text {numerical }}$ values: CDFs for different breakaway friction coefficients (top); regression analysis of numerical data points with identification of mean and $90^{\text {th }}$ percentile curves

In particular, the mean and the $90^{\text {th }}$ percentile values of the obtained trigger acceleration values in $[\mathrm{g}$ ] units are described very well $\left(R^{2}=0.99715\right.$ and $R^{2}=0.99527$, respectively) by the following relations in terms of $\mu_{B}$, which are obtained by nonlinear regression analysis:

$$
\begin{gathered}
a_{\text {trigger }}^{\text {mean }}[\mathrm{g}]=-0.6416 \mu_{B}^{2}+0.5908 \mu_{B}+0.01142 \\
a_{\text {trigger }}^{90}[\mathrm{~g}]=-1.232 \mu_{B}^{2}+1.093 \mu_{B}+0.02291
\end{gathered}
$$

The relations (10) are depicted in Figure 13-bottom superimposed to the data points. The high value of $R^{2}$ confirms that the chosen second-order polynomial (three-parameter) curve is very accurate for capturing the numerical data for both the mean and the $90^{\text {th }}$ percentile value.

The regression analysis relations (10) were derived based on the overall group of data points. It is interesting to assess whether more specific design formulae can be obtained by separately analyzing homogeneous subclasses of data points. It has been found that an important parameter for the trigger acceleration value is represented by the superstructure fundamental period $T_{s s 1}$. In particular, Figure 
14 shows that, for the same value of the breakaway friction coefficient $\mu_{B}$, the trigger acceleration decreases with decreasing of the superstructure fundamental period $T_{s s 1}$, at least based on the three $T_{S S 1}$ values relevant to the two-storey, four-storey and six-storey buildings analyzed in this parametric study (equal to $0.290,0.477$ and 0.648 , respectively).
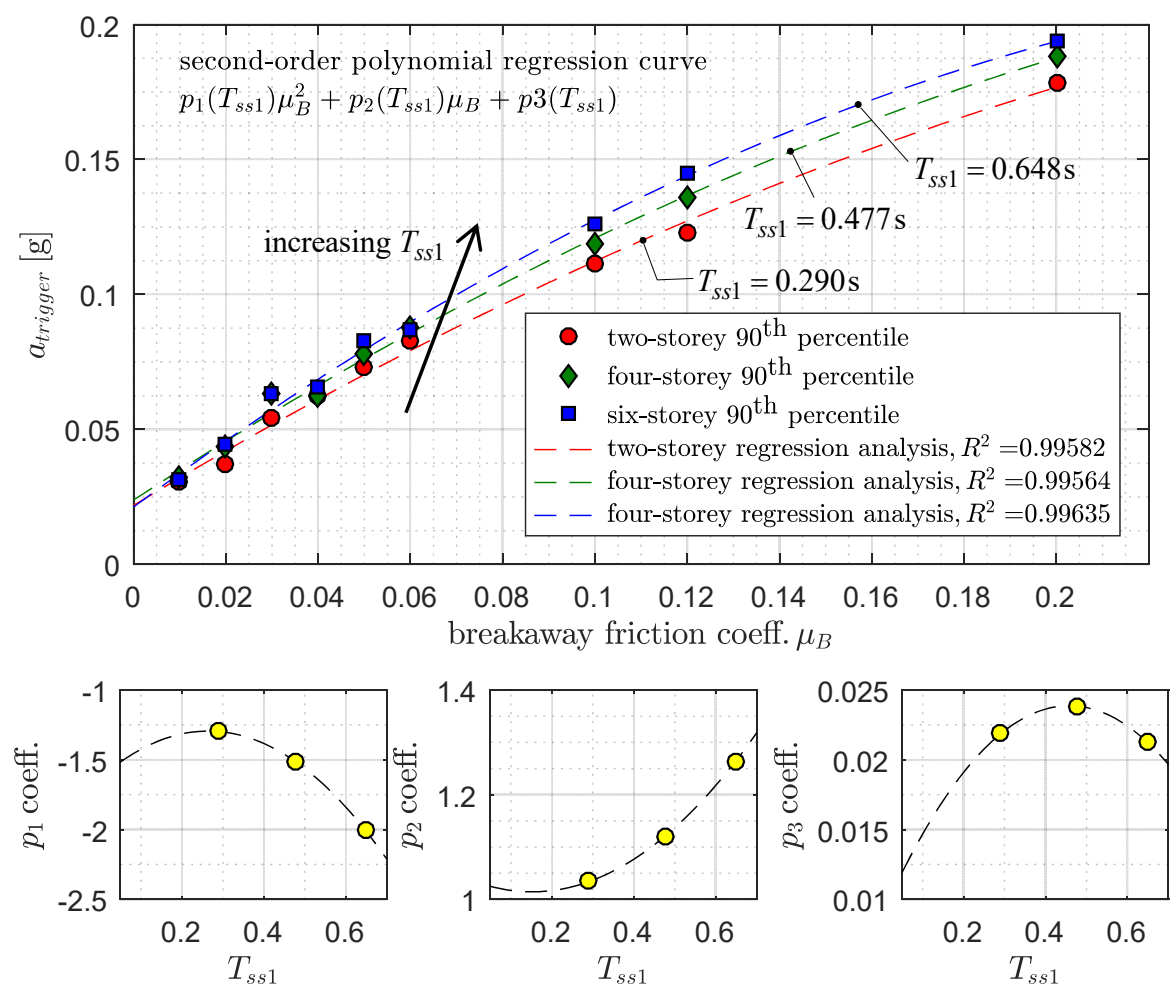

Figure 14 Second-order polynomial regression curves for the $90^{\text {th }}$ percentile value of the trigger acceleration as a function of the breakaway friction coefficient $\boldsymbol{\mu}_{\boldsymbol{B}}$ depending on the superstructure fundamental period $\boldsymbol{T}_{\boldsymbol{s} \boldsymbol{1} \mathbf{1}}$

Based on this consideration, a more case-specific second-order polynomial regression formula of the $90^{\text {th }}$ percentile of the trigger acceleration (in [g] units) is proposed as follows.

$a_{\text {trigger }}^{90}[\mathrm{~g}]=p_{1} \mu_{B}^{2}+p_{2} \mu_{B}+p_{3}$

where the three coefficients $p_{1}, p_{2}, p_{3}$ depend upon the superstructure fundamental period $T_{s s 1}$. A second-order polynomial regression for these three coefficients can be adopted as well

$$
\left\{\begin{array}{l}
p_{1}=p_{1 a}\left(T_{s s 1}\right)^{2}+p_{1 b}\left(T_{s s 1}\right)+p_{1 c} \\
p_{2}=p_{2 a}\left(T_{s s 1}\right)^{2}+p_{2 b}\left(T_{s s 1}\right)+p_{2 c} \\
p_{3}=p_{3 a}\left(T_{s s 1}\right)^{2}+p_{3 b}\left(T_{s s 1}\right)+p_{3 c}
\end{array}\right.
$$

The values of the nine coefficients of the regression formula are listed in Table 5. The formula (11) expresses the $90^{\text {th }}$ percentile value of the trigger acceleration as a function of the breakaway friction coefficient $\mu_{B}$ and $T_{s s 1}$. It leads to a more conservative assessment of the trigger acceleration than the analytical formula (7). However, despite the large number of NLTHAs, the regression coefficients reported in Table 5 are derived based on just eight response spectra, which are by no means representative of the ground-motion excitation meant as a random process. This formula can be used to predict the value of $a_{\text {trigger }}^{90}$ for RC buildings isolated with CSSs having a breakaway friction in the range $\mu_{B}=[0.01-0.20]$ and superstructure fundamental period $T_{S S 1}=[0.29-0.65]$, with a seismic 
excitation scenario similar to that considered in this study. Although the soil conditions have a significant influence on the occurrence of no-activation cases based on Figure 11, the analysis of $a_{\text {trigger }}^{90}$ has not shown a clear trend depending on the soil class. Moreover, it has been numerically found that the values of $a_{\text {trigger }}^{90}$ obtained with the two mass ratios $m_{b} / m_{f}$ (1.0 and 2.0) are generally comparable. Therefore, it is proposed that the generalized formula (12) can be used with satisfactory accuracy for both soil class $\mathrm{A}$ and $\mathrm{C}$, irrespectively of the mass ratio $m_{b} / m_{f}$.

Table 5 Regression coefficients $p_{i j}$ for the $90^{\text {th }}$ percentile curve of $a_{\text {trigger }}$, see Eq. (12), as a function of $\mu_{B}$ and $T_{s s 1}$

\begin{tabular}{cccc}
\hline coefficient/order & $j=a$ & $j=b$ & $j=c$ \\
\hline$i=1$ & -4.8338 & 2.5545 & -1.6315 \\
$i=2$ & 1.0116 & -0.30731 & 1.0378 \\
$i=3$ & -0.071826 & 0.065784 & 0.0088116 \\
\hline
\end{tabular}
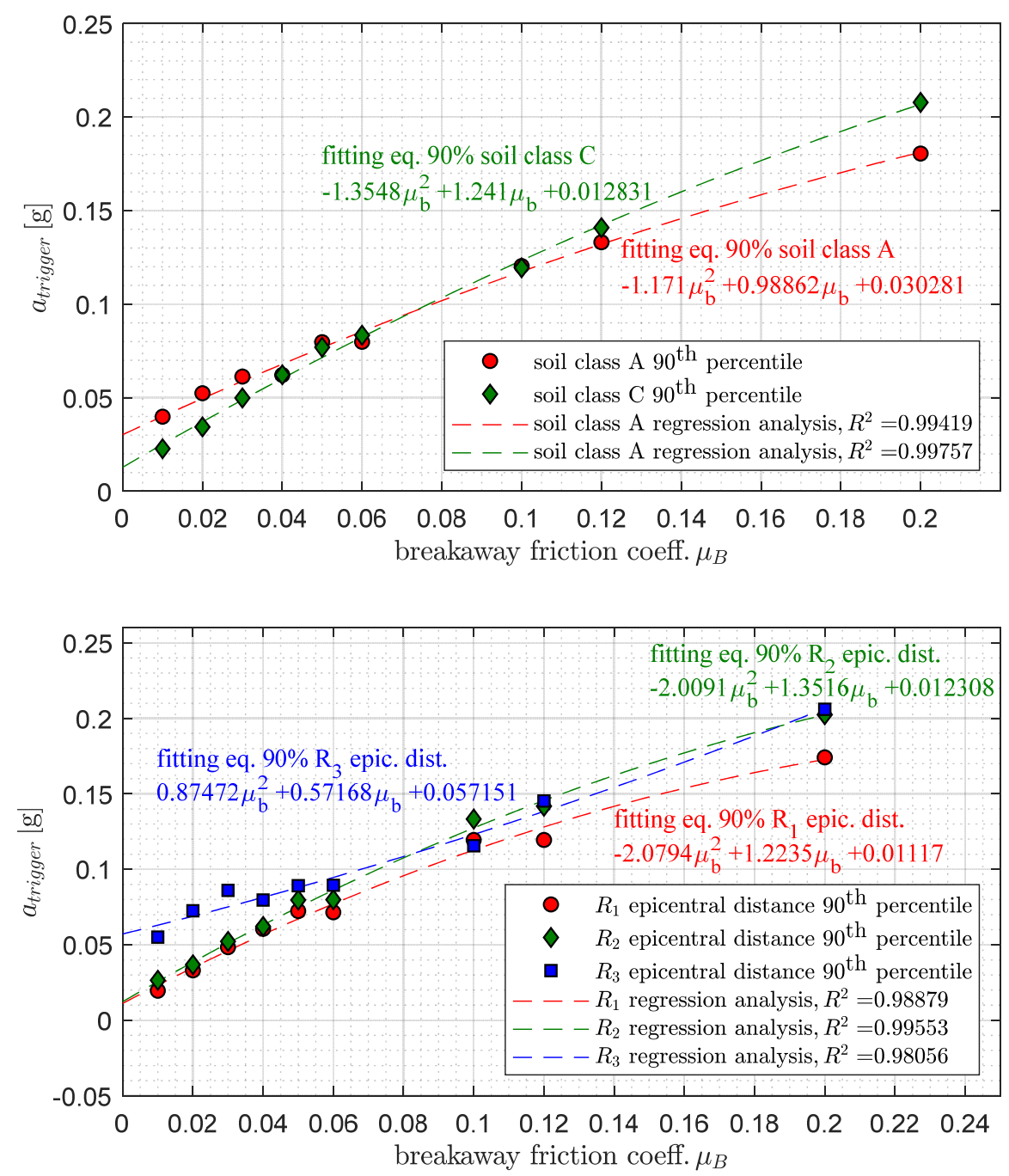

Figure 15 Second-order polynomial regression curves for the $90^{\text {th }}$ percentile value of the trigger acceleration as a function of the breakaway friction coefficient $\boldsymbol{\mu}_{\boldsymbol{B}}$ depending on soil class (top) and epicentral distance (bottom)

Moreover, the parametric study presented in this paper has included different soil classes and epicentral distances. It is interesting to assess whether these conditions have an impact on the trigger 
acceleration. To this aim, a more specific analysis of the influence of the soil classes and epicentral distances is presented in Figure 15 in terms of the $90^{\text {th }}$ percentile values of the trigger acceleration along with the corresponding second-order polynomial regression curves. Overall, it seems that the differences between the two soil classes are relatively negligible in the range of low-to-medium breakaway friction coefficients (up to $\mu_{B}=0.10$ ) and become somehow more significant for higher values of $\mu_{B}$, with the trigger acceleration for the soil class $\mathrm{C}$ being slightly higher than that for the soil class $A$. On the other hand, the numerical results do not suggest a clear trend in terms of epicentral distance. However, the trigger acceleration values related to epicentral distances $0 \leq R_{e p}<10 \mathrm{~km}$ $\left(\mathrm{R}_{1}\right.$ class) seem to be reasonably lower (for the entire range of friction coefficients analyzed) than those related to the other two epicentral distances $10 \leq R_{e p}<20 \mathrm{~km}\left(\mathrm{R}_{2}\right.$ class $)$ and $20 \leq R_{e p}<$ $50 \mathrm{~km}\left(\mathrm{R}_{3}\right.$ class). This may be ascribed to the potential pulse-like nature of near-fault ground motions, which are likely to trigger the sliding motion at lower values of acceleration due to their marked directivity effects compared to far-field ground motions. These aspects certainly deserve further investigation.

\subsection{Influence of the breakaway on the average seismic response}

The seismic response of the base-isolated structure is analyzed in terms of four response parameters, namely: (i) Peak Floor Acceleration (PFA); (ii) Interstorey Drift Ratio (IDR); (iii) displacement of the base isolation system $d_{i s o}$; (iv) shear force carried by the isolation system normalized to the total seismic weight $V_{i s o} / W_{t o t}$, where $W_{t o t}=W_{s s}+W_{b s}, W_{s s}=\sum_{i} m_{f} \cdot g$ ( $i$ being the number of storeys) and $W_{b s}=m_{b} \cdot \mathrm{g}$. The first two parameters are representative of the superstructure seismic response, while the last two parameters are useful to investigate the response of the base isolation system.
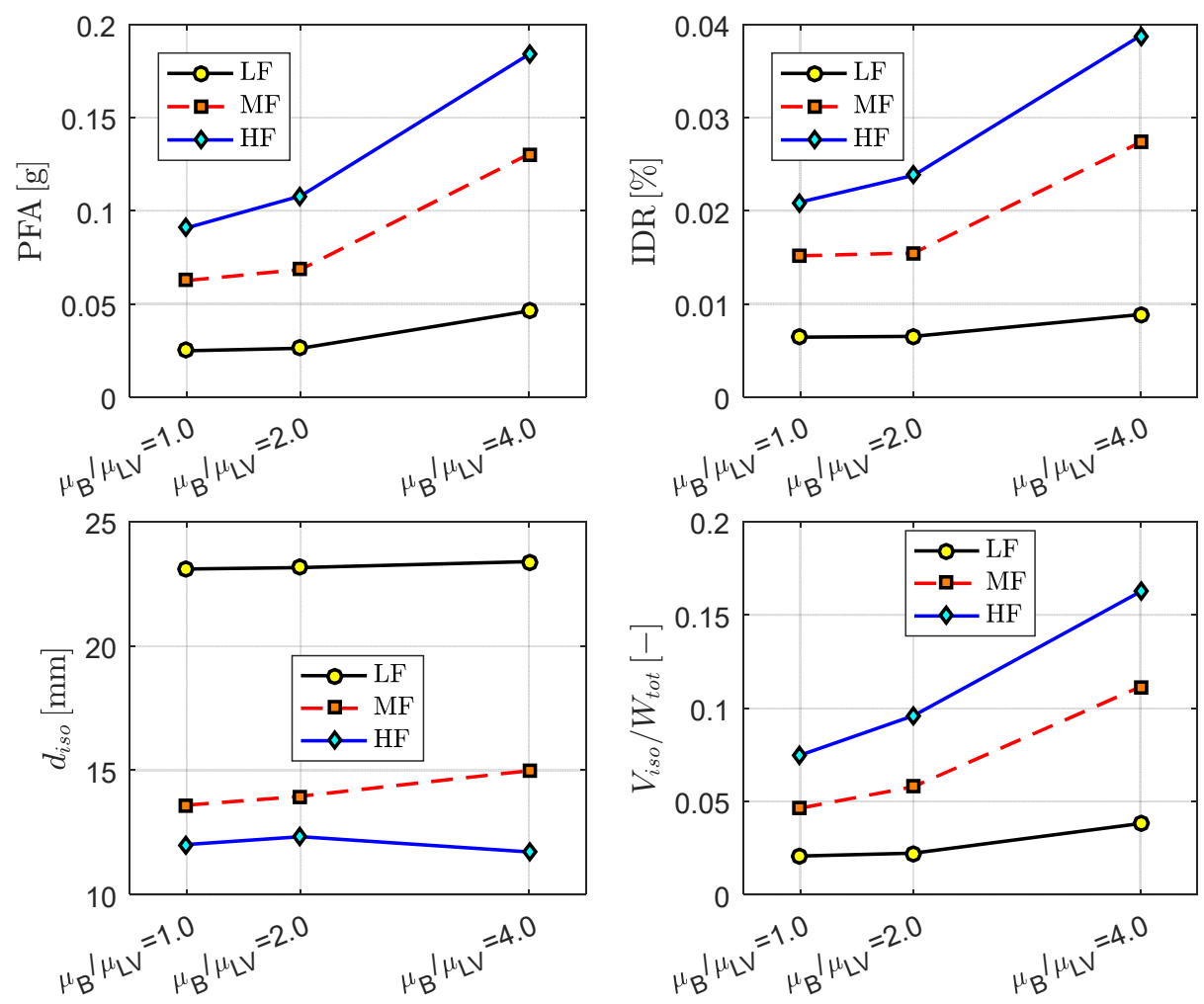

Figure 16 Average response parameters of base-isolated buildings for serviceability earthquakes (at SLD) in terms of PFA, maximum IDR, isolators' displacement, and normalized shear force carried by the isolation unit 

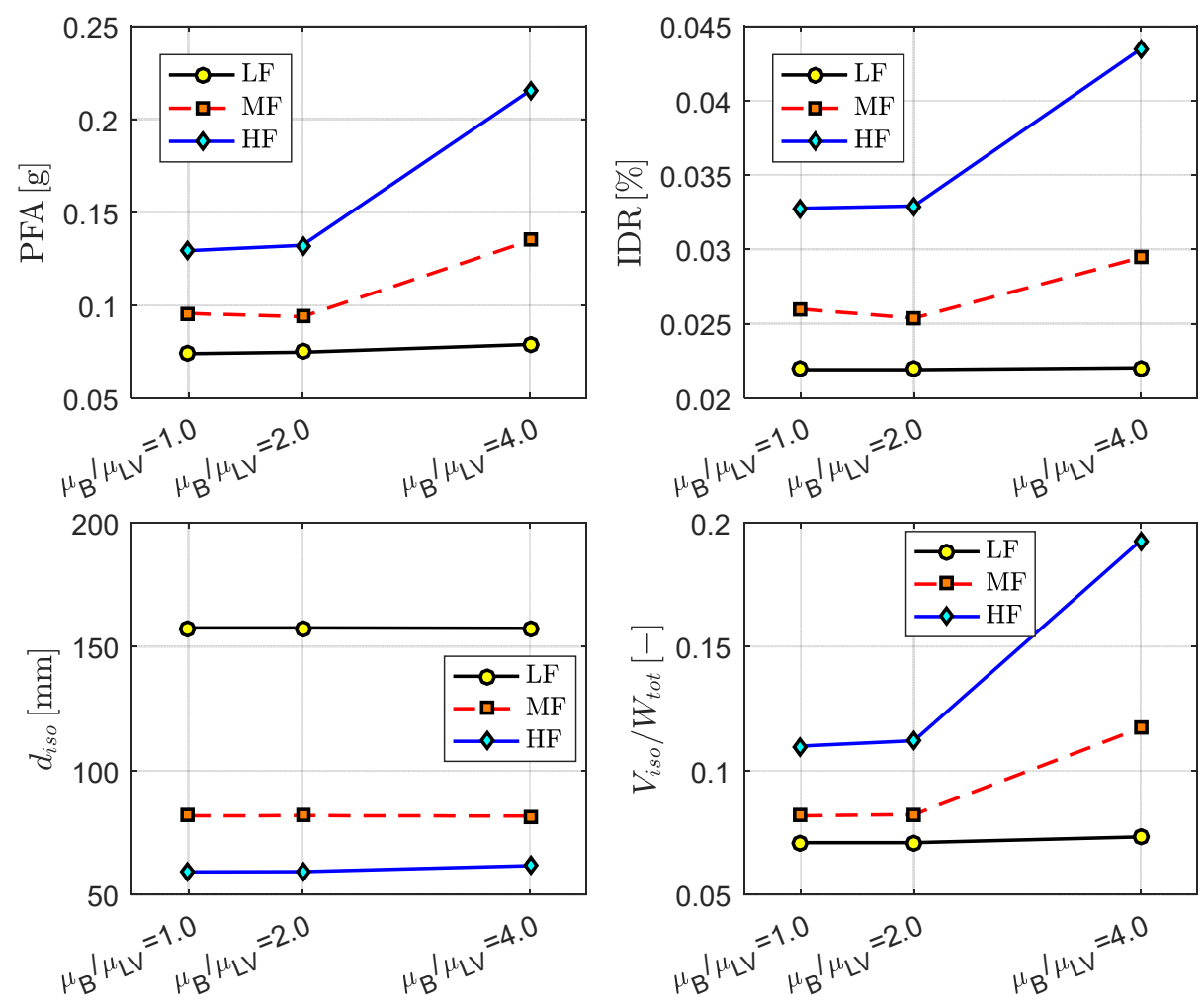

Figure 17 Average response parameters of base-isolated building for design earthquakes (at SLV) in terms of PFA, maximum IDR, isolators' displacement, and normalized shear force carried by the isolation unit

The maximum values of each parameter are extracted from the 9072 NLRHAs and then statistically processed to obtain average maximum response quantities. Considering the different performance requirements at the two considered limit states SLD and SLV, i.e. for serviceability and design earthquakes, a distinction is made when post-processing the results based on the two earthquake intensity levels. The results are illustrated in Figure 16 and Figure 17 for SLD and SLV, respectively. In particular, the results are organized based on the three distinct friction classes LF, MF, HF (characterized by the friction coefficients listed in Table 3), and on the three breakaway classes $\mu_{B} / \mu_{L V}=1.0,2.0,4.0$. Once again, it is worth recalling that the case $\mu_{B} / \mu_{L V}=1.0$ represents the baseline reference model in which the BV model reduces to the VelDependent friction model, with the breakaway friction being disregarded in the calculations. In this way, the effect of the breakaway friction on the seismic structural response can be clearly identified by a comparative analysis.

With regard to low-to-moderate intensity earthquakes, typical of SLD, the effect of the breakaway friction is to increase the PFA, maximum IDR and maximum normalized $V_{i s o}$ in comparison to the baseline reference model $\mu_{B} / \mu_{L V}=1.0$. As an example, compared to the reference case the average PFA for MF friction class isolators increases by about $10 \%$ and up to $108 \%$ for $\mu_{B} / \mu_{L V}=2.0$ and $\mu_{B} / \mu_{L V}=4.0$, respectively (see Figure 16-top left). These figures are rather similar for HF friction class isolators, for which the increase is about $18 \%$ and $102 \%$ for $\mu_{B} / \mu_{L V}=2.0$ and $\mu_{B} / \mu_{L V}=4.0$, respectively. However, the increase induced by the breakaway friction is slightly smaller for LF friction class isolators, with about $+5 \%$ and $+85 \%$ for $\mu_{B} / \mu_{L V}=2.0$ and $\mu_{B} / \mu_{L V}=4.0$, respectively. Similar trends are observed in the maximum IDR and $V_{i s o}$ responses as well. On the other hand, the effect of the breakaway friction on the displacement demand of the isolators is marginal, as the peak displacement $d_{i s o}$ in the models accounting for the breakaway friction does not show substantial 
differences compared to the baseline reference model $\mu_{B} / \mu_{L V}=1.0$.

With regard to design earthquakes, typical of SLV, it can be observed that the breakaway friction has a negligible influence on the seismic response when LF friction class isolators are considered. However, it does affect the PFA, IDR and $V_{i s o}$ responses for both MF and HF friction class CSSs, especially for $\mu_{B} / \mu_{L V}=4.0$ (typical case of filled PTFE). In particular, for $\mu_{B} / \mu_{L V}=4.0$ the average maximum shear force carried by the isolation system increases by $43 \%$ and $75 \%$ for $\mathrm{MF}$ and $\mathrm{HF}$ friction class, respectively. The increase of shear force through the isolators is directly related to the frictional forces at breakaway. Also for SLV, like in SLD, the maximum displacement of the isolators is not influenced by the breakaway friction coefficient.
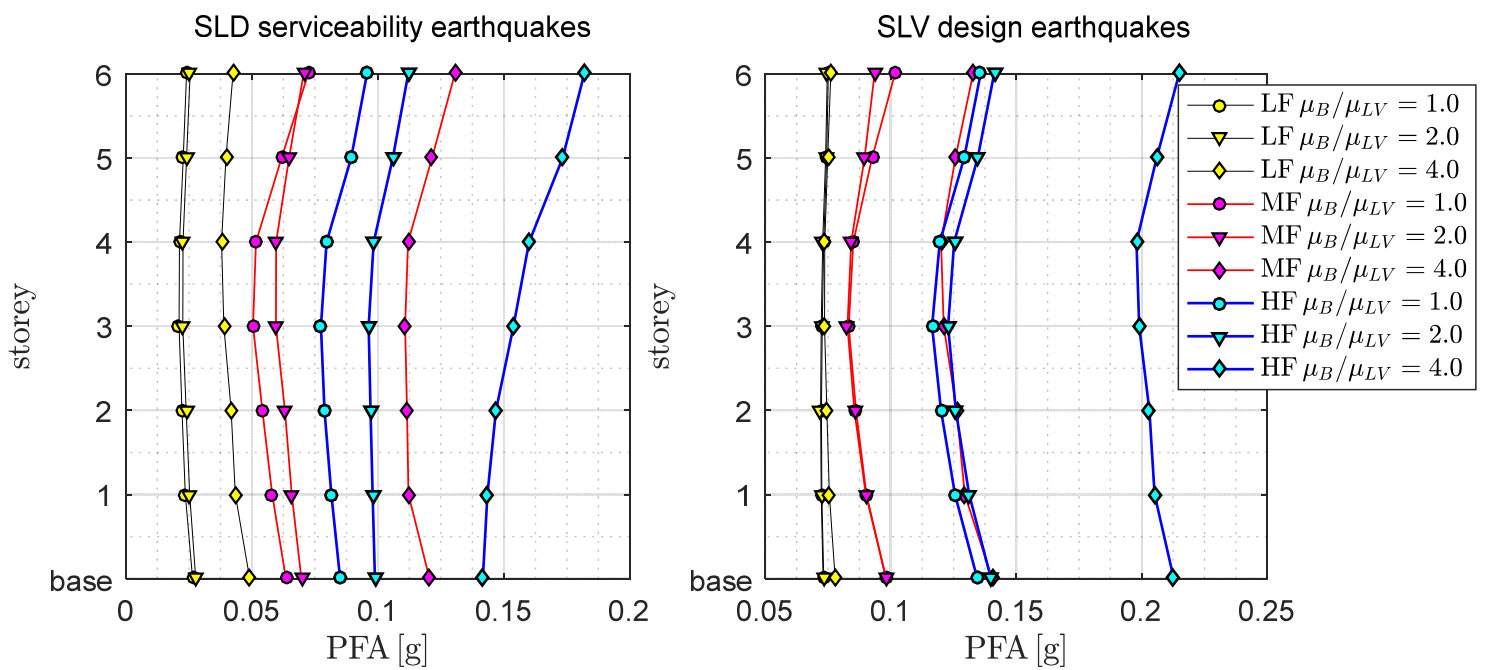

Figure 18 Average PFA profiles along the building height for building $6 \mathrm{~S}$ and different friction classes and $\boldsymbol{\mu}_{\boldsymbol{B}} / \boldsymbol{\mu}_{\boldsymbol{L} \boldsymbol{V}}$ ratios for serviceability earthquakes (left) and design earthquakes (right)

The superstructure model analyzed in NLRHAs experiences higher IDRs and PFAs due to the delayed engagement of the isolators at both SLD and SLV. In the limit case of no-activation (occurring for low-to-moderate intensity earthquakes at SLD), the structure behaves as a fixed-base building and the PFAs are much higher than in the isolation building scenario. A summary of the average PFA profiles for the six-storey building equipped with isolators belonging to different friction classes is depicted in Figure 18, where it is shown that the breakaway friction has a major influence especially in case of SLD earthquakes and MF and HF friction class.

The residual displacement at the end of the earthquake shaking $d_{\text {res }}$ is another important parameter in view of serviceability requirements and possible accrual of displacement in aftershock and future events [20], [74]-[78]. Previous studies [66], [79] demonstrated that the residual displacement is related to the maximum displacement $d_{\max }$ through a functional relation

$$
d_{\mathrm{res}}=d_{\mathrm{res}}\left(\frac{d_{\mathrm{max}}}{d_{\mathrm{rm}}}\right) \text {. }
$$

Based on Eq. (13), the actual residual displacement is affected by the ratio between the maximum displacement of the isolators $d_{\max }$ and the so-called maximum static residual displacement $d_{\mathrm{rm}}$, cf. Figure 1-right. The present study has demonstrated that $d_{\max }$ is only marginally affected by the breakaway friction coefficient $\mu_{B}$, whereas $d_{\mathrm{rm}}=\mu_{d} \cdot R_{\mathrm{eff}}$ is not affected at all by $\mu_{B}$. Consequently, it is concluded that the breakaway coefficient of friction has no direct influence, on average, on the 
residual displacement.

\subsection{Discussion and design recommendations}

Unlike commonly used structural analysis programs that neglect the influence of the breakaway frictional resistance, the proposed BVNC element coded in OpenSees software allows taking into account the transition between the sticking and the sliding phase of the CSSs, depending on the intensity of the earthquake excitation. The BVNC formulation enables one to perform NLTHAs with bidirectional seismic inputs, which was not allowed by the previous MMT formulation introduced in [61]. Although in the reduced BV model adopted in this paper the dynamic friction coefficient was described through the VelDependent friction material, in principle more complex friction models that also incorporate the effect axial load (VelNormalFrcDep material [62]) or both axial load and heating phenomena [63] can be used in the framework of the same theoretical formulation.

The attempt of the parametric study undertaken in this paper was to cover the largest combination that may be encountered in practical cases. As an example, the highest value of the breakaway friction coefficient considered in the study, i.e. $\mu_{B}=0.20$, is in line with published experimental findings: indeed, similar values of friction coefficient at breakaway were observed in unfilled PTFE at very low temperatures $\left(-40^{\circ} \mathrm{C}\right)$ [22], while exceptionally high values of up to 0.35 were reported for glassreinforced PTFE [80]. Breakaway friction values and $\mu_{B} / \mu_{L V}$ ratios considered in this study are also in line with values relevant to sliding materials used by European manufacturers, see e.g. [21], [27], [42], [81], [82].

The analyses shown in this paper have demonstrated that for combinations of high coefficient of friction and low PGA, the CSSs may remain in the sticking phase over the entire duration of the ground motion. This generally occurs for low-to-moderate intensity earthquakes, typical of SLD, and causes a large increase of the PFA and IDR response compared to the isolated building scenario. Besides these no-activation cases, in situations in which the engagement of sliding is delayed by a high breakaway frictional resistance, the CSSs persist in the sticking phase for a relatively long part of the ground motion. This phenomenon occurs for both serviceability and ultimate limit state earthquakes, and is responsible for the transmission of high accelerations to the superstructure.

Based on the previous considerations, a fundamental design parameter is the trigger acceleration $a_{\text {trigger }}$, meant as the minimum value of the ground acceleration capable of activating the sliding motion. Simplified analytical relations like Eq. (7), which accounts for the first vibration mode only, may lead to non-conservative predictions, as the actual $a_{\text {trigger }}$ value (obtained by NLTHAs) may be significantly underestimated. Considering the large scatter of data obtained in the present parametric study and the inability of extrapolating an analytical formula for $a_{\text {trigger }}$ based on reasonable mechanical parameters of the CSS isolation system, a regression analysis formula has been derived by processing the numerical data statistically. In particular, two second-order polynomial regression formulae of the $90^{\text {th }}$ percentile of $a_{\text {trigger }}$ were proposed, the first (more general) being a function of the breakaway friction coefficient $\mu_{B}$ only, the second (more case-specific) being a function of the breakaway friction coefficient $\mu_{B}$ and the superstructure fundamental period $T_{S S 1}$. The validity of these formulae is limited to RC buildings isolated with CSSs having a breakaway friction in the range $\mu_{B}=$ $[0.01-0.20]$ and superstructure fundamental period $T_{s s 1}=[0.29-0.65]$, with a seismic excitation scenario similar to that considered in this study, but a future study might investigate the possibility of extending the approach to a broader range of isolation ratio and further seismic scenarios. 
Besides the trigger acceleration, another subject examined in this study has concerned the evaluation of the structural response of the base-isolated building accounting for the breakaway friction coefficient. Whereas the breakaway friction has been demonstrated to have negligible influence on the seismic displacement of the isolators, it may considerably affect the PFA and IDR response of the superstructure, as well as the shear force carried by the isolation system $V_{i s o}$. These effects change from case to case, depending on the friction class of the CSSs. Indeed, the influence of the breakaway in low-friction CSSs (LF friction class) turned out to be lower than that observed in medium-friction and high-friction CSSs (MF and HF friction class, respectively). In order to draw design recommendations from the parametric study, the three response parameters PFA, IDR and $V_{\text {iso }}$ are processed statistically. In particular, the response parameters are evaluated in dimensionless form as $x / x^{0}$ (with $x=$ PFA, IDR, $V_{\text {iso }}$, and $x^{0}$ representing the same quantity computed in the baseline reference model with $\mu_{B} / \mu_{L V}=1.0$ ). Therefore, values of $x / x^{0}>0$ correspond to amplification of the structural response in comparison to the response calculated by ignoring the breakaway friction.
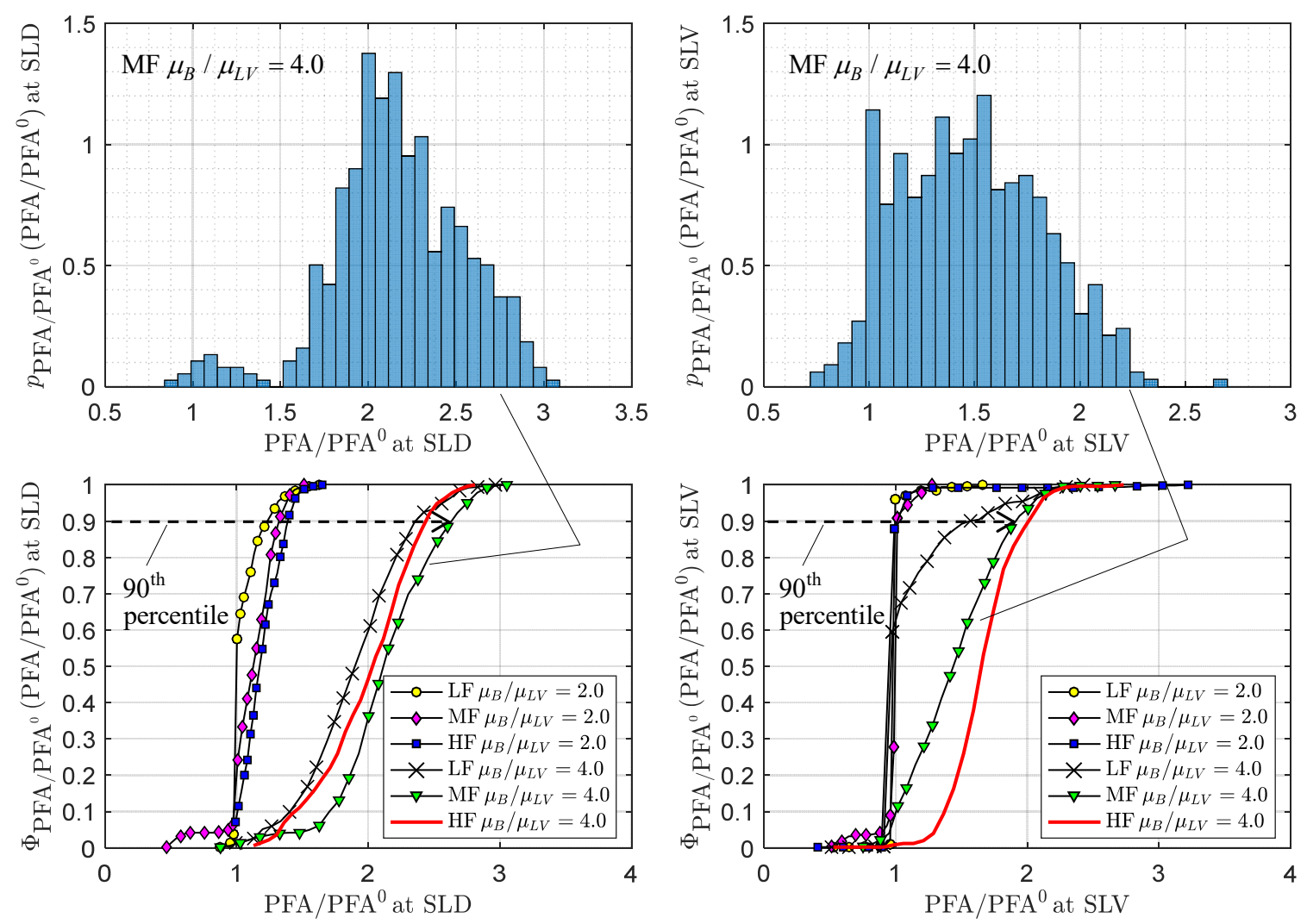

Figure 19 Statistical post-processing of PFA/PFA ratio: PDFs for friction class MF and $\boldsymbol{\mu}_{\boldsymbol{B}} / \boldsymbol{\mu}_{\boldsymbol{L} V}=\mathbf{4 . 0}$ (top) and CDFs for different values of breakaway friction coefficient (bottom) with identification of $90^{\text {th }}$ percentiles

As an example, the discrete PDF of the PFA/PFA ${ }^{0}$ ratio at both SLD and SLV for MF friction class and $\mu_{B} / \mu_{L V}=4.0$ is shown in Figure 19-top, and the CDFs obtained for different friction classes and breakaway classes are depicted in Figure 19-bottom. This figure shows that the distribution of the PFA/PFA ${ }^{0}$ ratio for MF friction class and $\mu_{B} / \mu_{L V}=4.0$ is mostly concentrated for values of about 2 for SLD events, and values $>1$ for SLV events, which implies a high probability of amplification. Moreover, this figure also shows that the CDFs have a different shape depending on the friction and breakaway class considered. As done before for the trigger acceleration, the $90^{\text {th }}$ percentile (i.e. $90 \%$ of the $x / x^{0}$ ratios do not exceed this threshold) is proposed by the authors as a design value to compute 
appropriate amplification factors. These amplification factors provide a sufficiently conservative safety margin with respect to the entire population of data. Evidently, the $90^{\text {th }}$ percentile of the $\mathrm{PFA} / \mathrm{PFA}^{0}$ ratio is related to the friction and breakaway classes, see again Figure 19-bottom.
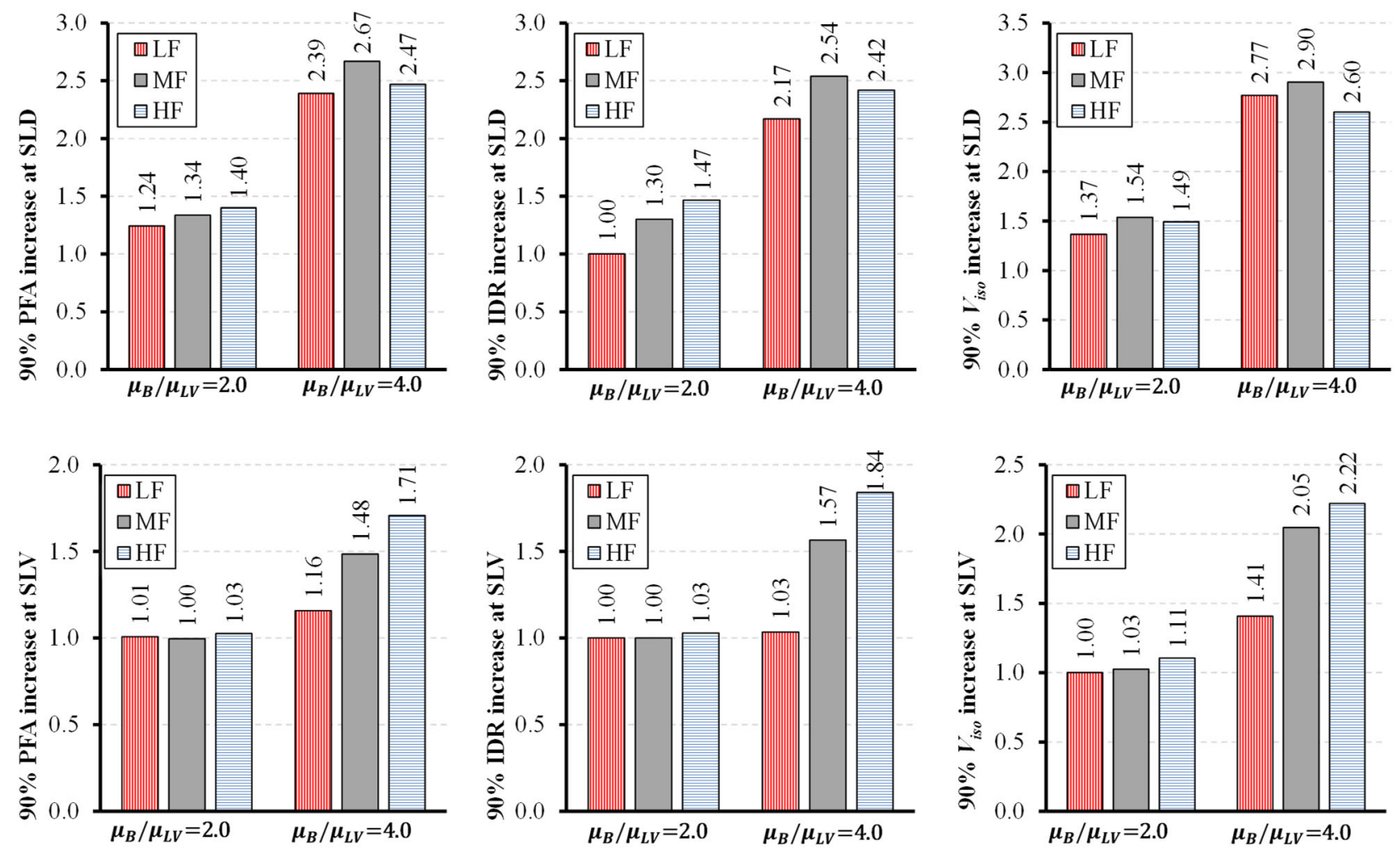

Figure 20 Amplification factors, calculated as $90^{\text {th }}$ percentile of the response parameter ratios $\boldsymbol{x} / \boldsymbol{x}^{\mathbf{0}}$, of PFA, IDR and $\boldsymbol{V}_{\text {iso }}$ for serviceability earthquakes at SLD (top), and for ultimate limit state earthquakes at SLV (bottom)

The computed amplification factors coefficients for PFA, IDR and $V_{i s o}$ are summarized in Figure 20 for both SLD and SLV, and for the considered friction classes. Obviously, the specific values of the amplification factors reported in Figure 20 are not applicable to all the design situations, being representative of seismic excitation scenario analyzed in the study. Although the validity of these factors is confined to the examined cases and cannot be meant as universally valid, the authors believe that this design tool is of general applicability and may be used in conjunction with structural analysis programs that ignore the breakaway friction, in order to estimate to what extent the breakaway friction would increase the structural response if it were incorporated in the model. In other words, the analysis can be carried out with the simple VelDependent friction model, and then the response can be amplified based on the amplification factors reported in Figure 20. As an example, most of the European manufacturers use PTFE or UHMWPE as sliding materials, which have $\mu_{B} / \mu_{L V}$ ratios of around 1.52.5. Based on Figure 20, in a base-isolated building with moderate-friction CSSs having breakaway friction $\mu_{B} / \mu_{L V}=2.0$, the PFA, IDR and $V_{i s o}$ calculated from the model ignoring the breakaway friction should be multiplied by $1.34,1.30,1.54$ for SLD (serviceability earthquakes), while generally no amplification should be applied for SLV (design earthquakes). The underestimation of the superstructure response for serviceability earthquakes is of major importance in view of possible consequences on the performance on acceleration-sensitive and drift-sensitive equipment and nonstructural components [83], [84]. On the other hand, in case of CSSs with unlubricated PTFE or 
UHMWPE at low temperatures and low contact pressure, or in case of contaminated surfaces, the $\mu_{B} / \mu_{L V}$ ratios can reach values of 4.0. In such cases, the amplification factors for PFA, IDR and $V_{\text {iso }}$ are 2.67, 2.54, and 2.90 for SLD (serviceability earthquakes), and 1.48, 1.57 and 2.05 for SLV (design earthquakes), respectively. These very high amplification factors confirm that neglecting the breakaway friction may lead to largely unsafe and non-conservative estimates of the structural response.

The obtained numerical results could be interpreted in view of current code provisions, in particular the simplified approach with the property modification factors included in the ASCE 7-16 [30] and EC8 part 2 [31]. With particular concern to the breakaway friction, the primary aim of an analysis based on the property modification factors should be focused on the "upper bound design parameter" of the characteristic strength of the CSS $F_{0}$ (force at zero displacement of an idealized bilinear lateral force-displacement model). Indeed, the breakaway friction coefficient is somehow related to the resisting force at zero displacement of the CSS. As an example, according to ASCE 7-16 the maximum property modification factor is evaluated as [30]:

$$
\lambda_{\text {max }}=\left[1+0.75 \cdot\left(\lambda_{\text {ae, } \max }-1\right)\right] \cdot \lambda_{\text {test, } \max } \cdot \lambda_{\text {spec, } \max } \geq 1.80
$$

where $\lambda_{a e}$ accounts for the variability due to the environmental exposure and ageing, $\lambda_{\text {test }}$ accounts for the variability due to heating and sliding velocity effects [33], and $\lambda_{\text {spec }}$ accounts for manufacturing variability. On the other hand, according to EC8 part 2 [31] (Annex J) the upper bound design properties (UBDPs) of the CSS can be determined by multiplying the nominal values with the following effective (amplification) coefficient

$$
\lambda_{\mathrm{UBDP}}=\lambda_{\mathrm{U}, f_{1}} \cdot \lambda_{\mathrm{U}, f_{2}} \cdot \lambda_{\mathrm{U}, f_{3}} \cdot \lambda_{\mathrm{U}, f_{4}}
$$

where the modification factors for each source of variability $f_{i}(i=1, \ldots, 4)$ are calculated as

$$
\lambda_{\mathrm{U}, f_{i}}=1+\left(\lambda_{\max , f_{i}}-1\right) \psi_{f_{i}} .
$$

In Eq. (16) $\psi_{f_{i}}$ is a combination factor (whose value, generally lower than one, depends on the importance class [31]) and the four main sources of variability are: $f_{1}$ for ageing, $f_{2}$ for temperature, $f_{3}$ for contamination and $f_{4}$ for cumulative travel (wear). Based on Eqns. (14)-(16), it appears that the two code provisions are quite consistent with each other, in that they assume that the upper bound design properties are simultaneously affected by different variability phenomena mutually interacting and combined together. Obviously, different modification factors are given for different conditions and design scenarios. Assuming default values for friction isolators (as indicated in [33]), namely $\lambda_{\text {ae } \text { max }}=1.56, \lambda_{\text {test } \text { max }}=1.3$ and $\lambda_{\text {spec, } \max }=1.15$ gives an upper-bound modification factor in Eq. (14) for ASCE 7-16 equal to $\lambda_{\max }=2.1$. Similarly, a reasonable yet conservative set of modification factors for EC8 provisions would be $\lambda_{\max , f_{1}}=1.5$ for ageing (relevant to unsealed, unlubricated PTFE in severe environment), $\lambda_{\max , f_{2}}=1.1$ for temperature (relevant to minimum temperature of $0^{\circ} \mathrm{C}$ ), $\lambda_{\text {max }, f_{3}}=1.2$ for contamination (relevant to unsealed, unlubricated PTFE with stainless steel surface facing down) and $\lambda_{\max , f_{4}}=1.2$ for wear (cumulative travel $\geq 1.0 \mathrm{~km}$ ), which produce an effective amplification coefficient in Eq. (15) for EC8 equal to $\lambda_{\mathrm{UBDP}}=1.88$ (assuming a combination coefficient $\psi_{f_{i}}=0.70$ for all sources of variability, relevant to an importance class II). These design scenarios would lead to an upper-bound friction coefficient almost doubled compared to the nominal friction coefficient and may, therefore, be representative of the case $\mu_{B} / \mu_{L V}=2.0$ analyzed in this 
study. Therefore, an analysis based on the above property modification factors would produce results quite in line with the graphs shown in Figure 20 for intermediate breakaway conditions. It is worth noting that the EC8 provisions are much more conservative for the upper-bound property modification factors of lubricated PTFE isolators. Indeed, under the same design assumptions made above but considering lubricated (in place of unlubricated) PTFE, the recommended values would be $\lambda_{\max , f_{1}}=$ 1.8, $\lambda_{\max , f_{2}}=1.3, \lambda_{\max , f_{3}}=3.0$ and $\lambda_{\max , f_{4}}=1.0$, which produce an effective amplification coefficient $\lambda_{\text {UBDP }}=4.5$. These design scenarios would lead to an upper-bound friction coefficient more than four times higher than the nominal friction coefficient and are, therefore, slightly more conservative than the case $\mu_{B} / \mu_{L V}=4.0$ analyzed in this study. Therefore, an analysis based on the above EC 8 property modification factors would produce more conservative results (in terms of superstructure response) than those reported in Figure 20 for high breakaway conditions.

Finally, the parametric study has also included two values of the mass ratio $m_{b} / m_{f}$, however the influence of this parameter on the results in terms of trigger acceleration as well as in terms of the considered seismic response parameters did not show a clear trend, and seems to be marginal at least for the building configurations and seismic excitations considered in this study.

\section{CONCLUSIONS}

The breakaway friction governs the transition between the sticking and the sliding phase of CSSs, thus affecting the seismic response of an isolated building. In practice, as long as the ground-motion acceleration is not able to overcome the breakaway frictional resistance, the isolators persist in the sticking phase and the superstructure undergoes larger accelerations and IDRs than the isolated building scenario. However, common structural analysis software programs neglect the static friction, and implement the dynamic friction coefficient throughout the response history analysis. In this paper, a friction model capable to reproduce the transition between the breakaway friction $\mu_{B}$ in the sticking phase and the velocity-dependent friction model in the subsequent sliding phase has been implemented in OpenSees to investigate the influence of the breakaway friction on the seismic response of baseisolated buildings. Based on this formulation, an extensive parametric study comprising more than 9000 bidirectional NLTHAs has been performed. The study has included three building examples, namely a two-storey, a four-storey and a six-storey ordinary RC framed building, two different mass distributions, three friction classes, representative of low-friction, moderate-friction and high-friction sliding materials, and three breakaway friction classes, characterized by three breakaway to lowvelocity friction ratios $\mu_{B} / \mu_{L V}$. In particular, the case $\mu_{B} / \mu_{L V}=1.0$ corresponds to the conventional model that disregards the breakaway friction, while cases $\mu_{B} / \mu_{L V}=2.0$ and 4.0 represent an intermediate breakaway and a high breakaway situation, the latter possibly caused by low temperature or poor maintenance conditions of the sliding surfaces. Moreover, for the characterization of the seismic input two intensity levels of the earthquake excitation, associated to either serviceability or ultimate limit states termed as SLD and SLV [64], two frequency contents in terms of soil characteristics (very rigid soil, soil class A, and medium-dense soil, soil class C), three epicentral distances, and two installation sites have been considered, thus including 168 spectrum-compatible bidirectional components of ground-motion acceleration.

The main findings of this research work can be summarized as follows:

1) When the breakaway friction coefficient is relatively high and the PGA of the seismic event is low, especially in case of low-to-moderate intensity earthquakes, the CSSs may persist in the 
sticking phase over the entire duration of the ground motion. This phenomenon was observed in 439 out of the 9072 NLTHAs included in the parametric study. The majority (85\%) of these no-activation cases occurred for ground-motion records relevant to soil class A, having a frequency content falling in the low-period (high-frequency) range, in which both the PGA and the spectral acceleration corresponding to the fundamental period of the superstructure are higher than in soil class $\mathrm{C}$.

2) Simplified analytical expressions based on free body equilibrium conditions are unable to reliably capture the actual value of the trigger acceleration $a_{\text {trigger }}$, meant as the minimum ground acceleration capable of activating the sliding motion (i.e., capable of overcoming the breakaway frictional resistance), in most cases leading to significant underestimations.

3) A regression analysis formula has been elaborated by processing the numerical $a_{\text {trigger }}$ data. In particular, a three-parameter regression formula that expresses the $90^{\text {th }}$ percentile of the trigger acceleration as a function of the breakaway friction coefficient $\mu_{B}$ has been developed by the authors. This formula can be further refined by including the influence of the superstructure fundamental period $T_{s s 1}$, which requires a total of nine (rather than three) independent regression coefficients. These expressions can be adopted for design purposes to obtain conservative estimates of the trigger acceleration with CSSs having a breakaway friction in the range $\mu_{B}=[0.01-0.20]$ and superstructure fundamental period $T_{S S 1}=[0.29-0.65]$.

4) Besides the aforementioned no-activation cases, generally occurring for serviceability earthquakes, in both serviceability and design earthquakes the sliding motion may be delayed by a high breakaway frictional resistance, and the CSSs may persist in the sticking phase for a relatively long part of the ground motion. It has been found that this phenomenon has a modest influence on the seismic displacement of the isolation system, but it may considerably affect the PFA and IDR responses of the superstructure, as well as the shear force carried by the isolation system $V_{i s o}$ in comparison with the baseline reference model that ignores $\mu_{B}$. To this aim, amplification factors for each of these three structural response parameter can be introduced, in relation to the friction class and the breakaway class. These amplification factors are defined as the $90^{\text {th }}$ percentiles of selected response parameters computed in the structural analysis model that includes the breakaway friction divided by the corresponding response parameter in the model disregarding the breakaway friction. Although the validity of these factors is confined to the examined cases and cannot be meant as universally valid, the authors believe that this design tool is of general applicability and may be used in conjunction with structural analysis programs that ignore the breakaway friction, in order to estimate to what extent the breakaway friction would increase the structural response if it were incorporated in the model. As an example, values of these amplification factors of around 1.5 for intermediate and around 2.5 for high breakaway have been found in the parametric study, confirm that neglecting the breakaway friction may lead to largely unsafe and non-conservative estimates of the structural response. 


\section{APPENDIX A}

Table 6 Details of earthquake ground motions for the Lamezia site, soil type A

\begin{tabular}{|c|c|c|c|c|c|c|c|c|c|c|c|c|c|}
\hline Earthquake name & Code & EQ ID & $\begin{array}{c}\text { Wave } \\
\text { ID }\end{array}$ & Station ID & Date & $M_{w}$ & $\begin{array}{c}R_{e p} \\
{[\mathrm{~km}]}\end{array}$ & $\mathrm{SF}_{\mathrm{x}}$ & $\mathrm{SF}_{\mathrm{y}}$ & $\begin{array}{c}\mathrm{PGA}_{\mathrm{X}} \\
{\left[\mathrm{m} / \mathrm{s}^{2}\right]}\end{array}$ & $\begin{array}{c}\mathrm{PGA}_{\mathrm{y}} \\
{\left[\mathrm{m} / \mathrm{s}^{2}\right]}\end{array}$ & $\begin{array}{l}\mathrm{PGV}_{\mathrm{x}} \\
{[\mathrm{m} / \mathrm{s}]}\end{array}$ & $\begin{array}{l}\mathrm{PGV}_{\mathrm{y}} \\
{[\mathrm{m} / \mathrm{s}]}\end{array}$ \\
\hline NE of Baja Luka & LA-A-SLD-R1-S1 & 1825 & 5655 & ST2950 & $13 / 08 / 1981$ & 5.7 & 10 & 1.212 & 1.196 & 0.730 & 0.740 & 0.061 & 0.034 \\
\hline Lazio Abbruzzo & LA-A-SLD-R1-S2 & 175 & 365 & ST140 & $07 / 05 / 1984$ & 5.9 & 5 & 0.898 & 0.819 & 0.985 & 1.080 & 0.037 & 0.037 \\
\hline Valnerina & LA-A-SLD-R1-S3 & 115 & 242 & ST225 & $19 / 09 / 1979$ & 5.8 & 5 & 0.586 & 0.440 & 1.510 & 2.012 & 0.076 & 0.140 \\
\hline South Iceland (aftershock) & LA-A-SLD-R1-S4 & 2142 & 6349 & ST2558 & $21 / 06 / 2000$ & 6.4 & 5 & 0.121 & 0.108 & 7.295 & 8.218 & 0.456 & 0.920 \\
\hline Vrancea & LA-A-SLD-R1-S5 & 227 & 471 & ST40 & $30 / 05 / 1990$ & 6.9 & 6 & 3.032 & 3.775 & 0.292 & 0.234 & 0.022 & 0.019 \\
\hline Vrancea & LA-A-SLD-R1-S6 & 228 & 473 & ST40 & $31 / 05 / 1990$ & 6.3 & 7 & 4.616 & 10.249 & 0.192 & 0.086 & 0.014 & 0.007 \\
\hline South Iceland & LA-A-SLD-R1-S7 & 1635 & 4674 & ST2486 & $17 / 06 / 2000$ & 6.5 & 5 & 0.284 & 0.267 & 3.118 & 3.311 & 0.612 & 0.238 \\
\hline Bingol & LA-A-SLD-R2-S1 & 2309 & 7142 & ST539 & $01 / 05 / 2003$ & 6.3 & 14 & 0.175 & 0.303 & 5.051 & 2.918 & 0.336 & 0.210 \\
\hline Lazio Abbruzzo (aftershock) & LA-A-SLD-R2-S2 & 176 & 383 & ST153 & $11 / 05 / 1984$ & 5.5 & 14 & 4.463 & 4.399 & 0.198 & 0.201 & 0.014 & 0.009 \\
\hline Lazio Abbruzzo (aftershock) & LA-A-SLD-R2-S4 & 65 & 149 & ST26 & $15 / 09 / 1976$ & 6 & 12 & 0.661 & 0.802 & 1.339 & 1.103 & 0.068 & 0.043 \\
\hline Friuli (aftershock) & LA-A-SLD-R2-S3 & 176 & 382 & ST140 & $11 / 05 / 1984$ & 5.5 & 16 & 3.491 & 6.017 & 0.254 & 0.147 & 0.013 & 0.009 \\
\hline Lazio Abbruzzo & LA-A-SLD-R2-S5 & 176 & 385 & ST155 & $11 / 05 / 1984$ & 5.5 & 15 & 2.021 & 1.945 & 0.438 & 0.455 & 0.030 & 0.017 \\
\hline South Iceland (aftershock) & LA-A-SLD-R2-S6 & 2142 & 6335 & ST2557 & $21 / 06 / 2000$ & 6.4 & 15 & 0.709 & 0.782 & 1.248 & 1.132 & 0.166 & 0.108 \\
\hline Mt. Hengill Area & LA-A-SLD-R2-S7 & 1464 & 5086 & ST2556 & 04/06/1998 & 5.4 & 15 & 3.943 & 5.153 & 0.224 & 0.172 & 0.019 & 0.023 \\
\hline Umbria Marche (aftershock) & LA-A-SLD-R3-S1 & 355 & 789 & ST225 & $12 / 10 / 1997$ & 5.2 & 22 & 3.590 & 4.722 & 0.247 & 0.187 & 0.015 & 0.011 \\
\hline Lazio Abbruzzo & LA-A-SLD-R3-S2 & 175 & 368 & ST143 & $07 / 05 / 1984$ & 5.9 & 22 & 1.409 & 1.320 & 0.628 & 0.671 & 0.056 & 0.039 \\
\hline Tithorea & LA-A-SLD-R3-S3 & 260 & 551 & ST212 & $18 / 11 / 1992$ & 5.9 & 37 & 5.536 & 4.205 & 0.160 & 0.210 & 0.012 & 0.012 \\
\hline Umbria Marche & LA-A-SLD-R3-S4 & 290 & 603 & ST225 & $26 / 09 / 1997$ & 5.7 & 35 & 3.232 & 3.322 & 0.274 & 0.266 & 0.013 & 0.011 \\
\hline Umbria Marche & LA-A-SLD-R3-S5 & 286 & 604 & ST225 & $26 / 09 / 1997$ & 6 & 37 & 4.172 & 4.337 & 0.212 & 0.204 & 0.011 & 0.011 \\
\hline Kalamata & LA-A-SLD-R3-S6 & 1885 & 5819 & ST1321 & $13 / 10 / 1997$ & 6.4 & 48 & 0.747 & 0.772 & 1.185 & 1.146 & 0.070 & 0.081 \\
\hline South Iceland & LA-A-SLD-R3-S7 & 1635 & 6267 & ST2565 & $17 / 06 / 2000$ & 6.5 & 46 & 3.993 & 3.698 & 0.222 & 0.239 & 0.017 & 0.020 \\
\hline Friuli (aftershock) & LA-A-SLV-R1-S1 & 60 & 116 & ST33 & $11 / 09 / 1976$ & 5.3 & 9 & 5.894 & 6.536 & 0.440 & 0.397 & 0.034 & 0.020 \\
\hline South Iceland & LA-A-SLV-R1-S2 & 1635 & 6263 & ST2484 & $17 / 06 / 2000$ & 6.5 & 7 & 0.422 & 0.516 & 6.136 & 5.018 & 0.389 & 0.498 \\
\hline Vrancea & LA-A-SLV-R1-S3 & 228 & 473 & ST40 & $31 / 05 / 1990$ & 6.3 & 7 & 13.516 & 30.014 & 0.192 & 0.086 & 0.014 & 0.007 \\
\hline South Iceland (aftershock) & LA-A-SLV-R1-S4 & 2142 & 6332 & ST2483 & $21 / 06 / 2000$ & 6.4 & 6 & 0.499 & 0.465 & 5.188 & 5.570 & 0.218 & 0.830 \\
\hline
\end{tabular}




\begin{tabular}{|c|c|c|c|c|c|c|c|c|c|c|c|c|c|}
\hline South Iceland & LA-A-SLV-R1-S5 & 1635 & 4674 & ST2486 & $17 / 06 / 2000$ & 6.5 & 5 & 0.831 & 0.783 & 3.118 & 3.311 & 0.612 & 0.238 \\
\hline Kalamata & LA-A-SLV-R1-S6 & 192 & 413 & ST164 & 13/09/1986 & 5.9 & 10 & 1.229 & 0.891 & 2.108 & 2.910 & 0.327 & 0.323 \\
\hline Dinar & LA-A-SLV-R1-S7 & 349 & 879 & ST271 & 01/10/1995 & 6.4 & 8 & 0.969 & 0.828 & 2.674 & 3.131 & 0.294 & 0.406 \\
\hline Bingol & LA-A-SLV-R2-S1 & 2309 & 7142 & ST539 & $01 / 05 / 2003$ & 6.3 & 14 & 0.513 & 0.888 & 5.051 & 2.918 & 0.336 & 0.210 \\
\hline South Iceland & LA-A-SLV-R2-S2 & 1635 & 4675 & ST2487 & $17 / 06 / 2000$ & 6.5 & 13 & 2.006 & 1.691 & 1.292 & 1.533 & 0.161 & 0.101 \\
\hline South Iceland (aftershock) & LA-A-SLV-R2-S3 & 2142 & 6335 & ST2557 & $21 / 06 / 2000$ & 6.4 & 15 & 2.076 & 2.289 & 1.248 & 1.132 & 0.166 & 0.108 \\
\hline Mt. Hengill Area & LA-A-SLV-R2-S4 & 1464 & 5090 & ST2495 & 04/06/1998 & 5.4 & 18 & 8.429 & 5.338 & 0.307 & 0.486 & 0.020 & 0.038 \\
\hline Izmit (aftershock) & LA-A-SLV-R2-S5 & 473 & 1243 & ST575 & 13/09/1999 & 5.8 & 15 & 3.630 & 0.833 & 0.714 & 3.112 & 0.055 & 0.145 \\
\hline South Iceland (aftershock) & LA-A-SLV-R2-S6 & 2142 & 6326 & ST2496 & $21 / 06 / 2000$ & 6.4 & 14 & 1.483 & 2.269 & 1.748 & 1.142 & 0.097 & 0.177 \\
\hline Mt. Hengill Area & LA-A-SLV-R2-S7 & 1464 & 5085 & ST2497 & 04/06/1998 & 5.4 & 15 & 21.613 & 15.114 & 0.120 & 0.171 & 0.019 & 0.023 \\
\hline Campano Lucano & LA-A-SLV-R3-S1 & 146 & 292 & ST98 & $23 / 11 / 1980$ & 6.9 & 25 & 4.409 & 4.410 & 0.588 & 0.588 & 0.044 & 0.059 \\
\hline Mt. Vatnafjoll & LA-A-SLV-R3-S2 & 1338 & 5271 & ST2483 & $25 / 05 / 1987$ & 6 & 42 & 18.811 & 19.804 & 0.138 & 0.131 & 0.010 & 0.012 \\
\hline Lazio Abbruzzo & LA-A-SLV-R3-S3 & 175 & 368 & ST143 & $07 / 05 / 1984$ & 5.9 & 22 & 4.126 & 3.864 & 0.628 & 0.671 & 0.056 & 0.039 \\
\hline Sicilia-Orientale & LA-A-SLV-R3-S4 & 424 & 960 & ST296 & $13 / 12 / 1990$ & 5.6 & 50 & 3.651 & 4.052 & 0.710 & 0.640 & 0.044 & 0.036 \\
\hline Friuli & LA-A-SLV-R3-S5 & 34 & 55 & ST20 & $06 / 05 / 1976$ & 6.5 & 23 & 0.741 & 0.837 & 3.499 & 3.097 & 0.206 & 0.326 \\
\hline Montenegro & LA-A-SLV-R3-S6 & 93 & 198 & ST64 & 15/04/1979 & 6.9 & 21 & 1.461 & 1.179 & 1.774 & 2.199 & 0.171 & 0.259 \\
\hline Campano Lucano & LA-A-SLV-R3-S7 & 146 & 290 & ST96 & $23 / 11 / 1980$ & 6.9 & 32 & 1.222 & 0.818 & 2.121 & 3.166 & 0.330 & 0.553 \\
\hline
\end{tabular}

Table 7 Details of earthquake ground motions for the Lamezia site, soil type C

\begin{tabular}{|c|c|c|c|c|c|c|c|c|c|c|c|c|c|}
\hline Earthquake name & Code & EQ ID & $\begin{array}{c}\text { Wave } \\
\text { ID }\end{array}$ & Station ID & Date & $M_{w}$ & $\begin{array}{c}R_{e p} \\
{[\mathrm{~km}]}\end{array}$ & $\mathrm{SF}_{\mathrm{x}}$ & $\mathrm{SF}_{\mathrm{y}}$ & $\begin{array}{c}\mathrm{PGA}_{\mathrm{X}} \\
{\left[\mathrm{m} / \mathrm{s}^{2}\right]}\end{array}$ & $\begin{array}{c}\mathrm{PGA}_{\mathrm{y}} \\
{\left[\mathrm{m} / \mathrm{s}^{2}\right]}\end{array}$ & $\begin{array}{l}\mathrm{PGV}_{\mathrm{x}} \\
{[\mathrm{m} / \mathrm{s}]}\end{array}$ & $\begin{array}{l}\mathrm{PGV}_{\mathrm{y}} \\
{[\mathrm{m} / \mathrm{s}]}\end{array}$ \\
\hline Friuli (aftershock) & LA-C-SLD-R1-S1 & 63 & 133 & ST33 & $15 / 09 / 1976$ & 6 & 9 & 1.242 & 1.424 & 1.069 & 0.932 & 0.108 & 0.112 \\
\hline Friuli (aftershock) & LA-C-SLD-R1-S2 & 60 & 116 & ST33 & 11/09/1976 & 5.3 & 9 & 3.019 & 3.348 & 0.440 & 0.397 & 0.034 & 0.02 \\
\hline Vrancea & LA-C-SLD-R1-S3 & 227 & 471 & ST40 & $30 / 05 / 1990$ & 6.9 & 6 & 4.549 & 5.662 & 0.292 & 0.234 & 0.022 & 0.019 \\
\hline Friuli (aftershock) & LA-C-SLD-R1-S4 & 61 & 122 & ST33 & 11/09/1976 & 5.5 & 9 & 0.587 & 1.289 & 2.261 & 1.030 & 0.216 & 0.089 \\
\hline Kalamata & LA-C-SLD-R1-S5 & 192 & 413 & ST164 & $13 / 09 / 1986$ & 5.9 & 10 & 0.630 & 0.456 & 2.108 & 2.910 & 0.327 & 0.323 \\
\hline South Iceland & LA-C-SLD-R1-S6 & 1635 & 4674 & ST2486 & $17 / 06 / 2000$ & 6.5 & 5 & 0.426 & 0.401 & 3.118 & 3.311 & 0.612 & 0.238 \\
\hline Dinar & LA-C-SLD-R1-S7 & 349 & 879 & ST271 & 01/10/1995 & 6.4 & 8 & 0.496 & 0.424 & 2.674 & 3.131 & 0.294 & 0.406 \\
\hline Umbria Marche (aftershock) & LA-C-SLD-R2-S1 & 350 & 772 & ST223 & $03 / 10 / 1997$ & 5.300 & 20 & 2.340 & 3.277 & 0.567 & 0.405 & 0.048 & 0.028 \\
\hline Alkion & LA-C-SLD-R2-S2 & 157 & 333 & ST121 & $24 / 02 / 1981$ & 6.6 & 20 & 0.588 & 0.437 & 2.257 & 3.036 & 0.223 & 0.226 \\
\hline Friuli (aftershock) & LA-C-SLD-R2-S3 & 65 & 147 & ST28 & $15 / 09 / 1976$ & 6 & 14 & 0.959 & 0.572 & 1.384 & 2.319 & 0.118 & 0.187 \\
\hline Ionian & LA-C-SLD-R2-S4 & 30 & 42 & ST8 & $04 / 11 / 1973$ & 5.8 & 15 & 0.258 & 0.531 & 5.146 & 2.498 & 0.570 & 0.255 \\
\hline
\end{tabular}




\begin{tabular}{|c|c|c|c|c|c|c|c|c|c|c|c|c|c|}
\hline Campano Lucano (aftershock) & LA-C-SLD-R2-S5 & 153 & 315 & ST97 & $16 / 01 / 1981$ & 5.200 & 15 & 6.591 & 6.866 & 0.201 & 0.193 & 0.012 & 0.016 \\
\hline Umbria Marche (aftershock) & LA-C-SLD-R2-S6 & 291 & 625 & ST223 & 06/10/1997 & 5.500 & 20 & 1.237 & 1.704 & 1.073 & 0.779 & 0.075 & 0.05 \\
\hline Mt. Hengill Area & LA-C-SLD-R2-S7 & 1464 & 5085 & ST2497 & 04/06/1998 & 5.400 & 15 & 11.071 & 7.742 & 0.120 & 0.171 & 0.019 & 0.023 \\
\hline Izmit (aftershock) & LA-C-SLD-R3-S1 & 2159 & 7010 & ST772 & $11 / 11 / 1999$ & 5.6 & 41 & 7.761 & 5.548 & 0.171 & 0.239 & 0.013 & 0.016 \\
\hline Izmit (aftershock) & LA-C-SLD-R3-S2 & 473 & 1242 & ST576 & 13/09/1999 & 5.8 & 49 & 2.170 & 1.792 & 0.612 & 0.741 & 0.044 & 0.088 \\
\hline Umbria Marche & LA-C-SLD-R3-S3 & 286 & 600 & ST223 & 26/09/1997 & 6 & 22 & 0.788 & 1.276 & 1.685 & 1.041 & 0.145 & 0.118 \\
\hline Izmit (aftershock) & LA-C-SLD-R3-S4 & 473 & 6960 & ST3266 & 13/09/1999 & 5.8 & 27 & 4.382 & 2.688 & 0.303 & 0.494 & 0.025 & 0.041 \\
\hline Patras & LA-C-SLD-R3-S5 & 276 & 571 & ST215 & 14/07/1993 & 5.6 & 37 & 6.637 & 4.300 & 0.200 & 0.309 & 0.022 & 0.018 \\
\hline Adana & LA-C-SLD-R3-S6 & 561 & 1726 & ST549 & 27/06/1998 & 6.3 & 30 & 0.615 & 0.502 & 2.158 & 2.644 & 0.278 & 0.203 \\
\hline Izmit (aftershock) & LA-C-SLD-R3-S7 & 473 & 6963 & ST3268 & 13/09/1999 & 5.8 & 38 & 3.340 & 3.116 & 0.398 & 0.426 & 0.033 & 0.034 \\
\hline South Iceland & LA-C-SLV-R1-S1 & 1635 & 4674 & ST2486 & $17 / 06 / 2000$ & 6.5 & 5 & 1.088 & 1.025 & 3.118 & 3.311 & 0.612 & 0.238 \\
\hline Friuli (aftershock) & LA-C-SLV-R1-S2 & 65 & 151 & ST33 & $15 / 09 / 1976$ & 6 & 11 & 4.187 & 3.838 & 0.810 & 0.884 & 0.079 & 0.063 \\
\hline Duzce 1 & LA-C-SLV-R1-S3 & 497 & 1703 & ST553 & $12 / 11 / 1999$ & 7.2 & 8 & 0.917 & 0.674 & 3.699 & 5.036 & 0.357 & 0.635 \\
\hline Dinar & LA-C-SLV-R1-S4 & 349 & 879 & ST271 & 01/10/1995 & 6.4 & 8 & 1.269 & 1.084 & 2.674 & 3.131 & 0.294 & 0.406 \\
\hline Izmit & LA-C-SLV-R1-S5 & 472 & 1231 & ST575 & 17/08/1999 & 7.6 & 9 & 2.152 & 1.547 & 1.576 & 2.192 & 0.190 & 0.266 \\
\hline Montenegro (aftershock) & LA-C-SLV-R1-S6 & 108 & 230 & ST73 & 24/05/1979 & 6.2 & 8 & 2.894 & 1.293 & 1.172 & 2.624 & 0.189 & 0.269 \\
\hline Campano Lucano & LA-C-SLV-R1-S7 & 146 & 291 & ST276 & $23 / 11 / 1980$ & 6.9 & 16 & 2.224 & 1.967 & 1.526 & 1.725 & 0.271 & 0.275 \\
\hline Alkion & LA-C-SLV-R2-S1 & 157 & 334 & ST122 & $24 / 02 / 1981$ & 6.6 & 19 & 1.195 & 2.031 & 2.838 & 1.671 & 0.227 & 0.220 \\
\hline South Iceland (aftershock) & LA-C-SLV-R2-S2 & 2142 & 6335 & ST2557 & $21 / 06 / 2000$ & 6.400 & 15 & 2.718 & 2.996 & 1.248 & 1.132 & 0.166 & 0.108 \\
\hline South Iceland & LA-C-SLV-R2-S3 & 1635 & 4675 & ST2487 & $17 / 06 / 2000$ & 6.5 & 13 & 2.626 & 2.214 & 1.292 & 1.533 & 0.161 & 0.101 \\
\hline Montenegro & LA-C-SLV-R2-S4 & 93 & 199 & ST67 & $15 / 04 / 1979$ & 6.9 & 16 & 0.922 & 0.954 & 3.680 & 3.557 & 0.421 & 0.520 \\
\hline Friuli (aftershock) & LA-C-SLV-R2-S5 & 65 & 146 & ST24 & $15 / 09 / 1976$ & 6 & 14 & 0.999 & 1.029 & 3.395 & 3.296 & 0.229 & 0.232 \\
\hline Campano Lucano & LA-C-SLV-R2-S6 & 146 & 291 & ST276 & $23 / 11 / 1980$ & 6.9 & 16 & 2.224 & 1.967 & 1.526 & 1.725 & 0.271 & 0.275 \\
\hline Izmit & LA-C-SLV-R2-S7 & 472 & 1257 & ST772 & 17/08/1999 & 7.6 & 20 & 1.168 & 1.417 & 2.903 & 2.395 & 0.525 & 0.476 \\
\hline Umbria Marche & LA-C-SLV-R3-S1 & 286 & 600 & ST223 & 26/09/1997 & 6 & 22 & 2.013 & 3.260 & 1.685 & 1.041 & 0.145 & 0.118 \\
\hline Adana & LA-C-SLV-R3-S2 & 561 & 1726 & ST549 & 27/06/1998 & 6.3 & 30 & 1.572 & 1.283 & 2.158 & 2.644 & 0.278 & 0.203 \\
\hline Ishakli (aftershock) & LA-C-SLV-R3-S3 & 2296 & 7104 & ST856 & 03/02/2002 & 5.8 & 35 & 8.608 & 6.692 & 0.394 & 0.507 & 0.031 & 0.053 \\
\hline Izmit (aftershock) & LA-C-SLV-R3-S4 & 473 & 6978 & ST3273 & 13/09/1999 & 5.8 & 25 & 2.445 & 4.845 & 1.387 & 0.700 & 0.089 & 0.094 \\
\hline Alkion & LA-C-SLV-R3-S5 & 158 & 335 & ST121 & $25 / 02 / 1981$ & 6.3 & 25 & 2.966 & 2.885 & 1.144 & 1.176 & 0.109 & 0.149 \\
\hline Cubuklu & LA-C-SLV-R3-S6 & 587 & 1794 & ST65 & $20 / 04 / 1988$ & 5.5 & 34 & 8.283 & 7.642 & 0.410 & 0.444 & 0.051 & 0.071 \\
\hline Izmit (aftershock) & LA-C-SLV-R3-S7 & 473 & 6975 & ST3272 & 13/09/1999 & 5.8 & 26 & 5.248 & 6.626 & 0.646 & 0.512 & 0.061 & 0.074 \\
\hline
\end{tabular}


Table 8 Details of earthquake ground motions for the Naples site, soil type A

\begin{tabular}{|c|c|c|c|c|c|c|c|c|c|c|c|c|c|}
\hline Earthquake name & Code & EQ ID & $\begin{array}{c}\text { Wave } \\
\text { ID }\end{array}$ & Station ID & Date & $M_{w}$ & $\begin{array}{c}R_{e p} \\
{[\mathrm{~km}]}\end{array}$ & $\mathrm{SF}_{\mathrm{x}}$ & $\mathrm{SF}_{\mathrm{y}}$ & $\begin{array}{c}\mathrm{PGA}_{\mathrm{X}} \\
{\left[\mathrm{m} / \mathrm{s}^{2}\right]}\end{array}$ & $\begin{array}{c}\mathrm{PGA}_{\mathrm{y}} \\
{\left[\mathrm{m} / \mathrm{s}^{2}\right]}\end{array}$ & $\begin{array}{l}\mathrm{PGV}_{\mathrm{x}} \\
{[\mathrm{m} / \mathrm{s}]}\end{array}$ & $\begin{array}{l}\mathrm{PGV}_{\mathrm{y}} \\
{[\mathrm{m} / \mathrm{s}]}\end{array}$ \\
\hline NE of Baja Luka & NA-A-SLD-R1-S1 & 1825 & 5655 & ST2950 & $13 / 08 / 1981$ & 5.7 & 10 & 0.799 & 0.788 & 0.730 & 0.740 & 0.061 & 0.034 \\
\hline Valnerina & NA-A-SLD-R1-S2 & 115 & 242 & ST225 & $19 / 09 / 1979$ & 5.8 & 5 & 0.386 & 0.290 & 1.510 & 2.012 & 0.076 & 0.140 \\
\hline Vrancea & NA-A-SLD-R1-S3 & 227 & 471 & ST40 & $30 / 05 / 1990$ & 6.9 & 6 & 1.999 & 2.488 & 0.292 & 0.234 & 0.022 & 0.019 \\
\hline Umbria Marche (aftershock) & NA-A-SLD-R1-S4 & 291 & 651 & ST236 & 06/10/1997 & 5.5 & 5 & 0.262 & 0.317 & 2.229 & 1.838 & 0.101 & 0.084 \\
\hline Vrancea & NA-A-SLD-R1-S5 & 228 & 473 & ST40 & $31 / 05 / 1990$ & 6.3 & 7 & 3.043 & 6.756 & 0.192 & 0.086 & 0.014 & 0.007 \\
\hline South Iceland (aftershock) & NA-A-SLD-R1-S6 & 2142 & 6332 & ST2483 & $21 / 06 / 2000$ & 6.4 & 6 & 0.112 & 0.105 & 5.188 & 5.570 & 0.218 & 0.830 \\
\hline South Iceland & NA-A-SLD-R1-S7 & 1635 & 4674 & ST2486 & $17 / 06 / 2000$ & 6.5 & 5 & 0.187 & 0.176 & 3.118 & 3.311 & 0.612 & 0.238 \\
\hline Bingol & NA-A-SLD-R2-S1 & 2309 & 7142 & ST539 & $01 / 05 / 2003$ & 6.3 & 14 & 0.115 & 0.200 & 5.051 & 2.918 & 0.336 & 0.210 \\
\hline Lazio Abbruzzo (aftershock) & NA-A-SLD-R2-S2 & 176 & 382 & ST140 & $11 / 05 / 1984$ & 5.5 & 16 & 2.301 & 3.966 & 0.254 & 0.147 & 0.013 & 0.009 \\
\hline Lazio Abbruzzo (aftershock) & NA-A-SLD-R2-S3 & 176 & 383 & ST153 & $11 / 05 / 1984$ & 5.5 & 14 & 2.942 & 2.900 & 0.198 & 0.201 & 0.014 & 0.009 \\
\hline Lazio Abbruzzo (aftershock) & NA-A-SLD-R2-S4 & 176 & 385 & ST155 & $11 / 05 / 1984$ & 5.5 & 15 & 1.332 & 1.282 & 0.438 & 0.455 & 0.030 & 0.017 \\
\hline Mt. Hengill Area & NA-A-SLD-R2-S5 & 1464 & 5078 & ST2496 & 04/06/1998 & 5.4 & 18 & 4.402 & 2.444 & 0.133 & 0.239 & 0.011 & 0.019 \\
\hline Mt. Hengill Area & NA-A-SLD-R2-S6 & 1464 & 5090 & ST2495 & 04/06/1998 & 5.4 & 18 & 1.897 & 1.201 & 0.307 & 0.486 & 0.020 & 0.038 \\
\hline Mt. Hengill Area & NA-A-SLD-R2-S7 & 1464 & 5085 & ST2497 & 04/06/1998 & 5.4 & 15 & 4.865 & 3.402 & 0.120 & 0.171 & 0.019 & 0.023 \\
\hline Lazio Abbruzzo & NA-A-SLD-R3-S1 & 175 & 368 & ST143 & $07 / 05 / 1984$ & 5.9 & 22 & 0.929 & 0.870 & 0.628 & 0.671 & 0.056 & 0.039 \\
\hline Tithorea & NA-A-SLD-R3-S2 & 260 & 551 & ST212 & $18 / 11 / 1992$ & 5.9 & 37 & 3.649 & 2.772 & 0.160 & 0.210 & 0.012 & 0.012 \\
\hline Umbria Marche (aftershock) & NA-A-SLD-R3-S3 & 355 & 789 & ST225 & $12 / 10 / 1997$ & 5.2 & 22 & 2.366 & 3.112 & 0.247 & 0.187 & 0.015 & 0.011 \\
\hline Umbria Marche & NA-A-SLD-R3-S4 & 286 & 604 & ST225 & $26 / 09 / 1997$ & 6.0 & 37 & 2.750 & 2.859 & 0.212 & 0.204 & 0.011 & 0.011 \\
\hline Sicilia-Orientale & NA-A-SLD-R3-S5 & 424 & 960 & ST296 & $13 / 12 / 1990$ & 5.6 & 50 & 0.822 & 0.912 & 0.710 & 0.640 & 0.044 & 0.036 \\
\hline Valnerina & NA-A-SLD-R3-S6 & 115 & 246 & ST61 & $19 / 09 / 1979$ & 5.8 & 22 & 0.972 & 0.670 & 0.600 & 0.870 & 0.040 & 0.052 \\
\hline Montenegro & NA-A-SLD-R3-S7 & 93 & 198 & ST64 & $15 / 04 / 1979$ & 6.9 & 21 & 0.329 & 0.265 & 1.774 & 2.199 & 0.171 & 0.259 \\
\hline Vrancea & NA-A-SLV-R1-S1 & 227 & 471 & ST40 & $30 / 05 / 1990$ & 6.9 & 6 & 5.638 & 7.018 & 0.292 & 0.234 & 0.022 & 0.019 \\
\hline South Iceland (aftershock) & NA-A-SLV-R1-S2 & 2142 & 6349 & ST2558 & $21 / 06 / 2000$ & 6.4 & 5 & 0.226 & 0.200 & 7.295 & 8.218 & 0.456 & 0.920 \\
\hline South Iceland & NA-A-SLV-R1-S3 & 1635 & 6263 & ST2484 & $17 / 06 / 2000$ & 6.5 & 7 & 0.268 & 0.328 & 6.136 & 5.018 & 0.389 & 0.498 \\
\hline Vrancea & NA-A-SLV-R1-S4 & 228 & 473 & ST40 & $31 / 05 / 1990$ & 6.3 & 7 & 8.582 & 19.056 & 0.192 & 0.086 & 0.014 & 0.007 \\
\hline South Iceland (aftershock) & NA-A-SLV-R1-S5 & 2142 & 6332 & ST2483 & $21 / 06 / 2000$ & 6.4 & 6 & 0.317 & 0.295 & 5.188 & 5.570 & 0.218 & 0.830 \\
\hline Umbria Marche & NA-A-SLV-R1-S6 & 286 & 592 & ST221 & $26 / 09 / 1997$ & 6.0 & 5 & 0.843 & 0.754 & 1.951 & 2.183 & 0.174 & 0.140 \\
\hline South Iceland & NA-A-SLV-R1-S7 & 1635 & 4674 & ST2486 & $17 / 06 / 2000$ & 6.5 & 5 & 0.528 & 0.497 & 3.118 & 3.311 & 0.612 & 0.238 \\
\hline Bingol & NA-A-SLV-R2-S1 & 2309 & 7142 & ST539 & $01 / 05 / 2003$ & 6.3 & 14 & 0.326 & 0.564 & 5.051 & 2.918 & 0.336 & 0.210 \\
\hline Mt. Hengill Area & NA-A-SLV-R2-S2 & 1464 & 5078 & ST2496 & 04/06/1998 & 5.4 & 18 & 12.417 & 6.894 & 0.133 & 0.239 & 0.011 & 0.019 \\
\hline
\end{tabular}




\begin{tabular}{|c|c|c|c|c|c|c|c|c|c|c|c|c|c|}
\hline Lazio Abbruzzo (aftershock) & NA-A-SLV-R2-S3 & 176 & 382 & ST140 & $11 / 05 / 1984$ & 5.5 & 16 & 6.491 & 11.187 & 0.254 & 0.147 & 0.013 & 0.009 \\
\hline South Iceland & NA-A-SLV-R2-S4 & 1635 & 4675 & ST2487 & $17 / 06 / 2000$ & 6.5 & 13 & 1.274 & 1.074 & 1.292 & 1.533 & 0.161 & 0.101 \\
\hline Mt. Hengill Area & NA-A-SLV-R2-S5 & 1464 & 5090 & ST2495 & 04/06/1998 & 5.4 & 18 & 5.352 & 3.389 & 0.307 & 0.486 & 0.020 & 0.038 \\
\hline South Iceland (aftershock) & NA-A-SLV-R2-S6 & 2142 & 6335 & ST2557 & $21 / 06 / 2000$ & 6.4 & 15 & 1.318 & 1.453 & 1.248 & 1.132 & 0.166 & 0.108 \\
\hline Mt. Hengill Area & NA-A-SLV-R2-S7 & 1464 & 5086 & ST2556 & 04/06/1998 & 5.4 & 15 & 7.331 & 9.581 & 0.224 & 0.172 & 0.019 & 0.023 \\
\hline Tithorea & NA-A-SLV-R3-S1 & 260 & 551 & ST212 & $18 / 11 / 1992$ & 5.9 & 37 & 10.292 & 7.818 & 0.160 & 0.210 & 0.012 & 0.012 \\
\hline Lazio Abbruzzo & NA-A-SLV-R3-S2 & 175 & 368 & ST143 & $07 / 05 / 1984$ & 5.9 & 22 & 2.620 & 2.453 & 0.628 & 0.671 & 0.056 & 0.039 \\
\hline Umbria Marche & NA-A-SLV-R3-S3 & 286 & 604 & ST225 & 26/09/1997 & 6.0 & 37 & 7.757 & 8.063 & 0.212 & 0.204 & 0.011 & 0.011 \\
\hline Sicilia-Orientale & NA-A-SLV-R3-S4 & 424 & 960 & ST296 & $13 / 12 / 1990$ & 5.6 & 50 & 2.318 & 2.573 & 0.710 & 0.640 & 0.044 & 0.036 \\
\hline Umbria Marche (aftershock) & NA-A-SLV-R3-S5 & 355 & 789 & ST225 & $12 / 10 / 1997$ & 5.2 & 22 & 6.675 & 8.779 & 0.247 & 0.187 & 0.015 & 0.011 \\
\hline Umbria Marche (aftershock) & NA-A-SLV-R3-S6 & 292 & 642 & ST225 & $14 / 10 / 1997$ & 5.6 & 23 & 3.140 & 2.662 & 0.524 & 0.618 & 0.051 & 0.052 \\
\hline Campano Lucano & NA-A-SLV-R3-S7 & 146 & 290 & ST96 & $23 / 11 / 1980$ & 6.9 & 32 & 0.776 & 0.520 & 2.121 & 3.166 & 0.330 & 0.553 \\
\hline
\end{tabular}

Table 9 Details of earthquake ground motions for the Naples site, soil type C

\begin{tabular}{|c|c|c|c|c|c|c|c|c|c|c|c|c|c|}
\hline Earthquake name & Code & EQ ID & $\begin{array}{c}\text { Wave } \\
\text { ID }\end{array}$ & Station ID & Date & $M_{w}$ & $\begin{array}{c}R_{e p} \\
{[\mathrm{~km}]}\end{array}$ & $\mathrm{SF}_{\mathrm{x}}$ & $\mathrm{SF}_{\mathrm{y}}$ & $\begin{array}{l}\mathrm{PGA}_{\mathrm{x}} \\
{\left[\mathrm{m} / \mathrm{s}^{2}\right]}\end{array}$ & $\begin{array}{c}\mathrm{PGA}_{\mathrm{y}} \\
{\left[\mathrm{m} / \mathrm{s}^{2}\right\rceil}\end{array}$ & $\begin{array}{l}\mathrm{PGV}_{\mathrm{x}} \\
{[\mathrm{m} / \mathrm{s}]}\end{array}$ & $\begin{array}{c}\mathrm{PGV}_{\mathrm{y}} \\
{[\mathrm{m} / \mathrm{s}]}\end{array}$ \\
\hline Friuli (aftershock) & NA-C-SLD-R1-S1 & 63 & 133 & ST33 & $15 / 09 / 1976$ & 6.0 & 9 & 0.819 & 0.938 & 1.069 & 0.932 & 0.108 & 0.112 \\
\hline Kalamata & NA-C-SLD-R1-S2 & 192 & 413 & ST164 & $13 / 09 / 1986$ & 5.9 & 10 & 0.415 & 0.301 & 2.108 & 2.910 & 0.327 & 0.323 \\
\hline Vrancea & NA-C-SLD-R1-S3 & 227 & 471 & ST40 & $30 / 05 / 1990$ & 6.9 & 6 & 2.998 & 3.732 & 0.292 & 0.234 & 0.022 & 0.019 \\
\hline Friuli (aftershock) & NA-C-SLD-R1-S4 & 60 & 116 & ST33 & $11 / 09 / 1976$ & 5.3 & 9 & 1.990 & 2.207 & 0.440 & 0.397 & 0.034 & 0.020 \\
\hline South Iceland & NA-C-SLD-R1-S5 & 1635 & 4674 & ST2486 & $17 / 06 / 2000$ & 6.5 & 5 & 0.281 & 0.264 & 3.118 & 3.311 & 0.612 & 0.238 \\
\hline Gulf of Corinth & NA-C-SLD-R1-S6 & 280 & 578 & ST178 & $04 / 11 / 1993$ & 5.3 & 10 & 1.301 & 0.858 & 0.673 & 1.020 & 0.048 & 0.095 \\
\hline Dinar & NA-C-SLD-R1-S7 & 349 & 879 & ST271 & 01/10/1995 & 6.4 & 8 & 0.327 & 0.279 & 2.674 & 3.131 & 0.294 & 0.406 \\
\hline Alkion & NA-C-SLD-R2-S1 & 157 & 333 & ST121 & $24 / 02 / 1981$ & 6.6 & 20 & 0.388 & 0.288 & 2.257 & 3.036 & 0.223 & 0.226 \\
\hline Montenegro (aftershock) & NA-C-SLD-R2-S2 & 108 & 232 & ST77 & 24/05/1979 & 6.2 & 20 & 1.563 & 1.613 & 0.560 & 0.543 & 0.036 & 0.043 \\
\hline Friuli (aftershock) & NA-C-SLD-R2-S3 & 65 & 147 & ST28 & $15 / 09 / 1976$ & 6.0 & 14 & 0.632 & 0.377 & 1.384 & 2.319 & 0.118 & 0.187 \\
\hline Basso Tirreno & NA-C-SLD-R2-S4 & 81 & 170 & ST46 & $15 / 04 / 1978$ & 6.0 & 18 & 1.217 & 0.552 & 0.719 & 1.585 & 0.062 & 0.154 \\
\hline Alkion & NA-C-SLD-R2-S5 & 157 & 334 & ST122 & $24 / 02 / 1981$ & 6.6 & 19 & 0.308 & 0.524 & 2.838 & 1.671 & 0.227 & 0.220 \\
\hline South Iceland & NA-C-SLD-R2-S6 & 1635 & 4675 & ST2487 & $17 / 06 / 2000$ & 6.5 & 13 & 0.677 & 0.571 & 1.292 & 1.533 & 0.161 & 0.101 \\
\hline Campano Lucano & NA-C-SLD-R2-S7 & 146 & 291 & ST276 & $23 / 11 / 1980$ & 6.9 & 16 & 0.574 & 0.507 & 1.526 & 1.725 & 0.271 & 0.275 \\
\hline Izmit (aftershock) & NA-C-SLD-R3-S1 & 2159 & 7010 & ST772 & $11 / 11 / 1999$ & 5.6 & 41 & 5.116 & 3.657 & 0.171 & 0.239 & 0.013 & 0.016 \\
\hline Izmit (aftershock) & NA-C-SLD-R3-S2 & 473 & 1242 & ST576 & $13 / 09 / 1999$ & 5.8 & 49 & 1.430 & 1.181 & 0.612 & 0.741 & 0.044 & 0.088 \\
\hline
\end{tabular}




\begin{tabular}{|c|c|c|c|c|c|c|c|c|c|c|c|c|c|}
\hline Umbria Marche & NA-C-SLD-R3-S3 & 286 & 600 & ST223 & 26/09/1997 & 6.0 & 22 & 0.519 & 0.841 & 1.685 & 1.041 & 0.145 & 0.118 \\
\hline Spitak & NA-C-SLD-R3-S4 & 213 & 439 & ST173 & 07/12/1988 & 6.7 & 36 & 0.488 & 0.487 & 1.793 & 1.796 & 0.149 & 0.208 \\
\hline Umbria & NA-C-SLD-R3-S5 & 174 & 360 & ST41 & 29/04/1984 & 5.6 & 43 & 1.699 & 1.879 & 0.515 & 0.466 & 0.035 & 0.026 \\
\hline Izmit (aftershock) & NA-C-SLD-R3-S6 & 473 & 6978 & ST3273 & 13/09/1999 & 5.8 & 25 & 0.631 & 1.250 & 1.387 & 0.700 & 0.089 & 0.094 \\
\hline Cubuklu & NA-C-SLD-R3-S7 & 587 & 1794 & ST65 & 20/04/1988 & 5.5 & 34 & 2.137 & 1.971 & 0.410 & 0.444 & 0.051 & 0.071 \\
\hline Montenegro (aftershock) & NA-C-SLV-R1-S1 & 108 & 232 & ST77 & $24 / 05 / 1979$ & 6.2 & 20 & 4.280 & 4.417 & 0.560 & 0.543 & 0.036 & 0.043 \\
\hline South Iceland & NA-C-SLV-R1-S2 & 1635 & 4674 & ST2486 & $17 / 06 / 2000$ & 6.5 & 5 & 0.769 & 0.724 & 3.118 & 3.311 & 0.612 & 0.238 \\
\hline Vrancea & NA-C-SLV-R1-S3 & 227 & 471 & ST40 & $30 / 05 / 1990$ & 6.9 & 6 & 8.211 & 10.222 & 0.292 & 0.234 & 0.022 & 0.019 \\
\hline Dinar & NA-C-SLV-R1-S4 & 349 & 879 & ST271 & 01/10/1995 & 6.4 & 8 & 0.896 & 0.765 & 2.674 & 3.131 & 0.294 & 0.406 \\
\hline Montenegro (aftershock) & NA-C-SLV-R1-S5 & 108 & 230 & ST73 & 24/05/1979 & 6.2 & 8 & 2.044 & 0.913 & 1.172 & 2.624 & 0.189 & 0.269 \\
\hline Montenegro & NA-C-SLV-R1-S6 & 93 & 199 & ST67 & $15 / 04 / 1979$ & 6.9 & 16 & 0.651 & 0.674 & 3.680 & 3.557 & 0.421 & 0.520 \\
\hline South Iceland (aftershock) & NA-C-SLV-R1-S7 & 2142 & 6341 & ST2497 & $21 / 06 / 2000$ & 6.4 & 20 & 4.751 & 2.336 & 0.504 & 1.026 & 0.088 & 0.107 \\
\hline Gazli & NA-C-SLV-R2-S1 & 43 & 74 & ST27 & $17 / 05 / 1976$ & 6.7 & 11 & 0.397 & 0.339 & 6.038 & 7.065 & 0.502 & 0.626 \\
\hline Alkion & NA-C-SLV-R2-S2 & 157 & 334 & ST122 & 24/02/1981 & 6.6 & 19 & 0.844 & 1.435 & 2.838 & 1.671 & 0.227 & 0.220 \\
\hline South Iceland (aftershock) & NA-C-SLV-R2-S3 & 2142 & 6335 & ST2557 & $21 / 06 / 2000$ & 6.4 & 15 & 1.920 & 2.117 & 1.248 & 1.132 & 0.166 & 0.108 \\
\hline Ano Liosia & NA-C-SLV-R2-S4 & 474 & 1713 & ST1257 & 07/09/1999 & 6.0 & 18 & 2.204 & 2.856 & 1.087 & 0.839 & 0.102 & 0.105 \\
\hline Erzincan & NA-C-SLV-R2-S5 & 250 & 535 & ST205 & 13/03/1992 & 6.6 & 13 & 0.628 & 0.477 & 3.814 & 5.028 & 1.018 & 0.718 \\
\hline Friuli (aftershock) & NA-C-SLV-R2-S6 & 65 & 146 & ST24 & $15 / 09 / 1976$ & 6.0 & 14 & 0.706 & 0.727 & 3.395 & 3.296 & 0.229 & 0.232 \\
\hline Campano Lucano & NA-C-SLV-R2-S7 & 146 & 291 & ST276 & $23 / 11 / 1980$ & 6.9 & 16 & 1.571 & 1.389 & 1.526 & 1.725 & 0.271 & 0.275 \\
\hline Izmit (aftershock) & NA-C-SLV-R3-S1 & 2159 & 7010 & ST772 & $11 / 11 / 1999$ & 5.6 & 41 & 14.010 & 10.015 & 0.171 & 0.239 & 0.013 & 0.016 \\
\hline Alkion & NA-C-SLV-R3-S2 & 157 & 333 & ST121 & 24/02/1981 & 6.6 & 20 & 1.062 & 0.789 & 2.257 & 3.036 & 0.223 & 0.226 \\
\hline Izmit (aftershock) & NA-C-SLV-R3-S3 & 473 & 6960 & ST3266 & 13/09/1999 & 5.8 & 27 & 7.911 & 4.853 & 0.303 & 0.494 & 0.025 & 0.041 \\
\hline Umbria Marche & NA-C-SLV-R3-S4 & 286 & 600 & ST223 & 26/09/1997 & 6.0 & 22 & 1.422 & 2.303 & 1.685 & 1.041 & 0.145 & 0.118 \\
\hline Adana & NA-C-SLV-R3-S5 & 561 & 1726 & ST549 & 27/06/1998 & 6.3 & 30 & 1.111 & 0.906 & 2.158 & 2.644 & 0.278 & 0.203 \\
\hline Ishakli (aftershock) & NA-C-SLV-R3-S6 & 2296 & 7104 & ST856 & 03/02/2002 & 5.8 & 35 & 6.081 & 4.728 & 0.394 & 0.507 & 0.031 & 0.053 \\
\hline Izmit (aftershock) & NA-C-SLV-R3-S7 & 473 & 6975 & ST3272 & 13/09/1999 & 5.8 & 26 & 3.707 & 4.681 & 0.646 & 0.512 & 0.061 & 0.074 \\
\hline
\end{tabular}




\section{REFERENCES}

[1] Strauss, A., Apostolidi, E., Zimmermann, T., Gerhaher, U., Dritsos, S. Experimental investigations of fiber and steel reinforced elastomeric bearings: Shear modulus and damping coefficient. Engineering Structures 2014; 75: 402-413, doi: 10.1016/j.engstruct.2014.06.008.

[2] Losanno, D., Sierra, I. E. M., Spizzuoco, M., Marulanda, J., Thomson, P. Experimental performance of unbonded polyester and carbon fiber reinforced elastomeric isolators under bidirectional seismic excitation. Engineering Structures 2019; 110003, doi: 10.1016/j.engstruct.2019.110003.

[3] Losanno, D., Calabrese, A., Madera-Sierra, I. E., Spizzuoco, M., Marulanda, J., Thomson, P., Serino, G. Recycled versus Natural-Rubber Fiber-Reinforced Bearings for Base Isolation: Review of the Experimental Findings. Journal of Earthquake Engineering 2020, 1-20, doi: 10.1080/13632469.2020.1748764.

[4] Ragni, L., Cardone, D., Conte, N., Dall'Asta, A., Di Cesare, A., Flora, A., Leccese, G., Micozzi, F., Ponzo, C. Modelling and seismic response analysis of Italian code-conforming base-isolated buildings. Journal of Earthquake Engineering 2018; 22(sup2): 198-230, doi: 10.1080/13632469.2018.1527263.

[5] Ponzo, F. C., Di Cesare, A., Leccese, G., Nigro, D. Shaking table tests of a base isolated structure with double concave friction pendulum bearings. Bulletin of the New Zealand Society for Earthquake Engineering 2015; 48(2): 136-144, doi: 10.5459/bnzsee.48.2.136-144.

[6] Kitayama, S., Constantinou, M. C. Collapse performance of seismically isolated buildings designed by the procedures of ASCE/SEI 7. Engineering Structures 2018; 164: 243-258, doi: 10.1016/j.engstruct.2018.03.008.

[7] Castaldo, P., Alfano, G. Seismic reliability-based design of double sliding devices for softening structures. COMPDYN 2019, Crete, Greece, 24-26 June 2019, doi: 10.7712/120119.7272.19098.

[8] Zayas, V.A., Low, S.S., Mahin, S.A. The FPS earthquake protection system. Report No. 87-01, 1987, Earthquake Engineering Research Center, Berkeley.

[9] Zayas, V.A., Low, S.S., Mahin, S.A. A simple pendulum technique for achieving seismic isolation. Earthquake Spectra 1990; 6(2): 317-333, doi: 10.1193/1.1585573.

[10] Mokha, A.S., Constantinou, M.C., Reinhorn, A.M. Experimental study of friction-pendulum isolation system. Journal of Structural Engineering ASCE 1991; 117(4): 1201-1217, doi: 10.1061/(ASCE)07339445(1991)117:4(1201).

[11] Fenz, D.M., Constantinou, M.C. Behaviour of the double concave Friction Pendulum bearing. Earthquake Engineering and Structural Dynamics 2006; 35(11): 1403-1424, doi: 10.1002/eqe.589.

[12] Bao, Y., Becker, T. C., Hamaguchi, H. Failure of double friction pendulum bearings under pulse-type motions. Earthquake Engineering and Structural Dynamics 2017; 46(5): 715-732.

[13] Becker, T. C., Mahin, S. A. Experimental and analytical study of the bi-directional behavior of the triple friction pendulum isolator. Earthquake Engineering and Structural Dynamics 2012; 41(3): 355-373.

[14] Sarlis, A.A., Constantinou, M.C., Reinhorn, A.M. Shake table testing of Triple Friction Pendulum Isolators under extreme conditions. Report No. NCEER-13-0011, 2013, National Center for Earthquake Engineering Research, Buffalo.

[15] Becker, T. C., Bao, Y., Mahin, S. A. Extreme behavior in a triple friction pendulum isolated frame. Earthquake Engineering and Structural Dynamics 2017; 46(15): 2683-2698.

[16] Naeim F, Kelly JM. Design of Seismic Isolated Structures: From Theory to Practice. John Wiley \& Sons. New York, 1999.

[17] Eggert, E., Kauschke, W. Structural Bearings, 2nd Edition. 2002, Ernst \& Sohn, Berlin.

[18] Imbsen, R.A. Use of Isolation for Seismic Retrofitting Bridges, ASCE Journal of Bridge Engineering 2001; 6: 425-438, doi: 10.1061/(ASCE)1084-0702(2001)6:6(425).

[19] Quaglini V. High damping curved surface sliding isolators for bridges. In: Biondini, F., Frangopol, D.M., editors. Bridge Maintenance, Safety, Management, Resilience and Sustainability, 2012. CRC Press, Boca Raton.

[20] Cardone, D., Gesualdi, G., Brancato, P. Restoring capability of friction pendulum seismic isolation systems. Bulletin of Earthquake Engineering 2015; 13(8): 2449-2480, doi: 10.1007/s10518-014-9719-5.

[21] Calvi, G.M., Pietra, D., Moratti, M. Criteri per la progettazione di sistemi di isolamento a pendolo scorrevole, Progettazione Sismica 2009; 3(1): 7-30 (in Italian). 
[22] Constantinou, M.C., Tsopelas, P., Kasalanati, A., Wolff, E.D. Property modification factors for seismic isolation bearings. Report No. MCEER-99-0012, 1999, National Center for Earthquake Engineering Research, Buffalo.

[23] Campbell, T.I., Fatemi, M.J., Manning, D.G. Friction in bridge bearings with contaminated TFE slide surface. Journal of Structural Engineering ASCE 1993; 119(11): 3169-3177, doi: 10.1061/(ASCE)07339445(1993)119:11(3169).

[24] Dolce, M., Cardone, D., Croatto, F. Frictional behavior of steel-PTFE interfaces for seismic isolation. Bulletin of Earthquake Engineering 2005; 3(1): 75-99, doi:10.1007/s10518-005-0187-9.

[25] Quaglini, V., Dubini, P., and Poggi, C. Experimental assessment of sliding materials for seismic isolation systems. Bulletin of Earthquake Engineering 2012; 10(2): 717-740, doi: 10.1007/s10518-011-9308-9.

[26] Quaglini, V., Dubini, P., Ferroni, D., Poggi, C. Influence of counterface roughness on friction properties of engineering plastics for bearing applications. Materials and Design 2009; 30(5): 1650-1658, doi: 10.1016/j.matdes.2008.07.025.

[27] Quaglini, V., Bocciarelli, M., Gandelli, E., Dubini, P. Numerical assessment of frictional heating in sliding bearings for seismic isolation. Journal of Earthquake Engineering 2014; 18(8): 1198-1216, doi: 10.1080/13632469.2014.924890.

[28] Furinghetti, M., Pavese, A., Quaglini, V., Dubini, P. Experimental investigation of the cyclic response of double curved surface sliders subjected to radial and bidirectional sliding motions. Soil Dynamics and Earthquake Engineering 2019; 117: 190-202, doi: 10.1016/j.soildyn.2018.11.020.

[29] De Domenico, D., Ricciardi, G., Infanti, S., Benzoni, G. Frictional heating in double curved surface sliders and its effects on the hysteretic behavior: An experimental study. Frontiers in Built Environment 2019; 5, 74, doi: 10.3389/fbuil.2019.00074.

[30] American Society of Civil Engineers (ASCE). Minimum Design Loads and Associated Criteria for Buildings and Other Structures ASCE/SEI 7-16, 2017, doi: 10.1061/9780784414248.

[31] European Committee for Standardization (CEN). Eurocode 8 - Design of structures for earthquake resistance - Part 2: Bridges. EN 1998-2, 2005.

[32] American Association of State Highway and Transportation Officials (AASHTO). Guide Specification for Seismic Isolation Design. Washington D. C., 1999.

[33] Benzoni, G., Lomiento, G. Experimental assessment of property modification factors for friction isolators. In Proceedings of the 8th World Congress on Joints, Bearings and Seismic Systems for Concrete Structures, Georgia, Atlanta, September 2016.

[34] Constantinou, M.C., Mokha, A., Reinhorn, A. Teflon bearings in base isolation II: modeling. Journal of Structural Engineering ASCE 1990; 116(2): 455-474, doi: 10.1061/(ASCE)0733-9445(1990)116:2(455).

[35] Fagà, E., Ceresa, P., Nascimbene, R., Moratti, M., Pavese, A. Modelling curved surface sliding bearings with bilinear constitutive law: effects on the response of seismically isolated buildings. Materials and Structures 2015; 49(6): 2179-2196, doi: 10.1617/s11527-015-0642-2.

[36] Constantinou, M.C., Caccese, J., Harris, H.G. Frictional characteristics of Teflon-steel interfaces under dynamic conditions. Earthquake Engineering and Structural Dynamics 1987; 15(6): 751-759, doi: 10.1002/eqe.4290150607.

[37] Hwang, J.S., Chang, K.C., and Lee, G.C. Quasi-Static and Dynamic Sliding Characteristics of TeflonStainless Steel Interfaces. Journal of Structural Engineering ASCE 1990; 116(10): 2747-2762, doi: 10.1061/(ASCE)0733-9445(1990)116:10(2747).

[38] Mokha, A., Constantinou, M.C., Reinhorn, A. Teflon bearings in base isolation I: Testing, Journal of Structural Engineering ASCE 1990; 116(2), 438-454, doi: 10.1061/(ASCE)0733-9445.

[39] Mokha, A., Constantinou, M.C., Reinhorn, A.M. Verification of friction model of teflon bearings under triaxial load. Journal of Structural Engineering ASCE 1993; 119(1): 240-261, doi: 10.1061/(ASCE)07339445(1993)119:1(240), 240-261.

[40] Bondonet, G., and Filiatrault, A. Frictional Response of PTFE Sliding Bearings at High Frequencies. Journal of Bridge Engineering 1997; 2(4): 139-148, doi: 10.1061/(ASCE)1084-0702(1997).

[41] Constantinou, M.C., Whittaker, A.S., Kalpakidis, Y., Fenz, D.M., Warn, G.P. Performance of seismic isolation hardware under service and seismic loading. Report No. MCEER-07-0012, 2007, National Center for Earthquake Engineering Research, Buffalo.

[42] Barone, S., Calvi, G.M., Pavese, A. Experimental dynamic response of spherical friction-based isolation devices. Journal of Earthquake Engineering 2019; 23(9): 1465-1484, doi: 10.1080/13632469.2017.1387201. 
[43] Chang, K., Hwang, J., Lee, G. Analytical model for sliding behavior of Teflon-stainless steel interfaces. Journal of Engineering Mechanics ASCE 1990; 116(12): 2749-2763, doi: 10.1061/(ASCE)07339399(1990)116:12(2749).

[44] Kumar, M., Whittaker, A.S., Constantinou, M.C. Characterizing friction in sliding isolation bearings. Earthquake Engineering and Structural Dynamics 2015; 44(9): 1409-1425, doi: 10.1002/eqe.2524.

[45] Lomiento, G., Bonessio, N., Benzoni, G. Friction model for sliding bearings under seismic excitation. Journal of Earthquake Engineering 2013; 17(8): 1162-1191, doi:10.1080/13632469.2013.814611.

[46] De Domenico, D., Ricciardi, G., Benzoni, G. Analytical and finite element investigation on the thermomechanical coupled response of friction isolators under bidirectional excitation. Soil Dynamics and Earthquake Engineering 2018; 106: 131-147, doi: 10.1016/j.soildyn.2017.12.019.

[47] Mokha, A., Constantinou, M.C., Reinhorn, A. Teflon Bearings in Aseismic Base Isolation: Experimental Studies and Mathematical Modelling. Report No. NCEER-880038, 1988, National Center for Earthquake Engineering Research, Buffalo.

[48] ABAQUS. Standard User's Manual Version 6.10, 2011. Dassault Systèmes Simulia Corp., Providence.

[49] Simo, J.C., Hughes, T.J.R. Computational inelasticity, 1998, Springer, New York.

[50] Park, Y.J., Wen, Y.K., Ang, A.H.S. Random vibration of hysteretic systems under bi-directional ground motions. Earthquake Engineering and Structural Dynamics 1986; 14(4): 543-557, doi: 10.1002/eqe.4290140405.

[51] Nagarajaiah, S., Reinhorn, A.M., Constantinou, M.C. Nonlinear dynamic analysis of 3-dbase-isolated structures. Journal of Structural Engineering ASCE 1991; 117(7): 2035-2054, doi: 10.1061/(ASCE)07339445(1991)117:7(2035).

[52] Gandelli, E. Advanced tools for the design of sliding isolation systems for seismic-retrofitting of hospitals. $\mathrm{PhD}$ dissertation 2017, Politecnico di Milano, Milan.

[53] Computer and Structures. SAP2000 Analysis Reference, Vol. 1., 1997, Berkeley.

[54] Midas, Midas Gen V7.6.1, 2008, On-line Manual, http://www.MidasUser.com.

[55] Tsopelas, P.C., Constantinou, M.C., Reinhorn, A.M. 3D-BASIS-ME: Computer program for nonlinear dynamic analysis of seismically isolated single and multiple structures and liquid storage tanks. Report No. NCEER-94-0010, 1994, National Center for Earthquake Engineering Research, Buffalo.

[56] Tsopelas, P.C., Roussis, P.C., Constantinou, M.C., Buchanan, R., Reinhorn, A.M. 3D-BASIS-ME-MB: Computer Program for Nonlinear Dynamic Analysis of Seismically Isolated Structures. Report No. MCEER-05-0009, 2005, National Center for Earthquake Engineering Research, Buffalo.

[57] CEN Comité Européen de Normalisation. Eurocode 8 - Design of structures for earthquake resistance Part 2: Bridges, 2005, Brussels.

[58] AASHTO American Association of State Highway and Transportation Officials. Guide Specifications for Seismic Isolation Design. 2014, 4th ed., Washington.

[59] ASCE/SEI 7-16 American Society of Civil Engineers. Minimum Design Loads and Associated Criteria for Buildings and Other Structures, 2016, Reston.

[60] McKenna, F., Fenves, G., Scott, M. Computer program OpenSees: open system for earthquake engineering simulation, 2006, https://opensees.berkeley.edu.

[61] Gandelli, E., Quaglini, V. Effect of the static coefficient of friction of curved surface sliders on the response of an isolated building. Journal of Earthquake Engineering 2018; doi: 10.1080/13632469.2018.1467353.

[62] OpenSeesWiki, online manual, available at: http://opensees.berkeley.edu/wiki/index.php/Main_Page.

[63] Gandelli, E., Penati, M., Quaglini, V., Lomiento, G., Miglio, E., Benzoni G. A novel OpenSees element for single curved surface sliding isolators. Soil Dynamics and Earthquake Engineering 2019; 119: 433-454, doi: 10.1016/j.soildyn.2018.01.044.

[64] NTC2018. CSLLPP - Consiglio Superiore dei Lavori Pubblici. Norme Tecniche per le Costruzioni. Gazzetta Ufficiale 495 della Repubblica Italiana, No. 42 of 20 February 2018. Rome, Italy, (in Italian).

[65] European Standard. Eurocode 8: design of structures for earthquake resistance - Part 1: general rules, seismic actions and rules for buildings. 2003.

[66] Quaglini V, Gandelli E, Dubini P, Limongelli MP. Total displacement of curved surface sliders under nonseismic and seismic actions: A parametric study. Struct Contr Health Monit 2017; 24(12): e2031, doi: $10.1002 /$ stc. 2031 
[67] Pavese, A., Furinghetti, M., Casarotti, C. Investigation of the consequences of mounting laying defects for curved surface slider devices under general seismic input. Journal of Earthquake Engineering 2019; 23(3): 377-403, doi: 10.1080/13632469.2017.1323046.

[68] De Domenico, D., Falsone, G., Ricciardi, G. Improved response-spectrum analysis of base-isolated buildings: A substructure-based response spectrum method. Engineering Structures 2018; 162: 198-212, doi: 10.1016/j.engstruct.2018.02.037.

[69] Hall, J.F. Problems encountered from the use (or misuse) of Rayleigh damping. Earthquake Engineering \& Structural Dynamics 2006, 35(5): 525-545, doi: doi.org/10.1002/eqe.541.

[70] Ryan, K.L., Polanco, J. Problems with Rayleigh damping in base-isolated buildings. Journal of Structural Engineering 2008; 134(11): 1780-1784, doi: 10.1061/(ASCE)0733-9445(2008)134:11(1780).

[71] OPCM 3274. Ordinanza del Presidente del Consiglio dei Ministri n. 3274. Primi elementi in materia di criteri generali per la classificazione sismica del territorio nazionale e di normative tecniche per le costruzioni in zona sismica [in Italian], 2003.

[72] Ambraseys, N., Smit, P., Sigbjornsson, R., Suhadolc, P., Margaris, B. Internet-Site for European StrongMotion Data, European Commission, Research-Directorate General, Environment and Climate Programme 2002.

[73] Iervolino, I., Galasso, C., Cosenza, E. REXEL: computer aided record selection for code-based seismic structural analysis. Bull Earthq Eng 2010; 8: 339-362, doi: 10.1007/s10518-009-9146-1.

[74] Medeot, R. Re-centring capability evaluation of seismic isolation systems based on energy concepts. In Proceedings of the 13th world conference on earthquake engineering 2004; Vancouver, Canada, Vol. 3106.

[75] Katsaras, C.P., Panagiotakos, T.B., Kolias, B. Restoring capability of bilinear hysteretic seismic isolation systems. Earthq Eng Struct Dyn 2008; 37(4): 557-575.

[76] Ponzo, F.C., Di Cesare, A., Leccese, G., Nigro, D. Shake table testing on restoring capability of double concave friction pendulum seismic isolation systems. Earthq Eng Struct Dyn 2017; 46(14): 2337-2353.

[77] De Domenico, D., Gandelli, E., Quaglini, V. Adaptive isolation system combining low-friction sliding pendulum bearings and SMA-based gap dampers. Engineering Structures 2020; 212: 110536, doi: 10.1016/j.engstruct.2020.110536.

[78] De Domenico, D., Gandelli, E., Quaglini V. Effective base isolation combining low-friction curved surface sliders and hysteretic gap dampers. Soil Dynamics and Earthquake Engineering 2020; 130: 105989, doi: 10.1016/j.soildyn.2019.105989.

[79] Quaglini, V., Gandelli, E., Dubini, P. Experimental investigation of the re-centring capability of curved surface sliders. Struct Contr Health Monit 2017; 24(2): e1870.

[80] Stanton, J.F., Roeder, C.W., Campbell, T.I. High-load multi-rotational bridge bearings. Report NCHRP 432, 1999, National Academy Press, Washington, DC.

[81] Sartori, M. Seismic protection of railway bridges with sliding pendulum and high friction special sliding materials. Proc. of the 15th World Congress on Earthquake Engineering 2012; Lisbon, Portugal.

[82] Braun, C., Butz, C. Static and dynamic friction in curved surface sliders. IABSE Symposium Report, IABSE Symposium 2010, Venice, pp.33-40. doi: 10.2749/222137810796025140.

[83] Gandelli E, Taras A, Distl J, Quaglini V. Seismic retrofit of hospitals by means of hysteretic braces: influence on acceleration-sensitive non-structural components. Frontiers in Built Environment Earthquake Engineering 2019; doi: 10.3389/fbuil.2019.00100.

[84] Gandelli, E., Quaglini, V., Dubini, P., Limongelli, M.P., Capolongo, S. Seismic isolation retrofit of hospital buildings with focus on non-structural components, Ingegneria Sismica - International Journal of Earthquake Engineering 2018; Vol. 2018 (4). 